UNIVERSIDADE DE SÃO PAULO

ESCOLA DE EDUCAÇÃO FÍSICA E ESPORTE

"HIPERTROFIA CARDÍACA E SÍNTESE DE COLAGENO INDUZIDOS PELO USO DE ESTERÓIDES ANABOLIZANTES ASSOCIADO AO TREINAMENTO FÍSICO POR NATAÇÃO EM RATOS: PARTICIPAÇÃO DO SISTEMA RENINA ANGIOTENSINA ALDOSTERONA"

EVERTON CRIVOI DO CARMO

SÃO PAULO

2009 
"HIPERTROFIA CARDÍACA E SÍNTESE DE COLAGENO INDUZIDOS PELO USO DE ESTERÓIDES ANABOLIZANTES ASSOCIADO AO TREINAMENTO FÍSICO POR NATAÇÃO EM RATOS: PARTICIPAÇÃO DO SISTEMA RENINA ANGIOTENSINA ALDOSTERONA"

EVERTON CRIVOI DO CARMO

Dissertação apresentada à Escola de Educação Física e Esporte da Universidade de São Paulo, como requisito parcial para obtenção do grau de Mestre em Educação Física.

ORIENTADOR: PROF ${ }^{a}$. DR ${ }^{a}$. EDILAMAR MENEZES DE OLVEIRA 


\section{AGRADECIMENTOS}

- Primeiramente a meus pais, Edna Crivoi e Edgard Alves do Carmo, que me criaram com todo amor e carinho, educando e me preparando para a vida.

- Rose, minha esposa, amiga e confidente, por ter me apoiado em todos os momentos bons e, principalmente, nos ruins, com seus conselhos e carinho, dando-me forças para continuar na nessa empreitada.

- Avós, tios e primos por todos os momentos que passamos juntos e por serem a base da minha vida.

- Edilamar, professora e orientadora, por ter confiado em mim e aberto as portas para que eu pudesse seguir em direção aos meus objetivos, pelos seus ensinamentos durante esses anos, contribuindo muito na minha formação acadêmica.

- Tiago Fernandes, Daniel Koike, Natan, Katt, Diego, Fernanda, Kaleizu e Profa. Maria Claudia Irigoyen - que participaram diretamente desse trabalho e colaboraram muito para que essa etapa pudesse ser concluída.

- Amigos dos laboratórios de bioquímica e fisiologia celular da EEFE, pelo tempo que passamos juntos, pela amizade e troca de experiências, o que contribuiu muito para meu crescimento.

- Marcelo, Tiago, Diego, Luiz, Guga, Rodrigão, Camila, Telma e Stephano, amigos e pessoas especiais que conheci pelo caminho e passaram a fazer parte de minha vida. Muito obrigado pela amizade e companheirismo.

- Técnicas do laboratório, Katt, Marcele e Glorinha, pelos ensinamentos, colaboração e paciência durante esses anos.

- A todos os professores com quem convivi e que, direta ou indiretamente, contribuíram para esse trabalho, agregando conhecimento e exemplos a serem seguidos.

- CAPES - pelo apoio financeiro durante a realização desse trabalho.

- E, principalmente, a Deus, meu maior amigo, que me deu uma família e amigos maravilhosos, saúde e oportunidade de estar aqui hoje. Sem ele, nada disso seria possível. 
Página

LISTA DE TABELAS........................................................... iv

LISTA DE FIGURAS............................................................ v

LISTA DE SIGLAS, ABREVIAÇÕES E SÍMBOLOS......................... vi

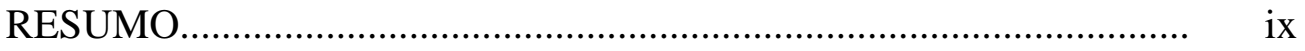

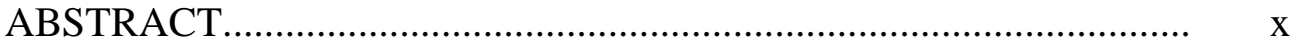

1 INTRODUÇÃO........................................................................... 1

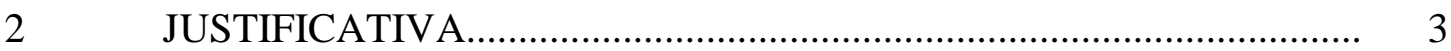

3 OBJETIVOS

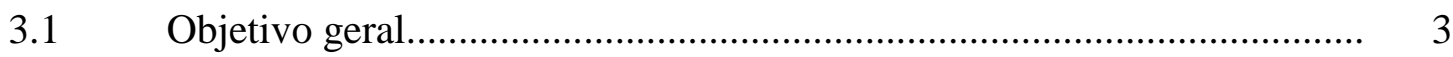

3.2 Objetivos específicos........................................................................... 4

$4 \quad$ REVISÃO DA LITERATURA.......................................................... 4

4.1 Esteróides Anabólicos Androgênicos........................................................ 4

4.1.2 Histórico................................................................................................. 6

4.1.3 Epidemiologia......................................................................... 7

4.1.4 Mecanismos de ação............................................................................ 8

4.1.5 Efeitos colaterais....................................................................... 10

4.2 Sistema Cardiovascular e Esteróides Anabolizantes............................... 11

4.3 Hipertrofia Cardíaca e Esteróides Anabolizantes..................................... 13

4.4 Sistema Renina Angiotensina............................................................ 15

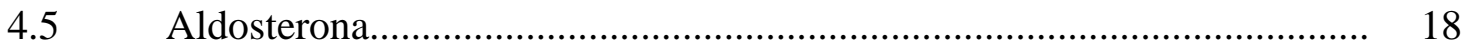

4.6 Regulação do Sistema Renina Angiotensina Aldosterona....................... 22

$5 \quad$ MATERIAIS E MÉTODOS ....................................................... 24

5.1 Animais Experimentais................................................................. 24

5.1.1 Grupos experimentais..................................................................... 25

$5.2 \quad$ Esteróides Anabolizantes.................................................................. 25

5.3 Bloqueio de Receptores AT1 e Receptores de Mineralocorticóides......... 25

5.4 Treinamento dos Animais.................................................................. 26

5.5 Medidas Hemodinâmicas........................................................................... 27

5.5.1 Avaliação da Pressão Arterial e Freqüência Cardíaca.............................. 27

5.5.2 Avaliação da Função Ventricular......................................................... 28 
5.6 Análises Morfológicas e Morfométricas................................................... 29

5.6.1 Hipertrofia Cardíaca........................................................................... 29

5.6.2 Diâmetro de Cardiomiócitos..................................................................... 29

5.6.3 Fração Volume de Colágeno Cardíaco.................................................... 30

5.7 Análises Bioquímicas e Moleculares..................................................... 30

5.7.1 Atividade da Enzima Conversora de Angiotensina Cardíaca................... 30

5.7.2 Expressão de Proteínas Cardíacas............................................................... 31

5.7.2.1 Preparação dos homogeneizados dos ventrículos.................................... 31

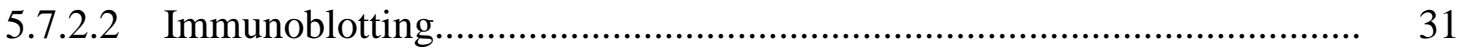

5.7.3 Expressão Gênica Cardíaca..................................................................... 32

5.7.3.1 Extração do RNA total......................................................................... 33

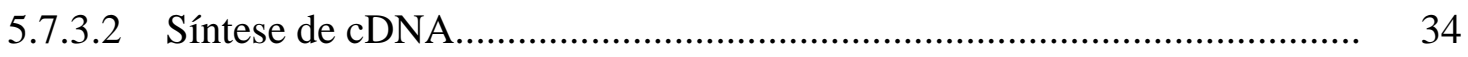

5.7.3.3 Transcrição Reversa (RT-PCR) ........................................................... 34

5.7.3.4 Avaliação Eletroforética dos Produtos de Amplificação ......................... 34

5.8 Análise Estatística.............................................................................. 35

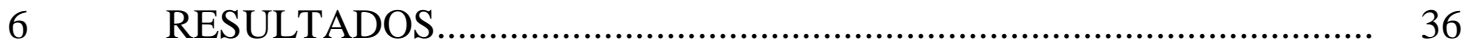

6.1 Pressão Arterial.......................................................................... 36

6.2 Frequência Cardíaca....................................................................... 37

Função Ventricular........................................................................ 38

6.4 Hipertrofia Cardíaca..................................................................... 40

6.5 Diâmetro de Cardiomiócitos.................................................................. 43

6.6 Colágeno Cardíaco............................................................................... 44

6.7 Sistema Renina Angiotensina Cardíaco.................................................. 48

6.7.1 Atividade Cardíaca da Enzima Conversora de Angiotensina Cardíaca..... 48

6.7.2 Expressão dos Receptores AT1 ........................................................... 49

6.7.3 Expressão dos Receptores AT2 ......................................................... 51

6.7.4 Expressão do Gene da Enzima Aldosterona Sintase (CYP11B2)

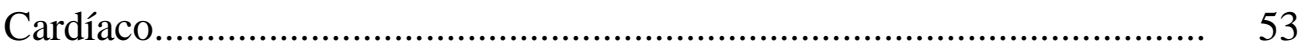

6.7.5 Expressão dos Receptores de Mineralocorticóides Cardíacos................. 55

6.7.6 Expressão da Enzima $11 \beta$ Hidroxisteróide Desidrogenase tipo 2 (11

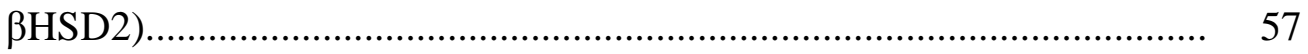

6.8 Fatores Inflamatórios.................................................................... 59

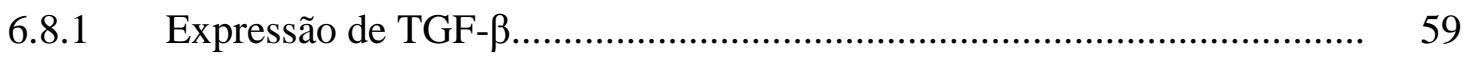


6.8.2 Expressão de Osteopontina.................................................................. 61

$7 \quad$ DISCUSS ÃO

$8 \quad$ CONCLUSÃO

$9 \quad$ REFERÊNCIAS BIBLIOGRÁFICAS.............................................. 75 


\section{LISTA DE TABELAS}

Página

TABELA 1 - Protocolo de treinamento físico

TABELA 2 - Seqüência dos oligonucleotídeos para os primers utilizados no RT-PCR

TABELA 3 - Índices de função ventricular sistólica e diastólica obtidos pelo exame ecocardiográfico nos grupos Sedentário controle (SC), Sedentário anabolizante (SA), Treinado controle (TC) e Treinado anabolizante (TA)

TABELA 4 - Índices de função ventricular sistólica e diastólica obtidos pelo exame ecocardiográfico nos grupos Treinado anabolizante (TA), Treinado anabolizante Losartan (TAL) e Treinado anabolizante Espironolactona (TAE)..................... 


\section{LISTA DE FIGURAS}

Página

FIGURA 1 Sistema de natação aquecido para ratos

FIGURA 2 Pressão arterial $(\mathrm{mmHg})$

FIGURA 3 Frequência cardíaca de repouso pré e pós treinamento físico (bpm)

FIGURA 4 Hipertrofia cardíaca (mg/g). Efeitos na administração de EA e a sua associação ao treinamento físico sobre a HC.

FIGURA 5 Hipertrofia cardíaca $(\mathrm{mg} / \mathrm{g})$. Efeitos do EA associado ao treinamento físico e ao Losartan ou a Espironolactona sobre a $\mathrm{HC}$

FIGURA 6 Diâmetro dos cardiomiócitos $(\mu \mathrm{M})$.

FIGURA 7 Colágeno cardíaco. Efeitos da administração de EA e a associação ao treinamento físico sobre o colágeno intersticial cardíaco.

FIGURA 8 Colágeno cardíaco. Efeitos da administração de EA, treinamento físico e Losartan sobre o colágeno intersticial cardíaco.

FIGURA 9 Colágeno cardíaco. Efeitos da administração de EA, treinamento físico e Espironolactona sobre o colágeno intersticial cardíaco.

FIGURA 10 Atividade da ECA cardíaca (UF/mg)....

FIGURA 11 Expressão dos receptores AT1 no coração (UA).

FIGURA 12 Expressão dos receptores AT2 no coração (UA).

FIGURA 13 Expressão do gene CYP11B2 no coração (UA)

FIGURA 14 Expressão dos receptores de mineralocorticóides no coração (UA)....... 56 
FIGURA 15 Expressão da enzima $11 \beta$ Hidroxisteróide Desidrogenase tipo 2 no

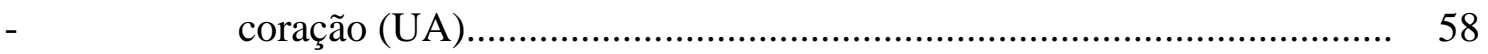

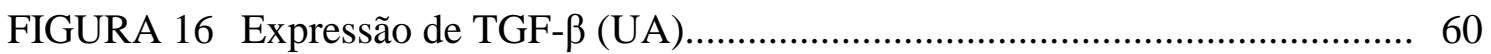

FIGURA 17 Expressão de Osteopontina (UA)................................................... 62 


\section{LISTA DE SIGLAS, ABREVIAÇÕES E SÍMBOLOS}

ABZ àcido ortho-aminobenzóico

Aldo Aldosterona

ANOVA análise de variância

AT1 receptor de angiotensina II tipo 1

AT2 receptor de angiotensina II tipo 2

BALCO bay area laboratory co-operative

cDNA acido desoxirribonucléico complementar

COBEA colégio brasileiro de experimentação animal

CTGF fator de crescimento de tecido conectivo

DDiaVE diâmetro diastólico do ventrículo esquerdo

DECA decanoato de nandrolona

DEPC dietil-pirocarbonato

DHT Dihidrotestosterona

DNA acido desoxirribonucléico

DNP Dinitrophenil

DOC 11-deoxicorticosterona

DP desvio padrão

DSisVE diâmetro sistólico do ventrículo esquerdo

EA esteróides anabólicos

ECA enzima conversora de angotensina

EPHESUS eplerenone post-acute myocardial infarction heart failure efficacy

ERK proteína regulada por sinais extracelulares

FC frequência cardíaca

FCrep frequiência cardíaca de repouso

FEj fração de ejeção

FEn fração de encurtamento

FVC fração de volume de colágeno

g Grama

GAPDH gliceraldeído-3-fosfato desidrogenase

HC hipertrofia cardíaca

HE hematoxilina e eosina 
HIV vírus da imunodeficiência humana

MAPK proteínas quinases ativadas por mitógeno

mg Miligrama

mmHg milímetros de mercúrio

MMP-1 metaloproteinase 1

MVE massa do ventrículo esquerdo

PA pressão arterial

PC peso corporal

PCR reação de polimerase em cadeia

PPVEDia parede posterior do ventrículo esquerdo em diástole

PPVESis parede posterior do ventrículo esquerdo em sístole

RALES randomized aldoctone evaluation study

RM receptores de mineralocorticóides

RNA acido ribonucléico

SA Sedentário tratado com Anabolizante

SAL Sedentário tratado com Anabolizante + Losartan

SAE Sedentário tratado com Anabolizante + Espironolactona

SC Sedentário Controle

SIVEDia septo interventricular na diástole

SIVESis septo interventricular na sístole

SRA sistema renina angiotensina

s/s sem sobrecarga

TA Treinado tratado com Anabolizante

TAL Treinado tratado com Anabolizante + Losartan

TAE Treinado tratado com Anabolizante + Eplerenona

TC Treinado Controle

TGF- $\beta$ fator de crescimento transformador beta

THG Tetrahidrogestrinona

TRIV tempo de relaxamento isovolumétrico

UA unidade arbitrária

UF unidade de fluorescência

USP Universidade de São Paulo

VE ventrículo esquerdo 


\begin{tabular}{|c|c|}
\hline $11 \beta$-HSD & $11 \beta$-hidroxisteroide dehidrogenase \\
\hline $11 \beta-$ & $11 \beta$-hidroxisteroide dehidrogenase tipo 2 \\
\hline HSD2 & \\
\hline$\alpha$ & Alfa \\
\hline$\beta$ & Beta \\
\hline$\mu \mathrm{m}$ & Micrometro \\
\hline \pm & mais ou menos \\
\hline$*$ & diferença significante vs grupo SC \\
\hline \# & diferença significante vs grupo TC \\
\hline$\dagger$ & diferença significante vs grupo SA \\
\hline$\ddagger$ & diferença significante vs grupo TA \\
\hline
\end{tabular}


RESUMO

\title{
HIPERTROFIA CARDÍACA E SÍNTESE DE COLÁGENO INDUZIDOS PELO USO DE ESTERÓIDES ANABOLIZANTES ASSOCIADO AO TREINAMENTO FÍSICO POR NATAÇÃO EM RATOS: PARTICIPAÇÃO DO SISTEMA RENINA ANGIOTENSINA ALDOSTERONA
}

\author{
Autor: EVERTON CRIVOI DO CARMO \\ Orientador: PROF ${ }^{\mathrm{a}}$. DR ${ }^{\mathrm{a}}$. EDILAMAR MENEZES DE OLIVEIRA
}

O uso de esteróide anabolizante é cada vez maior por pessoas que praticam exercícios como forma de lazer, sem se importarem com os possíveis efeitos colaterais, o que vem se tornando um importante problema de saúde pública. Dentre os seus principais efeitos colaterais, destacamos a hipertrofia cardíaca, que parece ser ainda mais pronunciada quando associado ao treinamento físico, sendo esta relacionada a maior atividade da enzima conversora de angiotensina cardíaca. Tendo em vista esse cenário, o presente trabalho visa verificar a participação do sistema renina angiotensina aldosterona sobre a hipertrofia cardíaca e síntese de colágeno induzida pelo esteróide anabolizante, associado ao treinamento físico por natação em ratos, por meio do bloqueio de receptores AT1 com Losartan e dos receptores de mineralocorticóides com Espironolactona. Resultados mostram que a administração de esteróide anabolizante aumenta a ativação do sistema renina angiotensina aldosterona cardíaco, o qual está diretamente relacionado aos seus efeitos colaterais, visto que o bloqueio dos receptores AT1 ou dos RM inibiu esses efeitos. Sendo mostrado pela primeira vez, os efeitos do esteróide anabolizante sobre o aumento na expressão do gene da aldosterona sintase e da enzima 11 $\beta$-HSD2, sugerindo os efeitos dos esteróides anabolizantes sobre o aumento da síntese e atividade da aldosterona cardíaca.

Palavras-chave: exercício físico, esteróides anabolizantes, angiotensina II, aldosterona, hipertrofia cardíaca, colágeno cardíaco. 


\begin{abstract}
CARDIAC HYPERTHROFIC AND COLLAGEN SYSTHESIS INDUCED BY ANABOLIC STEROIDS ASSOCIATED TO SWIMMING TRAINING IN RATS: RENIN ANGIOTENSIN ALDOSTERON SYSTEM PARTICIPATION
\end{abstract}

\author{
Author: EVERTON CRIVOI DO CARMO \\ Adviser: PROF ${ }^{a}$. DR $^{\mathrm{a}}$. EDILAMAR MENEZES DE OLIVEIRA
}

The anabolic steroid use is growing by recreational exercise practitioners, without worried about the possible collateral effects, becoming an important problem of public health. Among its deleterious effects we detach the cardiac hypertrophy, that looks to be still bigger when the swimming training was associated, being is related to bigger activity of the cardiac angiotensin converter enzime. With that, the present work is going to verify the renin angiotensin aldosteron system participation about the cardiac hypertrophy and collagen synthesis prompted by the anabolic steroid and the association with the swimming training in rat by means of the AT1 receivers blockade with Losartan and of the mineralocorticoids receivers blockade with Espironolacton. Our results show that the anabolic steroid administration increased the cardiac rennin angiotensin aldosteron system activity, that is straightly related to its deleterious effects, seen that the AT1 receivers blockade or the mineracorticoids receivers blockade inhibited those effects. Being shown by the first time the anabolic steroids effects about the increase of the aldosterone sintase gene expression and of the 11 $\beta$-HSD2 enzyme, suggesting the anabolic steroids effects about the cardiac aldosterone synthesis and activity increase.

Keywords: physical exercise, anabolic steroid, angiotensin II, aldosteron, cardiac hypertrophy, cardiac collagen 
Os esteróides anabolizantes (EA) são compostos sintéticos semelhantes ao hormônio masculino testosterona, que sofreram modificações estruturais com o objetivo de diminuir suas ações androgênicas e aumentar as anabólicas (KUHN, 2002; HARTGENS \& KUIPERS, 2004). Devido às suas ações anabólicas (DU TOIT, ROSSOUW, VAN ROOYEN \& LOCHNER, 2005) são usados por atletas, há mais de cinco décadas, para melhorar o desempenho físico (URHAUSEN, ALBERTS \& KINDERMANN, 2004), aparecendo, atualmente, entre as substâncias ergogênicas mais utilizadas no processo de doping (PARSSINEN \& SEPPALA, 2002).

No entanto, um fator que vem se tornando cada vez mais preocupante é a utilização dessas drogas fora do meio esportivo, por indivíduos que praticam atividade física como forma de lazer, principalmente jovens e adolescentes, que têm como objetivo apenas melhorar a aparência física (HARTGENS \& KUIPERS, 2004; URHAUSEN et al, 2004). Buscando alcançar esses objetivos, na maioria das vezes, fazem uso de doses suprafisiológicas que chegam a valores de 10 a 100 vezes maiores que os indicados para fins terapêuticos (WILSON, 1988), o que pode levar a sérios efeitos colaterais, entre eles, a hipertrofia cardíaca (MELCHERT \& WELDER, 1995).

Quando associado ao treinamento físico, o uso de EA pode induzir mudanças da hipertrofia cardíaca (HC) fisiológica, induzida pelo treinamento físico, para HC patológica (DICKERMAN, SCHALLER, PRATHER \& MCCONATHY 1995; PEREIRA JUNIOR, CHAVES, SOUZA, MASUDA, CARVALHO \& NASCIMENTO, 2006; ROCHA, CARMO, ROQUE, HASHIMOTO, ROSSONI, FRIMM, ANEÍAS, NEGRÃO, KRIEGER \& OLIVEIRA, 2007), cujo efeito é atribuído a alterações estruturais, como a formação e distribuição de colágeno no ventrículo esquerdo, o que pode levar a diminuição da complacência cardíaca (DU TOIT et al., 2005).

Os mecanismos pelos quais os EA agem sobre o sistema cardiovascular ainda não são completamente conhecidos e podem variar de estímulos mecânicos a fatores humorais circulantes (DU TOIT et al., 2005). Em recente trabalho realizado pelo nosso grupo, sugeriu-se, pela primeira vez, que a mudança da HC fisiológica para patológica em ratos tratados com EA, associado ao treinamento físico por natação está diretamente correlacionada à maior ativação do sistema renina angiotensina (SRA) cardíaco (ROCHA et al., 2007). 
A angiotensina II, potente promotora de hipertrofia e proliferação celular (ZHU, ZHU, LU, WANG, WANG \& YAO, 2003), age por meio de dois receptores específicos denominados AT1 e AT2 (VARAGIC \& FROHLICH, 2002). Os receptores AT1 são responsáveis pela grande maioria das ações da angiotensina II e podem ser encontrados em diferentes tecidos, entre eles, o coração (SANTOS, MOURA \& SILVA, 2000; PAUL, MEHR \& KREUTZ, 2006). Os receptores AT2 parecem ter efeitos opostos aos receptores AT1, porém sua atuação ainda é um tema muito controverso (PAUL et al., 2006).

Estudos realizados em modelos animais sugerem que o bloqueio dos receptores AT1 com antagonista específico, Losartan, é efetivo quando se trata de reduzir a HC (VAN KATS, DUNCKER, HAITSMA, SCHUIJT, NIEBUUR, STUBENITSKY, BOOMSMA, SCHALEKAMP, VERDOUW \& DANSER, 2000; BADER, 2002), cuja redução é associada à diminuição da fibrose intersticial (CHEN, MEHTA, LI, JOSEPH \& JOSEPH, 2004).

No entanto, os efeitos benéficos associados ao bloqueio dos receptores AT1 sobre a fibrose cardíaca parecem estar mais relacionados à diminuição na síntese e liberação de aldosterona, do que às ações da angiotensina II (KAWANO, TODA, NAKAMIZO, KOIDE, SETO \& YANO, 2005), visto que a angiotensina II, por meio dos receptores AT1, é uma das principais responsáveis pela regulação da secreção de aldosterona, a qual tem importante papel na síntese de colágeno. (IGLARZ, TOUYZ, VIEL, AMIRI \& SCHIFFRIN, 2004; KAWANO et al., 2005).

Além de sua síntese nas glândulas adrenais, a aldosterona também tem sido mostrada por ser sintetizada no coração (BONVALET, ALFAIDY, FARMAN \& LOMBES, 1995; SILVESTRE, HEYMES, OUBÉNAISSA, ROBERT, FAISANT, CARAYON, SWYNGHEDAUW \& DELCAYRE, 1999). Atuando de forma parácrina e autócrina em receptores de mineralocorticóides (RM) locais, desencadeia respostas inflamatórias levando à lesão tecidual (STRUTHERS, 2004), formação de colágeno, fibrose e remodelamento cardíaco (WHARTON, MORGAN, RUTHERFORD, CATRAVAS, CHESTER, WHITEHEAD, DE LEYAL, YACOUB \& POLAK, 1998). O bloqueio dos RM tem se mostrado eficiente na redução de marcadores de colágeno e HC (ZANNAD, ALLAN, DOUSSET, PERZ \& PITT, 2000).

Como demonstrado até o momento, tanto a angiotensina II como a aldosterona, produzidas no tecido cardíaco, exercem efeitos sobre o sistema 
cardiovascular, em especial sobre a fibrose e HC (YE, KENYON, MACKENZIE, SECKL, FRASE, CONNELL \& DAVIES, 2003; YONG \& FUNDER, 2004). No entanto, ainda não são claros os efeitos do EA e a sua associação ao treinamento físico, sobre a modulação desse sistema.

\section{JUSTIFICATIVA}

A utilização de drogas como os EA é bastante conhecida no meio esportivo, com a finalidade de melhorar o desempenho físico e aumentar a força muscular. Porém, a sua utilização é crescente no meio não competitivo, por jovens e praticantes de atividades físicas, o que vem se tornando um importante problema de saúde pública, devido aos seus efeitos colaterais.

Embora já se conheça os efeitos colaterais causados pelo uso de EA, principalmente sobre o sistema cardiovascular e $\mathrm{HC}$, pouco se sabe sobre os mecanismos que participam dessas adaptações e a influência do treinamento físico sobre esses mecanismos.

Recentemente tem sido sugerida a participação do Sistema Renina Angiotensina nos efeitos deletérios cardíacos induzidos pelos EA, sendo estes mais pronunciados quando associados ao treinamento físico aeróbio. Entretanto, os efeitos cardíacos atribuídos a angiotensina II têm sido associados à síntese e liberação de aldosterona no coração.

\section{OBJETIVOS}

\subsection{Objetivo Geral}

Verificar a participação do Sistema Renina Angiotensina Aldosterona sobre a hipertrofia cardíaca e síntese de colágeno induzidas pelo uso de EA e a sua associação ao treinamento físico por natação em ratos, por meio do bloqueio dos receptores AT1 com Losartan e dos receptores de mineralocorticóides com Espironolactona. 


\subsection{Objetivos Específicos}

Verificar e comparar a participação do Sistema Renina Angiotensina Aldosterona na hipertrofia cardíaca e síntese de colágeno induzidas pelo uso de EA, associado ao treinamento físico sob os seguintes aspectos:

1. As respostas de pressão arterial.

2. Função ventricular

3. Alterações morfológicas e morfométricas

- Hipertrofia cardíaca

- Diâmetro de miócito

- Fração volume de colágeno

4. Analisar a participação do sistema renina angiotensina aldosterona por meio de técnicas moleculares (expressão gênica do colágeno tipo I, do colágeno tipo III, da aldosterona sintase (CYP11B2), da 11 $\beta$-HSD2, dos fatores inflamatórios TGF- $\beta$ e osteopontina e dos receptores de mineralocorticóides, além da quantificação, por meio de western blotting, dos receptores AT1 e AT2 no coração.

\section{REVISÃO DE LITERATURA}

\subsection{Esteróides Anabólicos Androgênicos}

Os hormônios esteróides são de natureza lipídica e possuem um núcleo básico semelhante à estrutura química do colesterol. Sua biossíntese ocorre principalmente no córtex das glândulas adrenais e gônadas e podem ser classificados como corticosteróides, estrógenos, progestágenos e andrógenos (BIANCO \& RABELO, 1999).

A testosterona é o principal hormônio andrógeno, responsável pelas características sexuais masculinas, agindo tanto de forma androgênica como anabólica. Os efeitos androgênicos são responsáveis pelo engrossamento da voz e crescimento de pelos no púbis, axilas e face, além do aumento da libido e das glândulas sebáceas. Os efeitos anabólicos são responsáveis pelo crescimento da musculatura esquelética e dos ossos (KICMAN, 2008).

Em função dos efeitos anabólicos apresentados, a testosterona passou a ter um importante papel terapêutico em diversas condições patológicas, o que tem levado a síntese de muitos derivados. Os derivados sintéticos da testosterona, conhecidos como esteróides anabólicos androgênicos (EA), sofrem modificações estruturais na busca em 
aumentar sua atividade anabólica e diminuir sua atividade androgênica (KUHN, 2002; HARTGENS \& KUIPERS, 2004).

Dentre as modificações estruturais sofridas pela testosterona, podemos citar a $17 \alpha$ alcalinização, na qual um grupo metil (CH3) ou um grupo etil (C2H5) é introduzido na posição $\mathrm{C} 17 \alpha$, o que permite a utilização desses EA de forma oral, implicando em menor degradação da droga pelo fígado. (SHAHIDI, 2001).

Outra modificação muito encontrada é a esterificação do 17-hidroxi grupo, com uma longa cadeia de moléculas de hidrocarbonos, que atrasa a biodegradação do EA pelo organismo. Um exemplo desse tipo de EA é o Decanoato de nandrolona (decadurabolin), onde a esterificação do grupo 17 hidroxi da nandrolona com ácido decanóico - uma longa cadeia de ácidos graxos - permite uma ótima atividade anabólica da molécula de seis a sete dias (SHAHIDI, 2001).

Por fim, uma terceira modificação refere-se a alterações nos anéis estruturais da testosterona, que proporcionarão aumento da atividade dessas substâncias (SHAHIDI, 2001).

Atualmente, os EA são utilizados no tratamento de diferentes patologias na clínica médica, entre elas, quadros de deficiência do metabolismo protéico, pacientes com HIV, fase terminal de doenças renais, doença pulmonar obstrutiva crônica, doenças ósseas, crianças com retardo de crescimento e anemias (SHAHIDI, 2001; HARTGENS \& KUIPERS, 2004). Os principais efeitos induzidos pelo uso de EA estão relacionados à melhora no balanço nitrogenado em estados catabólicos, prevenindo a perda de massa magra e reduzindo o aumento do tecido adipose. (CREUTZBERG, WOUTERS, MOSTERT, PLUYMERS, \& SCHOOLS, 2003).

Devido aos efeitos anabólicos, o uso de EA deixou de ser associado apenas a fins terapêuticos, uma vez que passou a ser utilizado por atletas de diferentes modalidades e por praticantes de atividade física. Estes fazem uso de doses suprafisiológicas, geralmente utilizando-se de vários tipos, método chamado de "stacking", com valores de 10 a 100 vezes maiores que os indicados para fins terapêuticos (WILSON, 1988). Esse procedimento pode levar a sérios efeitos colaterais e colocar em risco a vida desses indivíduos. 


\subsubsection{Histórico}

Os primeiros relatos da utilização de EA, no meio esportivo, datam de 1950, por atletas russos, durante o campeonato mundial de levantamento de peso, realizado em Viena (HARTGENS \& KUIPERS, 2004). Com base nos bons resultados por eles alcançados, em 1956, o laboratório americano Ciba criou a metandrosterona, conhecido no mercado como Dianabol. (YESALIS, KENNEDY, KOPSTEIN \& BAHRKE, 1993). O uso de Dianabol passou a chamar a atenção de todos, em 1960, quando, no campeonato de fisiculturismo, o atleta Fred Ortiz apresentou massa muscular muito superior a de seus adversários (DU TOIT et al., 2005). Com isso, passados alguns anos, em 1972, durante o Mister América, foi estimado que 99\% dos atletas utilizaram EA (YESALIS et al., 1993).

A batalha contra o doping nos jogos olímpicos começou alguns anos antes: em 1960, o comitê olímpico internacional passou a controlar o uso de EA e, quatro anos mais tarde, em 1964, seu uso passou a ser proibido - era o primeiro controle antidoping, realizado nas olimpíadas do México, em 1968 (KUHN, 2002; HARTGENS \& KUIPERS, 2004). Durante os anos 1980 e 1990, o controle antidoping era realizado somente no final das competições. Com o passar dos anos, o período de realização e a quantidade de exames realizados aumentaram significativamente. Para se ter uma idéia, em Pequim, participaram dos jogos cerca de 10 mil atletas e foram realizados 4.500 testes (CATLIN, FITCH, LJUNGQVIST, 2008).

Com o maior controle antidoping, alguns casos de atletas que apresentaram testes positivos para EA começaram a surgir. Um dos mais divulgados ocorreu nas olimpíadas de Seul, em 1988: o exame feito com o atleta Benjamin S. Johnson revelou a presença de stanazolol na urina (CALFEE \& FADALE, 2006). Outro caso que provocou bastante repercussão ocorreu nas olimpíadas de Sidney, em 2000, quando diversos atletas apresentaram nandrolona nos exames, dentre eles, o medalhista de ouro em Barcelona, 1992, Linford Chirstie (ABBOTT, 2000).

Entretanto, o maior escândalo de doping no esporte ocorreu em 2003, com a descoberta do EA denominado tetrahidrogestrinona, o conhecido THG (CATLIN, SEKERA, AHRENS, STARCEVIC, CHANG \& HATTON, 2004). A partir de sua descoberta foi conhecido o chamado "Balco Negócio", pois a BALCO (Bay Area Laboratory Co-operative), uma companhia americana, maquiava EA como suplementos alimentares e distribuía a droga para atletas olímpicos. (CATLIN et al., 2004). 
O THG não foi mais detectado em exames antidoping. No entanto, como o teste para sua detecção tem de ser mais sensível, foi possível perceber uma grande variedade de outras drogas, resultando numa verdadeira epidemia de casos positivos para EA (CATLIN et al, 2008). Contudo, mesmo com os avanços ocorridos nas últimas décadas, no controle antidoping, quando muitas drogas foram descobertas e muitos atletas punidos, conseguir controlar o mercado clandestino do doping continua sendo um desafio, cuja solução só o futuro poderá oferecer.

\subsubsection{Epidemiologia}

O uso de EA no esporte aparece com maior prevalência entre atletas de força e velocidade, embora os de resistência aeróbia e esportes coletivos também utilizem essas drogas (ALARANTA, ALARANTA, HOLMILA, PALMU, PIETILA \& HELENIUS, 2006).

Atletas de modalidades aeróbias utilizam EA com o objetivo de evitar ações catabólicas, aumentar síntese protéica, disposição para o treinamento, devido às ações provocadas no sistema nervoso central (GEORGIEVA \& BOYADJIEV, 2004), produção de eritropoetina e entrega de oxigênio para os tecidos (SHAHIDI, 2001). Esses efeitos ainda são controversos na literatura e dependem de fatores como sexo, conduta do estudo, dose, regime de aplicação e duração do protocolo (KUHN, 2002).

Mesmo não tendo os efeitos totalmente comprovados, o uso de EA vem sendo cada vez maior no meio atlético e, também, entre praticantes de atividade física como forma de lazer, principalmente entre jovens em academias e centros de práticas esportivas (BUCKLEY, YESALIS, FRIEDL, ANDERSON STREIT \& WRIGHT, 1988; KOCHAKIAN, 1993; HARTGENS \& KUIPERS, 2004; DAL PIZZOL, BRANCO, CARVALHO, PASQUALOTTI, MACIEL \& MIGOTT, 2006; WOOD, 2006) - um problema de saúde pública que vem ganhando importância.

O principal fator que leva esses indivíduos a utilizarem EA é a busca por melhor aparência física (LOBO, NAPPO, SANCHEZ \& CARLINI, 2003). Conquistar um "corpo perfeito", em um curto espaço de tempo, faz com que essas pessoas lancem mão de métodos que produzam resultados rápidos, sem se preocuparem com os possíveis efeitos colaterais (IRIART \& ANDRADE, 2002). Pesquisas recentes mostram que mais de um milhão de americanos fazem uso de EA, com o objetivo de melhorar a aparência física (PARSSINEN \& SEPPALA, 2002). 
Wood 2006 mostrou que o uso de EA entre jovens escolares é comparado ao uso de outras drogas como a cocaína e a heroína. Pesquisa realizada na Suíça revelou que 50 a 100 mil indivíduos, em uma população de nove milhões, fazem ou fizeram uso de EA, o que representa $1 \%$ de toda a população (SJOQVIST, GARLE \& RANE, 2008). Na Alemanha, um estudo avaliou que 13,5\% dos freqüentadores de academias usam EA (STRIEGEL, SIMON, FRISCH, ROECKER, DIETZ, DICKHUTH \& ULRICH, 2006). No Brasil, os resultados encontrados também são muito preocupantes: em 2001, os EA foram os agentes que mais causaram intoxicação em seres humanos, sendo um dos mais utilizados entre os medicamentos considerados drogas de abuso (NOTO, BAPTISTA, FARIA, NAPPO, GALURÓZ \& CARLINI, 2003). Estudo realizado com jovens escolares, no sul do Brasil, mostrou que 2,2\% dos entrevistados declararam já terem usado EA e que a grande influência para o uso veio de amigos da academia. Este estudo também revela a facilidade em adquirir o produto no Brasil, em $40 \%$ dos casos, eles foram adquiridos em farmácias sem a apresentação de receita médica (DAL PIZOOL et al., 2006).

\subsubsection{Mecanismos de Ação}

Os mecanismos de ação dos EA ainda não são completamente entendidos e podem diferir por sua variação molecular (HARTGENS \& KUIPERS, 2004). Como são substâncias sintéticas similares à testosterona, podem ser incorporados à corrente sanguínea por administração oral ou injetável.

$\mathrm{Na}$ corrente sanguínea, os EA, em sua forma livre, se difundem diretamente através da membrana plasmática de células-alvo, ligando-se à receptores de esteróides. (CELOTTI \& CESI, 1992). Após a ligação com o receptor, esses por sua vez, migram para o núcleo celular e se unem à determinada região do DNA, iniciando o processo de transcrição gênica (KUHN, 2002).

As repostas dos EA, em diferentes órgãos, variam conforme as concentrações de receptores e as ações de enzimas específicas locais como a $5 \alpha$ redutase e a aromatase (KAM \& YARROW, 2005), que transformam a testosterona em outros metabólitos mais ativos.

O processo chamado aromatização ocorre por meio da ação da enzima aromatase sobre o EA, convertendo-o, de forma irreversível, nos estrógenos estradiol e estrona. Esses hormônios se ligam aos receptores de estrogênio e agem, principalmente, em células adiposas, células de Leydig, células de Sertoli e sistema nervoso central 
(KUHN, 2002). Esse processo ocorre quando os EA circulantes causam saturação dos receptores androgênicos e é responsável por diversos efeitos colaterais, entre eles, a ginecomastia, no caso de homens (KUHN, 2002; HARTGENS \& KUIPERS, 2004).

A 5 $\alpha$-redutase converte a testosterona em dihidrotestosterona (DHT), um andrógeno considerado mais potente, devido a sua afinidade duas a seis vezes maior ao receptor do que a testosterona. Por apresentar maior atividade dessa enzima, esse processo é mais proeminente no cérebro, tecido adiposo e órgãos sexuais masculinos. Entretanto, em tecidos como o coração e a musculatura esquelética, a atividade da $5 \alpha-$ redutase é muito baixa (SHAHIDI, 2001). Segundo se pode demonstrar "in vitro", sua formação é praticamente ausente na musculatura de ratos (MATSUMINE, HIRATO, TAMADA \& YOSHIDA, 1986).

Além da baixa atividade da $5 \alpha$-redutase, foi observado no músculo esquelético uma alta atividade da enzima $3 \alpha$-hidroxisteróide-desidrogenase, cuja função é converter a DHT em $3 \alpha$-diol, um metabolito inativo aos receptores androgênicos. Isso torna as concentrações de DHT ainda menores na musculatura estriada esquelética e pode distinguir os músculos de outros tecidos andrógeno-dependentes, explicando, em parte, a dissociação da ação anabólica da androgênica nesse tecido (SHAHIDI, 2001).

Os efeitos anabólicos dos EA sobre a musculatura esquelética podem estar relacionados à sua ligação direta a receptores de andrógenos, convertendo um balanço nitrogenado negativo para um positivo, provocando o aumento da fixação de nitrogênio (BAHRKE \& YESALIS, 2004). Porém, essas ações não são uniformes e dependem das concentrações dos receptores no músculo esquelético. Regiões do corpo como pescoço, ombro, braço e tórax são mais suscetíveis aos efeitos dos EA, por apresentarem maior predominância de receptores androgênicos (HARTGENS \& KUIPERS, 2004). Outro fator que pode influenciar os efeitos tróficos dos EA é a associação com exercício físico, visto que receptores androgênicos podem ser mais sensibilizados quando expostos ao treinamento físico (BAMMAN, SHIPP, JIANG, GOWER, HUNTER, GOODMAN, MCLAFFERTY \& URBAN, 2001), aumentando os sitos de ligações disponíveis e intensificando seus efeitos (BRICOUT, GERMAIN, SERRURIER \& GUEZENNEC, 1994).

No entanto, os efeitos dos EA sobre a musculatura esquelética não estão apenas relacionados à síntese protéica. Quando administradas altas doses de EA e as concentrações fisiológicas são excedidas, a relação dose-resposta entre testosterona e crescimento muscular alcança um platô. Neste caso, fica sugerido que nessas condições, 
comumente observada em usuários, os efeitos sobre o crescimento muscular podem estar relacionados ao menor catabolismo nesses indivíduos, visto que os EA também apresentam grande afinidade aos receptores de glicocorticóides, o que reduziria a ação dos glicocorticóides sobre esses receptores inibindo suas ações catabólicas (HICKSON, CZERWINSKI, FALDUTO \& YOUNG, 1990).

\subsubsection{Efeitos Colaterais}

O uso de doses suprafisiológicas de EA pode levar a sérios efeitos colaterais, entre eles, a acne, o crescimento de pelos, a diminuição dos níveis de testosterona endógena, a diminuição da espermatogênese e conseqüentemente a atrofia testicular. Esses efeitos normalmente desaparecem tão logo seja interrompido o uso da droga, embora possam durar até seis meses (MARAVELIS, DONA, STEFANIDOU \& SPILIOPOULOU, 2005). Nas mulheres podem causar mudança da voz, hipertrofia de clitóris, irregularidade menstrual, diminuição da gordura corporal e aumento de pelos faciais (STRAUSS, LIGGETT \& LANESE,1985).

O uso de EA está associado a alterações do sistema endócrino, tais como: diminuição da tolerância à glicose, aumento na resistência à insulina e diminuição dos hormônios da tireóide (SHAHIDI, 2001). Podemos observar, também, danos sobre o tecido hepático, onde são encontrados níveis elevados da enzima aspartato aminotransferase, alanina aminotransferase e lactato desidrogenase (MARABELIAS et al., 2005), tumores e hepatite (DOURAKIS \& TOLIS, 1998).

Os EA podem causar danos sobre a estrutura óssea, sendo observadas alterações no tecido cartilaginoso e efeitos deletérios sobre tendões, o que resulta em diminuição da força tensional (STANNARD \& BUCKNELL, 1993). Em crianças e jovens, o EA pode levar ao fechamento prematuro das epífises, antecipando a fase final de crescimento (CALFEE \& FADALE, 2006).

Os efeitos renais dos EA estão associados a um quadro de necrose tubular aguda, caracterizado por inchaço de células tubulares com redução no número de células, túbulos distais hemorrágicos, denaturação protéica e deposição de fibrina. (TAKAHASHI, TATSUGI, KOHNO, 2004). Dados semelhantes foram encontrados pelo nosso grupo ao verificar que ratos tratados com EA apresentaram lesão estrutural em túbulos proximais e distais (dados não publicados).

Mudanças no comportamento também têm sido identificadas com o uso de EA incluindo irritabilidade, agressividade, euforia, depressão e alterações de humor 
(UZYCH, 1992). Esses efeitos têm sido associados a possíveis alterações sobre o sistema nervoso central (TAKAHASHI et al., 2004), ou ainda a alterações na expressão dos receptores de dopamina (BIRGNER, HOGBERG, ALSIO, LINDBLOM, SCHIOTH \& BERGSTROM, 2008). No entanto, esses efeitos podem ser questionados, já que outros trabalhos não observaram alterações de comportamento (WANG, ALEXANDER, BERMAN, SALEHIAN, DAVIDSON, MACDONALD, STEINER, HULL, CALLEGARI \& SWERDLOFF, 1996).

Os EA podem ainda levar a sérios prejuízos sobre o sistema cardiovascular, um dos sistemas mais afetados pelo uso indiscriminado, razão pela qual será dada maior atenção ao assunto, logo abaixo.

\subsection{Sistema Cardiovascular e Esteróides Anabolizantes}

O uso indiscriminado de EA tem sido mostrado por provocar sérias alterações no sistema cardiovascular, como as complicações vasculares, cardiomiopatias, aterosclerose (MELCHERT \& WELBER, 1995), hipertensão (TAKAHASHI et al., 2004) e aumento do colágeno tecidual (PARSSINEN, KARILA, KOVANEN \& SEPPALA, 2000). Entretanto, seus verdadeiros efeitos ainda aguardam mais esclarecimentos.

O efeito do EA sobre a pressão arterial (PA) é um fator muito discutido na literatura. Existem trabalhos que mostram o aumento da PA induzido pelo uso de EA em atletas, aumento esse que pode persistir mesmo após a interrupção do uso, como mostrado em um estudo, segundo o qual mesmo depois de cinco meses sem o uso da droga a PA sistólica permaneceu cerca de $6 \mathrm{mmHg}$ maior em repouso nos usuários, quando comparados com não usuários (PEARSON, SCHIFF, MROSEK, LABOVITZ \& WILLIAMS, 1986). O aumento da PA e da resistência vascular periférica também foram observados em pesquisas com animais, em que níveis pressóricos mais altos foram mantidos após seis semanas, sem a administração de EA (URHAUSEN et al., 2004). Uma possível causa para o aumento da PA seria a maior retenção de sódio e água devido à estrutura do EA ser similar a da aldosterona, o que levaria ao aumento no volume sanguíneo e consequentemente da PA (MELCHERT \& WELBER, 1995). Uma segunda hipótese seria a ação dos EA sobre o sistema nervoso simpático, sendo que em ratos, espontaneamente hipertensos, o bloqueio dos receptores androgênicos foi eficaz em reduzir a PA em estágios iniciais, o que revela o importante papel da testosterona em fase inicial da hipertensão. Também não poderiam ser descartadas possíveis alterações 
sobre respostas vasodilatoras dependentes do endotélio ou ainda alterações sobre o controle barorreflexo (BEUTEL, BERGAMASCHI \& CAMPOS, 2005).

Por outro lado, outros autores não observaram aumento da PA induzida pelo uso de EA. Fisiculturistas usuários de EA não apresentaram diferenças na PA quando comparados a não usuários (NOTTIN, NGUYEN, TERBAH \& OBERT, 2006). Estudo realizado com levantadores de peso não observou aumento da PA em repouso e durante o exercício em usuários de EA (KRIEG, SCHARHAG, ALBERS, KINDERMANN \& URHAUSEN, 2007). Dados semelhantes também foram observados, por nosso grupo, em trabalhos anteriores, onde ratos tratados com EA e treinados por natação, não apresentaram mudanças significantes da PA (ROCHA et al., 2007). As discrepâncias de resultados encontrados na literatura sobre a administração de EA induzindo alteração na PA podem estar relacionadas às diferentes metodologias aplicadas nos estudos.

O uso de EA também pode ser associado ao infarto agudo do miocárdio e morte súbita em jovens (MELCHERT \& WELBER, 1995). Em um estudo de caso, um jovem de 20 anos, usuário de EA, teve morte cardíaca instantânea com hemorragia pulmonar (DICKERMAN et al., 1995). Dado semelhante também foi observado em outro relato, em que um fisiculturista de 31 anos e usuário de EA por 10 anos, apresentou dor no peito, devido a infarto agudo no miocárdio, além de hipertrofia ventricular esquerda e moderada redução da função sistólica (WYSOCZANSKI, RACHKO \& BERGMANN, 2008).

O infarto agudo do miocárdio, causado pelo uso dos EA, pode estar relacionado a diversos fatores, dentre eles, suas ações diretas sobre as células do miocárdio, levando à morte celular e à cicatriz tecidual, ou ter efeito direto sobre o sistema coagulante/fibrinolítico, através de mudanças na função das plaquetas (MELCHERT \& WELBER, 1995).

Estudos têm demonstrado aumento do colágeno miocárdico associado ao uso de EA (NIEMINEN, RAMO, VIITASALO, HEIKKILA, KARJALAINEN, MANTYSAARI \& HEIKKILA, 1996; LE GROSS, MACCONNELL, MURRY, EDAVETTAL, RACEY, SHEPHERD \& BURNS, 2000; ROCHA et al., 2007), induzindo mudanças eletrofisiológicas com anormal propagação da onda de excitação (WYSOCZANSKI et al., 2008), facilitando a taquicardia, o que pode explicar as repetidas ocorrências de morte súbita em usuários (NIEMINEN et al.).

O aumento do colágeno intersticial no miocárdio pode ainda afetar sua estrutura, levando a um quadro de $\mathrm{HC}$, assunto que será discutido em seguida. 


\subsection{Hipertrofia Cardíaca e Esteróides Anabolizantes}

A HC constitui um dos principais mecanismos de adaptação do miocárdio e envolve processos complexos, que abrangem alterações genéticas, moleculares e celulares, atuando sobre miócitos e interstício (PONTES \& LEÃES, 2004), manifestadas com modificações no tamanho, massa, geometria e função cardíaca, em resposta a determinados estímulos (COHN, FERRARI, SHARPE, 2000).

Entre esses estímulos podemos citar o estresse hemodinâmico, detectado pelo miocárdio como um estresse mecânico sobre a membrana e alteração do citoesqueleto (PONTES \& LEÃES, 2004). Esse estresse pode ocorrer por sobrecarga de pressão ou por sobrecarga de volume. Na sobrecarga pressórica, ocorre adição de novos sarcômeros predominantemente em paralelo; dessa forma, a hipertrofia é considerada de padrão concêntrico (PONTES \& LEÃES, 2004). Na sobrecarga de volume, sarcômeros adicionais são dispostos em série (PONTES E LEÃES, 2004), caracterizando a hipertrofia de padrão excêntrico (LORELL \& CARABELLO, 2000).

A HC pode ocorrer tanto por estímulos patológicos como fisiológicos. $\mathrm{Na}$ HC patológica, como ocorre nos casos de hipertensão arterial, infarto do miocárdio e hiperatividade simpática, é observado um aumento de carga de trabalho do coração, redução da função do ventrículo esquerdo, queda da função cardíaca, aumento da frequência cardíaca (FC) de repouso e diminuição do volume sistólico (IEMITSU, MIYAUCHI, MAEDA, SAKAI, KOBAYASHI, FUJII, MIYAZAKI, MATSUDA \& YAMAGUCHI, 2001). Além disso, está associada à ativação de um programa molecular envolvendo vias de sinalização intracelulares relacionadas a situações patológicas (LIPS, DEWINDT, DAVE, KRAAIJ \& DOEVENDANS, 2003), levando ao aumento no tamanho de miócito pelo aumento da expressão de genes usualmente encontrados na vida fetal (SANTOS et al, 2000). Pode ser observado, ainda, aumento na deposição de colágeno na matriz extracelular (LIPS et al., 2003), especialmente colágeno do tipo I, III e fibronectina (SANTOS et al., 2000), o que pode comprometer a visco elasticidade cardíaca (BURLEW \& WEBER, 2000).

Outro fator bem demonstrado por induzir a HC patológica é a administração de EA. Nesse caso, foi observado que ratos tratados com o EA apresentaram maior massa cardíaca, quando corrigida pelo peso corporal (coração/peso corporal), (BEUTEL et al, 2005; PEREIRA JUNIOR et al, 2006), sendo essa, acompanhada de prejuízo nas 
miofibrilas, alongamento e inchaço mitocôndrial no miocárdio, o que consiste na fase inicial da insuficiência cardíaca (MELCHERT \& WELBER, 1995).

Por outro lado, estímulos como o treinamento físico podem levar a $\mathrm{HC}$ fisiológica, provocando respostas benéficas e adaptativas do sistema cardiovascular ao aumento de carga mecânica (LORELL \& CARABELLO, 2000).

No entanto, quando o treinamento físico é associado ao uso de EA pode induzir adaptações cardiovasculares não favoráveis (MELCHERT \& WELBER, 1995), ocorrendo mudança da $\mathrm{HC}$ fisiológica para patológica, que pode levar a prejuízo da função ventricular, em especial da função diastólica, fibrose do miocárdio e desarranjo de cardiomiócitos (DE MARCHI, ALLEMANN \& SEILER, 2000; YAMAMOTO, MASUYAMA, SAKATA, NISHIKAWA, MANO, YOSHIDA, MIWA, SUGAWARA, YAMAGUCHI, OOKAWARA, SUZUKI \& HORI, 2002).

O aumento da massa cardíaca, em usuários de EA, é muito bem descrito na literatura. Em estudo que analisou as alterações cardíacas por ecogardiograma foi observado aumento do índice de massa ventricular e espessura do septo intraventricular, em usuários comparados aos não usuários, onde também foi observada a redução no pico de velocidade durante a fase inicial de enchimento diastólico, não sendo observadas alterações da função sistólica (KRIEG et al., 2007). Em outros estudos, foi observado prejuízo da função diastólica em levantadores de peso, que utilizavam EA comparado aos que não usavam (PEARSON et al, 1986; DE PICCOLI, GIADA, BENETTIN, SARTORI, PICCOLO, 1991). Trabalhos realizados com ex-usuários observaram que os seus efeitos sobre a massa de ventrículo esquerdo e função ventricular persistiram mesmo após um ano sem o uso da droga (URHAUSEN et al., 2004). Entretanto, o prejuízo sobre a função ventricular é controverso e depende, em parte, da metodologia usada, tipos de EA e dosagens. Em um trabalho realizado com ratos tratados com EA não foi observada disfunção cardíaca analisada por ecocardiograma (PEREIRA JUNIRO et al., 2006).

O uso de EA associado ao exercício físico também pode estar relacionado a uma diminuição da complacência miocárdica, que pode ser atribuída à fibrose do miocárdio e desarranjo de cardiomiócitos (YAMAMOTO et al., 2002; LOMBARDI, BETOCCHI, LOSI, TOCCHETTI, AVERSA, MIRANDA, D`ALESSANDRO, CACACE, CIAMPI \& CHIARIELLO, 2003). Em atletas que utilizam EA, foram observadas alterações ventriculares atribuídas a mudanças estruturais, como formação e distribuição de colágeno no ventrículo (LE GROSS et al, 2000; WOODIWISS, 
TRIFUNOVIC, PHILIPPIDES \& NORTON, 2000). Efeitos semelhantes foram também observados em pesquisa realizada com cães, onde o uso de EA associado ao treinamento físico aumentou a concentração de colágeno cardíaco (TAKALA, RAMO, KIVILUOMA, KAINULAINEN, KETTUNEN, 1991).

Vários mecanismos têm sido propostos para explicar o efeito dos EA sobre a HC e o aumento do colágeno intersticial. Os EA podem agir por meio de receptores nucleares, atuando diretamente na transcrição gênica, aumentando a síntese protéica (KOCHAKIAN \& WELBER, 1993) ou também por afetar enzimas específicas, fluxo de íons e matriz estrutural no miocárdio (MELCHERT \& WELDER, 1995). Contudo, os exatos mediadores desses efeitos são diversos e variam de estímulos mecânicos a fatores circulantes humorais, liberados pelo coração e órgãos periféricos. Porém, os verdadeiros mecanismos pelos quais os EA causam HC e aumento do colágeno intersticial são desconhecidos, até o momento (DU TOIT et al., 2005).

Em trabalho anterior realizado por nosso grupo, ratos tratados com EA apresentaram HC em relação ao grupo controle. No entanto, quando a administração de EA foi associada ao treinamento físico de natação, essa hipertrofia foi ainda maior, ocasionando perda dos efeitos benéficos induzidos pelo treinamento físico sobre a função ventricular. Os efeitos deletérios mostrados nesse estudo foram associados ao aumento de colágeno cardíaco, encontrado nesse grupo, sendo esse aumento observado principalmente em fibras de colágeno tipo III. Um dado muito interessante verificado nesse estudo e mostrado, pela primeira vez na literatura, foi o aumento do colágeno intersticial induzido pelo uso de EA associado a maior ativação do SRA cardíaco, visto que o aumento da expressão do colágeno tipo III foi diretamente correlacionado ao aumento da atividade da enzima conversora de angotensina (ECA) cardíaca. Esses dados sugerem que o SRA cardíaco pode ter influência direta sobre o aumento do colágeno intersticial induzido pelo uso de EA (ROCHA et al., 2007).

\subsection{Sistema Renina Angiotensina}

No conceito clássico do SRA, a renina liberada pelos rins tem como substrato o angiotensinogênio, catalisado para formação de angiotensina I, que na circulação pulmonar sofre a ação da ECA, resultando na geração do octapeptídeo angiotensina II (VARAGIC \& FROHLICH, 2002), o qual, por sua vez, é o componente biologicamente ativo do sistema, tendo importante papel na regulação da PA, volume plasmático e atividade nervosa simpática (LEVY, 2005). 
No entanto, mais do que um sistema hormonal endócrino, o SRA pode ainda ser encontrado localmente (CAREY \& SIRAGY, 2003), onde os genes para todos os componentes têm sido clonados e verificada sua expressão e regulação em alguns tecidos, entre eles, cérebro (MORIMOTO \& SIGMUND, 2002), vasos (BADER, PETERS, BALTATU, MULLER, LUFT \& GANTEN, 2001), tecido adiposo (ENGELI, NEGREL \& SHARMA, 2000), pâncreas (SERNIA, 2001), placenta (NIELSEN, SCHAUSE \& POULSEN, 2000), rins (BADER et al., 2001) e coração (PAUL et al., 2006).

No coração já foram identificados todos os componentes do SRA (KOMURO, 2001), sendo a geração de angiotensina II cardíaca regulada independentemente do sistema endócrino (VARAGIC \& FROHLICH, 2002), como mostrado claramente pelos efeitos da angiotensina II ocorrerem independentes dos seus efeitos sobre a PA (PAUL et al., 2006). O coração pode sintetizar angiotensina I localmente e convertê-la em angiotensina II, a qual pode atingir concentrações duas a três vezes maiores do que as encontradas no plasma (DANSER \& SCHALEKAMP, 1996). Evidências mostram que enquanto o SRA plasmático está envolvido na estabilidade hemodinâmica, o sistema local está mais sujeito a mudanças estruturais.

A angiotensina II cardíaca é um dos mais potentes promotor da hipertrofia de cardiomiócitos (ZHU et al., 2003). Atuando de forma autócrina ou parácrina, ativa uma variedade de vias de sinalização molecular, que induzirão genes promotores de hipertrofia (SARKAR, VELLAICHAMY \& YONG, 2004). Os efeitos cardíacos da angiotensina II também podem ser observados na proliferação de fibroblastos e acúmulo de proteínas na matriz extracelular (BURLEW \& WEBER, 2000), por estimular a produção de colágeno e fibronectina (KOMURO, 2001), ou, ainda, por diminuir a expressão das metaloproteinase 1 (MMP-1), responsáveis pela degradação do colágeno (CHEN et al., 2004).

A maioria das ações da angiotensina II sobre o tecido cardíaco são desencadeadas pela sua ligação a receptores específicos, denominados AT1 e AT2 (VARAGIC \& FROHLICH, 2002), ambos pertencentes à superfamília de receptores acoplados a proteína G (LEVY, 2005). Os receptores AT1 são responsáveis pelas ações da angiotensina II sobre a hipertrofia e proliferação de células cardíacas, enquanto os receptores AT2 parecem ter efeitos opostos aos receptores AT1. No entanto, seu verdadeiro papel ainda é muito controverso (PAUL et al., 2006). 
Embora os receptores AT2 sejam pouco expressos em situações fisiológicas, em condições patológicas, como o infarto do miocárdio e insuficiência cardíaca, sua expressão parece ser aumentada (MATSUBARA, 1998; UNGER, 1999), sendo que, nessas situações, os receptores de AT2 foram localizados na região intersticial em áreas fibróticas, sugerindo sua participação na modulação da matriz extracelular. Para confirmar essa participação, foi administrado um antagonista desses receptores, tendo sido observado aumento da síntese de fibronectina por fibroblastos (FISCHER, STOLL \& UNGER, 1996), mostrando assim, que esses receptores podem ser de fundamental importância na manutenção e restauração da normalidade no sistema cardiovascular (GASPARO, CATT, INAGAMI \& UNGER, 2000).

Assim como os receptores AT2, a expressão dos receptores AT1 pode ser aumentada e regulada por diferentes fatores, como mostrado em um estudo, no qual a expressão desses receptores aumentou cerca de 300\% pela administração de glicocorticóides (DELLA BRUNA, RIES, HIMMELSTOSS \& KURTZ, 1995; GUO, UNO, \& INAGAMI, 1995), mostrando que sua expressão pode ser influenciada por hormônios esteróides.

Quanto aos mecanismos de ação dos receptores AT1, podemos observar que, quando ativados pela angiotensina II nos cardiomiócitos, ativam a proteína $\mathrm{G}$ acoplada que estimula a atividade da tirosina quinase, incluindo vários membros da família das proteínas quinases ativadas por mitógeno (MAPK), levando ao aumento de fatores transcricionais como o AP1, que inicia a expressão de genes relacionados ao crescimento (BADER, 2002) e necrose de miócitos (PONTES \& LEÃES, 2004). Outro fator estimulado por essa via é o fator de crescimento transformador beta (TGF- $\beta$ ), que, ao ser liberado pelos cardiomiócitos, age sobre os fibroblastos, promovendo proliferação, crescimento celular e expressão de proteínas relacionadas à fibrose, como colágeno e fibronectina. (BOOZ \& BAKER, 1995).

Os receptores AT1 podem também ser encontrados em fibroblastos cardíacos e, quando ativados pelo angiotensina II, estimulam por meio da proteína Gi acoplada ao receptor, a atividade da Src que, por sua vez, ativa as ERKs, levando à proliferação celular e a síntese de colágeno (BADER, 2002).

Visto a importância das ações da angiotensina II sobre o tecido cardíaco, atuando principalmente por meio dos receptores AT1, o bloqueio desses receptores passou a ser um importante fator no tratamento de diversas complicações cardiovasculares (GASPARO et al., 2000). Além dos efeitos benéficos ao bloquear as 
ações da angiotensina II, outra hipótese encontrada para explicar os benefícios desses antagonistas, ainda controversa, é que o bloqueio dos receptores AT1 aumenta os níveis de angiotensina II, sendo que essa, por sua vez, pode acabar estimulando as respostas sobre os receptores AT2, que aparecem por ter efeitos opostos aos receptores AT1 (URATA, NISHIMURA \& GANTER, 1996). No entanto, como citado anteriormente, os efeitos dos receptores AT2 ainda são controversos, e mais estudos se fazem necessários para confirmar essa hipótese.

A administração dos antagonistas dos receptores AT1 tem se mostrado eficaz em atenuar os efeitos deletérios da angiotensina II em diferentes situações. Por exemplo, em ratos infartados, nos quais foram observadas reduções da HC, dilatação ventricular e fibrose reacional (MIL, MILANEZ, BUSATTO, MORAES \& GOMES, 1997); em modelos de sobrecarga de volume (DENT, AROUTIOUNOVA, DHALLA \& TAPPIA, 2006) e ratos submetidos à estenose aórtica (GONÇALVES, ZORNOFF, RIBEIRO, OKOSHI, CORDARO, OKOSHI, PADOVANI, ARAGON \& CICOGNA, 2005), situação em que se verificou a redução da HC e melhora da função diastólica, que pode ser associada à diminuição da fibrose cardíaca (GONÇALVES et al, 2005; DENT et al, 2006). O uso de Losartan, um antagonista dos receptores AT1, foi eficaz em restaurar a atividade da colagênese, diminuindo o efeito pró-fibrótico da angiotensina II (CHEN et al, 2004; KAWANO et al, 2005).

No entanto, os efeitos pró-fibróticos da angiotensina II sobre o coração podem ser associados às suas ações sobre a aldosterona (BURLA, NEVES, OIGMAN \& MANDARIM-DE-LACERDA, 2006). Sendo assim, além da eficácia sobre o bloqueio das ações da angiotensina II, induzindo síntese de colágeno (CRABOS, ROTH, HAHN \& EME, 1994) e expressão de TGF- $\beta$ (SUN, ZHANG, ZHANG \& RAMIRES, 1998), os antagonistas dos receptores AT1 podem, ainda, agir de maneira benéfica sobre o sistema cardiovascular, por diminuir os níveis de aldosterona. Estudos mostram que a diminuição na síntese de colágeno observada com o bloqueio de receptores AT1 foi relacionada à diminuição nos níveis de aldosterona (KAWANO et al., 2005).

\subsection{Aldosterona}

A aldosterona é sintetizada a partir do colesterol predominantemente no córtex adrenal e modulada pela enzima aldosterona (Aldo) sintase, produto do gene CYP11B2, a partir da 11-deoxicorticosterona (DOC) (NOMURA, MOROHASHI, 
KIRITA, NONAKA, OKAMOTO, NAWATA \& OMURA, 1993). Sua síntese é regulada principalmente pela angiotensina II, níveis de potássio plasmáticos e hormônio adrecorticotrófico (ACTH) (SHIBATA, OGISHIMA, MITANI, SUZUKI, MURUKAMI \& SARUTA, 1991).

A aldosterona age sobre as células renais no néfron distal e células epiteliais do cólon distal, atuando como um modulador sobre o balanço eletrolítico, promovendo a retenção de $\mathrm{Na}^{+}$e excreção de $\mathrm{K}^{+}$(LAM, FUNDER, NIKOLIC-PATERSON, FULLER \& YOUNG, 2006). Pode ainda, agir sobre o sistema nervoso simpático, causar disfunção barorreflexa, estimular o aumento da fibrose em vasos e no miocárdio, além de ter importante papel no processo de HC, visto que concentrações plasmáticas elevadas estão diretamente correlacionadas com hipertrofia de ventrículo esquerdo e fibrose (NAGATA, OBATA, ICHIHRA, NODA, KIMATA, KATO, IZAWA, MUROHARA \& YOKOTA, 2006).

A grande maioria das ações da aldosterona ocorre pela interação com os receptores de mineralocorticóides (RM), pertencentes à superfamília de receptores esteróides, e exercem a maioria de suas ações por fatores de transcrição nuclear. Quando ligada a esses receptores, a aldosterona promove a dissociação de proteínas chaperones, que ativam o receptor e expõe os sinais de localização nuclear. No núcleo, o RM liga-se a regiões especificas do DNA, exercendo a regulação sobre a expressão gênica (FRIMM \& KOIKE, 2003).

As ações da aldosterona sobre os RM podem ser moduladas por diferentes fatores, entre eles, os glicocorticóides. Os RM apresentam maior afinidade pelos glicocorticóides do que pela aldosterona e, em condições fisiológicas, as concentrações de glicocorticóides são cerca de 10 vezes maiores do que as de aldosterona. Com isso, podemos supor que em determinadas situações os RM sejam mais estimulados por glicocorticóides do que pela aldosterona (STRUTHERS, 2004). Tem sido sugerido que os glicocorticóides podem atuar como antagonistas dos RM (QIN, RUDOLPH, BOND, ROCHA, BLOMME, GOELLNER \& ROBERT, 2003; M, SABRI, TROUVE, WASSEF, SWYNGHEDAUW \& DELCAYRE, 1995; FUNDER \& MCMAHON, 2003), visto que, em algumas condições, os níveis de aldosterona podem ser altos e mesmo assim não causar efeitos deletérios sobre órgãos e tecidos (NAGATA et al., 2006).

As ações dos glicocorticóides ou da aldosterona sobre os RM são reguladas

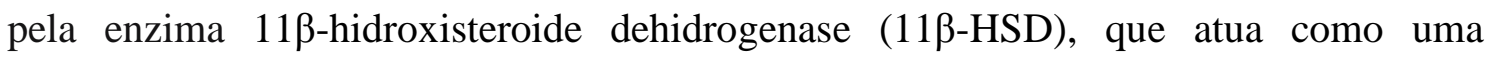


oxidase, inativando os glicocorticóides. (NAGATA et al., 2006). Dentre os diferentes subtipos encontrados dessa enzima, a 11ß-HSD tipo 2 é responsável pela conversão do cortisol e da corticosterona em 11-ceto cortisona e 11-dehidrocorticosterona, metabólitos inativos aos RM, o que contribui para maior ação da aldosterona sobre esses receptores (FRIMM \& KOIKE, 2003). Tem sido observada maior HC, quando ocorre aumento da expressão da $11 \beta-\mathrm{HSD} 2$, mostrando que o aumento do acesso da aldosterona aos RM pode ter efeitos prejudiciais ao coração (QIN et al., 2003). A atividade e a seletividade da $11 \beta-\mathrm{HSD} 2$ podem ser alteradas dependendo do tecido analisado e em alguns tipos de doenças (STRUTHERS, 2004).

Assim como o SRA, atualmente também têm sido identificados sítios extraadrenais de síntese de aldosterona, onde a expressão do gene da Aldo-sintase (CYP11B2) foi identificada em tecidos como artéria mesentérica, células musculares lisas endoteliais (TAKEDA, MIYAMORI, YONEDA, IKI, HATAKEYAMA, BLAIR, HSIEH \& TAKEDA, 1996) e coração (SILVESTRE et al., 1999). Foram detectados no tecido cardíaco, a expressão de RM, (LOMBES, OBLIN, GASC, BAULIEU, FARMAN \& BONVALET, 1992) da enzima 11ß-HSD2 (FUNDER, PEARCE, SMITH \& SMITH, 1988) e do gene da Aldo-sintase, CYP11B2, apesar de suas concentrações serem quase mil vezes menores do que nas glândulas adrenais (SILVESTRE, ROBERT, HEYMES, FAISANT MOUAS, MOALIC, SWYNGHEDAUW \& DELCAYRE, 1998).

A síntese local de aldosterona vem ganhando força na literatura, baseada em estudos realizados com ratos adrenolectomizados, em que a aldosterona plasmática não foi detectada. Entretanto, sua concentração foi aumentada no coração, quando comparado ao grupo controle, sendo a expressão do gene CYP11B2 aumentada (WEHLING, 2005). A expressão cardíaca do gene da Aldo-sintase também foi encontrada em casos de insuficiência cardíaca, onde foi mostrada a relação entre o aumento da sua expressão com o aumento de aldosterona cardíaca (YOSHIMURA, NAKAMURA, NAKAYAMA, HARDA, MIZUNO, SAKAMOTA, YAMAMURO, SAITO, NAHAO, YASUE, \& OGAWA, 2002), sendo que, em alguns casos, pode ser encontrada em níveis até seis vezes maiores, se comparado a indivíduos saudáveis (HATAKEYAMA, MIUAMORI, FUJITA, TAKEDA, YAMAMOTO \& TAKEDA, 1994), o que suporta ainda mais essa hipótese.

Uma das mais bem descritas ações da aldosterona sobre o coração é a sua ação sobre a matriz extracelular, levando ao aumento da fibrose cardíaca (ROBERT et 
al., 1995). Foi demonstrado em ratos, que a fibrose induzida pela administração de aldosterona ocorreu em ambos os ventrículos, sendo, esta, independente dos fatores hemodinâmicos (BRILLA, PICK, TAN, JANICKI \& WEBER, 1990). Em outro trabalho muito semelhante ao citado anteriormente, ratos tratados com aldosterona e altas concentrações de sódio também apresentaram aumento do colágeno cardíaco, além do aumento da fibronectina arterial e espessura da artéria carótida (NEHME, MERCIER, LABAT, BENETOS, SAFAR, DELCAYRE \& LACOLLEY, 2006). A ação da aldosterona sobre a fibrose cardíaca também tem sido demonstrada como um importante fator para o desenvolvimento do remodelamento cardíaco durante o infarto do miocárdio (SILVESTRE et al., 1999), onde o aumento da expressão cardíaca de CYP11B2 foi diretamente relacionado ao aumento fibrose (SATOH, NAKAMURA, SAITOH, SATOH, AKATSU, IWASAKA, MASUDA \& HIRAMORI, 2002).

A produção de aldosterona cardíaca foi associada à disfunção ventricular em pacientes com insuficiência cardíaca, sugerindo que o aumento da expressão do CYP11B2 aumenta a síntese de aldosterona que, por sua vez, leva à fibrose cardíaca, o que pode levar à disfunção ventricular (MIZUNO, YOSHIMURA, YASUE, SAKAMOTO, OGAWA, KUGIYAMA, HARADA, NAKAYAMA, NAKAMURA, TERUHIKO, SHIMASAKI, SAITO \& NAKAO, 2001).

Apesar das evidências já bem descritas na literatura sobre as ações da aldosterona induzindo a fibrose cardíaca, pouco se sabe sobre os verdadeiros mecanismos pelos quais isso ocorre. Em estudo recente, foi sugerido que o TGF $\beta$ pode participar das ações da aldosterona sobre a fibrose. Nesse estudo, os autores observaram que o aumento do TGF $\beta$ levou a um aumento do cálcio intracelular, o que estimulou a maior expressão do fator de crescimento de tecido conectivo (CTGF), possível responsável pelo aumento da fibrose cardíaca (SUN, ZHANG, LU, CHEN, QUINN \& WEBER, 2002).

Outro fator que tem sido recentemente sugerido por estar relacionado às ações da aldosterona sobre a fibrose cardíaca seria a osteopontina, que por sua vez, tem sido mostrada por não ser apenas um marcador inflamatório, mas também por ter um papel funcional no remodelamento cardíaco. Essa hipótese tem sido confirmada por trabalho, segundo o qual, em camundongos geneticamente modificados, apresentando deficiência para osteopontina, as ações da aldosterona sobre a fibrose cardíaca são inibidas (SAM, XIE, OOI, KERSTETTER, COLUCCI, SINGH \& SINGH, 2004). As ações da aldosterona sobre a fibrose do miocárdio e o remodelamento cardíaco, 
mediadas pela osteopontina, também têm sido mostradas em estudos nos quais o bloqueio da angiotensina II e da aldosterona foram eficazes em inibir a expressão de osteopontina no miocárdio de ratos infartados, reduzindo o colágeno cardíaco, o que nos mostra que o bloqueio das ações da angiotensina II e da aldosterona sobre seus receptores previnem a $\mathrm{HC}$ e o aumento de colágeno, em parte por inibir a expressão de osteopontina. (ZHANG, ZHOU, LEI, YUAN \& WANG, 2008).

O bloqueio da aldosterona por meio de antagonistas de RM é um eficiente método no tratamento de doenças cardíacas. Se administrados em baixa dose, os antagonistas de RM podem ser efetivos em reduzir a fibrose cardíaca, mesmo sem exercer efeitos sobre a PA e HC (NEHME et al., 2006). Estudos com esses antagonistas, como o RALES e o EPHESUS, mostram diminuição dos marcadores de colágeno e redução da dilatação do ventrículo esquerdo, sendo efetivo em reduzir a morbidade e mortalidade em pacientes com disfunção ventricular após infarto do miocárdio (FRACCAROLLO, GALUPPO, SCHMIDT \& BAUERSACHAS, 2005; FUNDER, 2005).

ZANNAD et al. (2000) mostraram que a inibição dos efeitos da aldosterona pela Espironolactona, um antagonista dos RM, diminuiu os níveis de pró-colágeno tipo I e III em pacientes com insuficiência cardíaca. Trabalhos mostram, ainda, que a Espironolactona foi efetiva em inibir a apoptose e fibrose cardíaca (BRILLA, MATSUBARA \& WEBER, 1993; LIJNEM \& PETROV, 1999).

Dados semelhantes também foram observados em animais; ratos infartados e tratados com Espironolactona apresentaram melhora da função miocárdica acompanhada por redução do colágeno cardíaco (TAKEDA, TATSUMI, MATSUNAGA, HAYASHI, KIMATA, HONSHO, NISHIKAWA, MANO, SHIRAISHI, YAMADA, TAKAHASHI, MATOBA, KOBARA \& MATSUBARA, 2007). Em ratos com insuficiência cardíaca, o tratamento com antagonista dos RM reduziu o peso de ventrículo esquerdo e a expressão de colágeno tipo I e tipo III quando comparados ao grupo placebo (FRACAROLLA et al., 2005). O uso desse antagonista mostrou-se também eficaz em ratos espontaneamente hipertensos, onde houveram importantes reduções da densidade de colágeno, perda de miócitos e HC (BURLA et al., 2006). 


\subsection{Regulação do Sistema Renina Angiotensina Aldosterona}

Como já citado anteriormente, as ações da angiotensina II sobre o coração podem ser mediadas pela aldosterona cardíaca. Em recente estudo foi observado que a infusão de angiotensina II, em ratos, induziu a fibrose cardíaca, sendo essa inibida, quando os animais foram tratados com um antagonista dos RM, mostrando que as ações da angiotensina II sobre a fibrose cardíaca estão diretamente relacionadas à aldosterona (LEA, KWAK, LUTHER, FOWLER, WANG, MA, FOGO \& BROWN, 2009). Em outro trabalho, os autores observaram que ratos tratados com angiotensina II apresentaram níveis de Aldo-sintase e DOC aumentados no coração (SILVESTRE et al., 1999).

O papel da angiotensina II sobre a regulação da aldosterona pode ainda ser confirmado por trabalhos realizados com inibidores do SRA, como observado em estudo, onde ratos tratados com angiotensina II apresentaram maiores níveis de aldosterona e quando administrado inibidor da ECA, ocorreu diminuição nesses níveis, acompanhada por redução da expressão do gene CYP11B2 (WEHLING, 2005). Resultados semelhantes também são encontrados quando os animais foram tratados com Losartan. Isso porque, em ratos infartados, a área não infartada do ventrículo esquerdo, mostrou aumento de duas vezes nas concentrações de Aldo-sintase e a administração de Losartan preveniu completamente esse aumento (SILVESTRE et al., 1999).

Apesar dos trabalhos citados acima, os quais mostram que a aldosterona cardíaca é regulada principalmente pela angiotensina II, alguns estudos têm proposto que os efeitos da aldosterona sobre o tecido cardíaco podem ser independentes das ações da angiotensina II (BROWN, 2003; SUSIC, VARAGIC, AHN, MATAVELLI \& FROHLICH, 2006). Observou-se que o tratamento com aldosterona foi surpreendentemente mais efetivo em aumentar a fibrose cardíaca em camundongos knockout para receptores AT1 do que em camundongos controle. Isso sugere que os receptores AT1 não são pré-requisitos para a aldosterona induzir fibrose cardíaca. (KAGIYAMA, MATSUMURA, FUKUHARA, SAKAGAMI, FUJII \& MITSUO, 2007).

Tem sido sugerido, ainda, um papel inverso na regulação do SRAaldosterona, onde a aldosterona seria responsável por potencializar os efeitos da angiotensina II. FRACCAROLLO et al., (2005), mostraram que a produção de aldosterona pode estimular a fibrose cardíaca tanto diretamente, atuando sobre RM, como indiretamente, por aumentar a responsividade dos receptores AT1 à angiotensina 
II, além de aumentar a expressão da ECA no coração. Também foi observada redução na expressão dos receptores AT1 com a utilização de um antagonista de RM (HARADA, YOSHIMURA, YASUE, NAKAGAWA, NAKAGAWA, HARADA, MIZUNO, NAKAYAMA, SHIMASAKI, ITO, NAKAMURA, KUWAHARA, SAITO, NAKAO \& OGAWA, 2001).

Outra hipótese mais recente seria um "cross-talking" entre os RM e receptores AT1. Nesse caso, a combinação da angiotensina II com a aldosterona induziriam efeitos específicos, diferentes dos induzidos quando apenas um é ativado (LEMARIÉ, PARADIS \& SHIFFRIM, 2008). No entanto, esses dados ainda são muito contestados na literatura e os verdadeiros mecanismos da interação e controle do SRAaldosterona são controversos.

Como demonstrado até o momento, o uso de EA induz a fibrose cardíaca e, quando associado ao treinamento físico, pode converter a $\mathrm{HC}$ fisiológica para patológica, caracterizada por aumento do colágeno intersticial e consequente perda da função ventricular, que podem estar diretamente relacionados às ações da angiotensina II e da aldosterona no coração, visto que o uso de EA pode aumentar a síntese local desse sistema, que está diretamente envolvido em alterações cardiovasculares.

Por tanto, esse projeto se justifica para melhor compreensão dos mecanismos envolvidos na estimulação da $\mathrm{HC}$ e síntese de colágeno, com o uso de EA e sua associação ao treinamento físico.

\section{MATERIAIS E MÉTODOS}

\subsection{Animais Experimentais}

Foram utilizados, no estudo, 56 ratos Wistar machos, com peso inicial entre 230-270g, provenientes do biotério da Universidade São Judas Tadeu. Os animais foram mantidos em gaiolas, três a quatro animais, separados por grupos, no biotério do Laboratório de Bioquímica da Escola de Educação Física e Esporte da USP, com temperatura mantida entre $22-24^{\circ} \mathrm{C}$ e controle de luz em ciclo invertido claro-escuro de 12 horas. Água e comida foram administradas "ad libitum". Os ratos foram identificados e pesados semanalmente.

Todos os procedimentos cirúrgicos e protocolos foram realizados de acordo com os Princípios Éticos de Experimentação Animal (COBEA, 1991). O projeto de 
pesquisa foi aprovado pelo Comitê de Ética em Pesquisa da Escola de Educação Física e Esporte da Universidade de São Paulo.

Os animais foram distribuídos randomicamente entre os grupos conforme descrito abaixo ( $n=7$ para cada grupo).

\subsubsection{Grupos Experimentais}

- $\quad$ Sedentário Controle (SC)

- $\quad$ Sedentário tratado com Anabolizante (SA)

- $\quad$ Sedentário tratado com Anabolizante + Losartan (SAL)

- $\quad$ Sedentário tratado com Anabolizante + Espironolactona (SAE)

- $\quad$ Treinado Controle (TC)

- $\quad$ Treinado tratado com Anabolizante (TA)

- $\quad$ Treinado tratado com Anabolizante + Losartan (TAL)

- $\quad$ Treinado tratado com Anabolizante + Espironolactona (TAE)

\section{2 $\quad$ Esteróides Anabolizantes}

Nos animais tratados com EA, foi administrado o Decanoato de Nandrolona (Decadurabolin; Organon, Roseland, NJ -50mg) por meio de injeções subcutâneas, duas vezes por semana, na dose de $5 \mathrm{mg} / \mathrm{kg}$ em cada aplicação, totalizando $10 \mathrm{mg} / \mathrm{kg} / \mathrm{semana}$. O EA foi diluído em veículo oleoso (óleo vegetal) e aplicado sempre no período da tarde.

A dosagem administrada nesse estudo equivale à utilizada por usuários abusivos destas substâncias - 700mg/semana em um indivíduo com $70 \mathrm{~kg}$ - equivalente a 100 vezes a dosagem terapêutica (POPE JUNIOR \& KATZ, 1988).

Os grupos que não foram tratados com EA receberam apenas doses de veículo (óleo vegetal).

\subsection{Bloqueio de Receptores AT1 e Receptores de Mineralocorticóides}

Os animais receberam o tratamento na água de beber, desde o começo da fase de adaptação, para que já no início do protocolo os sistemas estivessem inibidos. 
A fim de avaliar a participação da angiotensina II na HC e colágeno induzidos pelo uso de EA e por sua associação ao treinamento, foi utilizado o antagonista dos receptores AT1, Losartan, na dose de $20 \mathrm{mg} / \mathrm{kg} / \mathrm{dia}$, sendo previamente estipulado que cada animal consome em média 40ml/dia de água (LI, SHARIFI \& SCHIFFRIN, 1997).

A participação da aldosterona foi avaliada por meio do bloqueio dos RM com um antagonista, Espironolactona, na dose de 10mg/kg/dia (WEBER \& BRILLA, 1991).

As doses administradas nesse estudo, são bem descritas na literatura como suficientes para bloquear as ações da angiotensina II e da aldosterona, sem interferir na pressão arterial de ratos normotensos.

\section{$5.4 \quad$ Treinamento dos Animais}

O treinamento de natação foi realizado segundo protocolo adaptado de MEDEIROS, OLIVEIRA, GIANOLLA, CASARINI, NEGRÃO \& BRUM (2004), em sistema de natação com água aquecida entre $30-32^{\circ} \mathrm{C}$ (FIGURA 1).

O treinamento teve duração de 10 semanas. Foram realizadas cinco sessões semanais com aumento gradual do tempo, chegando a 60 minutos, e da sobrecarga de trabalho, peso na cauda do animal, até ser atingido 5\% do peso corporal (TABELA 1).

Esse protocolo foi caracterizado como treinamento de baixa intensidade e longa duração, sendo efetivo na promoção de adaptações cardiovasculares e no aumento da capacidade oxidativa muscular (MEDEIROS et al., 2004).

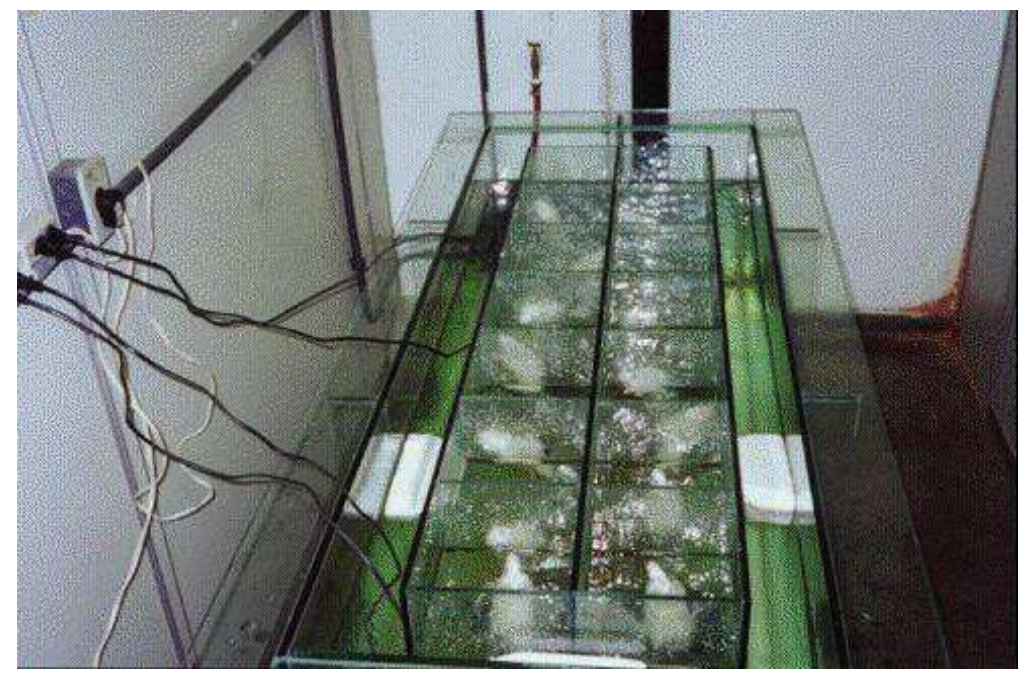

FIGURA 1 - Sistema de natação aquecido para ratos 
Tabela 1- Protocolo de treinamento físico.

\begin{tabular}{c|c|c|c|c|c}
\hline Semanas & $\mathbf{2}^{\mathbf{a}}$ & $\mathbf{3}^{\mathbf{a}}$ & $\mathbf{4}^{\mathbf{a}}$ & $\mathbf{5}^{\mathbf{a}}$ & $\mathbf{6}^{\mathbf{a}}$ \\
\hline 1 & $15 \mathrm{~min} . \mathrm{s} / \mathrm{s}$ & $20 \mathrm{~min} . \mathrm{s} / \mathrm{s}$ & $40 \mathrm{~min} . \mathrm{s} / \mathrm{s}$ & $60 \mathrm{~min} .5 \% \mathrm{pc}$ & $60 \mathrm{~min} .5 \% \mathrm{pc}$ \\
2 & $40 \mathrm{min.3 \% pc}$ & $50 \mathrm{~min} .4 \% \mathrm{pc}$ & $60 \mathrm{~min} .5 \% \mathrm{pc}$ & $60 \mathrm{~min} .5 \% \mathrm{pc}$ & $60 \min .5 \% \mathrm{pc}$ \\
3 a 10 & $40 \mathrm{~min} .5 \% \mathrm{pc}$ & $50 \min .5 \% \mathrm{pc}$ & $60 \min .5 \% \mathrm{pc}$ & $60 \min .5 \% \mathrm{pc}$ & $60 \min .5 \% \mathrm{pc}$ \\
\hline
\end{tabular}

Tabela demonstra o protocolo de natação, com o tempo de treinamento da $1^{\mathrm{a}}$ a $10^{\mathrm{a}}$ semana do protocolo, realizado de segunda a sexta-feira. $(\mathrm{s} / \mathrm{s})=$ sem sobrecarga $(\mathrm{pc})=$ peso corporal.

\subsection{Medidas Hemodinâmicas}

\subsubsection{Avaliação da Pressão Arterial e Frequência Cardíaca}

A PA foi aferida, semanalmente, pelo método não invasivo de pletismografia da artéria caudal (registro indireto da PA). Os animais foram previamente mantidos sob restrição de movimentos, em caixa de acrílico, e submetidos a aquecimento moderado, para promover a vasodilatação da artéria caudal. O registro da PA de cauda foi realizado por meio da colocação de manguito de borracha na região proximal da cauda e ligado ao esfigmomanômetro para insuflar e desinsuflar gradualmente o manguito de 0 a 250/300 mmHg. Numa porção mais distal da cauda foi acoplado um transdutor pneumático, para detecção dos sinais de passagem da onda de pulso da PA na artéria caudal e registrados no sistema AT/CODAS (DataQ Instruments, Inc., Ohio, USA), com frequência de amostragem de $1000 \mathrm{~Hz}$. A PA de cauda equivale a pressão do manguito em que o pulso de pressão desaparece ou reaparece, quando a pressão exercida sobre a cauda tornar-se ligeiramente menor que o valor da pressão intra-arterial, desobstruindo o fluxo sanguíneo na artéria caudal e permitindo a detecção do pulso de pressão. A FC é calculada a partir do intervalo de tempo de cada pulso de PA detectado pelo transdutor, sem a oclusão da passagem do fluxo sanguíneo na cauda. Foram realizadas, para cada animal, cinco medidas de PA de cauda e FC em repouso, sendo desprezadas a primeira e a última medida e calculada a média aritmética entre os valores restantes. 
A avaliação da função ventricular foi realizada por meio de avaliação ecocardiográfica. As medidas ecocardiográficas seguiram as recomendações do Comitê de Padronização do modo $\mathrm{M}$ da Sociedade Americana de Ecocardiografia (SAHN, DEMARIA, KISSLO \& WEYMAN, 1978; SCHILER, SHAH, CRAWFORD, DEMARIA, DEVEREUX, FEIGENBAUM, GUTGESELL, REICHEK, SAHN \& SCHNITTGER, 1989). É importante salientar que a acurácia e reprodutibilidade do exame ecocardiográfico transtorácico em estimar o tamanho e a função do ventrículo esquerdo em roedores têm sido confirmadas em uma série de estudos (LITWIN, KATZ, MORGAN \& DOUGLAS, 1994).

Os exames ecocardiográficos transtorácicos foram realizados após o período experimental em todos os grupos estudados. Eles foram realizados por um único observador, cego para os grupos de animais, e em cada exame foram coletadas um total de cinco medidas para cada variável, sendo calculadas posteriormente a média e o desvio padrão dessas medidas. Os exames ecocardiográficos foram realizados com os animais anestesiados, por via intraperitoneal, com uma mistura de Xilasina (10mg/Kg) e Ketamina (90 mg/Kg). O animal anestesiado foi colocado em decúbito dorsal, em uma mesa cirúrgica apropriada para o posicionamento do transdutor no hemitórax esquerdo do animal. Foi utilizado o equipamento Sequóia 512 (ACUSON Corporation, Mountain View, CA), com transdutor de $15 \mathrm{MHz}$. As imagens foram realizadas com frequência de cerca de $10 \mathrm{MHz}$, para otimização da resolução e a penetração no animal. Para os registros das imagens, foi utilizado gel de transmissão para ultrassom de viscosidade média/alta (General Imaging Gel, ATL. Reedsville, USA). As imagens foram armazenadas em fitas de videocassete para futuras análises.

A partir da visualização do ventrículo esquerdo (corte transversal), ao nível dos músculos papilares, foi realizado o modo $\mathrm{M}$ e obtidas às médias das seguintes variáveis: diâmetro diastólico (DDiaVE) e sistólico (DSisVE) do ventrículo esquerdo, a espessura do septo interventricular na diástole (SIVEDia), a espessura do septo interventricular na sístole (SIVESis) e da parede posterior do ventrículo esquerdo em sístole (PPVESis) e diástole (PPVEDia). A fração sistólica foi determinada pela fração de encurtamento (FEn) e a fração de ejeção (FEj). Já as imagens obtidas por meio do Doppler foram utilizadas para determinar a função diastólica (pico de velocidade da onda E, pico de velocidade da onda A, relação E/A e TRIV). Além disso, calculamos a 
massa do ventrículo esquerdo (MVE) segundo orientação da Sociedade Americana de Ecocardiografia (SAHN, et al., 1978; SCHILLER et al.; 1989), que estima a MVE por meio da utilização da seguinte fórmula matemática: LVM=[(DDVE+SIV+PP $)^{3}$ $\left.(\mathrm{DDVE})^{3}\right] \mathrm{x} 1,047$, onde $1,047\left(\mathrm{mg} / \mathrm{mm}^{3}\right)$ corresponde à densidade do miocárdio.

\subsection{Análises Morfológicas e Morfométricas}

Após o protocolo experimental (24 horas após a última sessão de treinamento), os animais foram decapitados; o coração foi removido da cavidade torácica e dissecado para separar o ventrículo direito do ventrículo esquerdo (parede livre e septo).

O ventrículo esquerdo foi dividido em duas partes, sendo a base congelada em nitrogênio líquido e mantida em freezer a $-80^{\circ} \mathrm{C}$ para análises bioquímicas e moleculares, e o ápice, mantido em formaldeído $6 \%$ por 24 horas e armazenado em álcool 70\% para análises morfométricas.

\subsubsection{Hipertrofia Cardíaca}

A hipertrofia cardíaca foi avaliada pela soma do peso do ventrículo esquerdo (parede livre e septo) corrigido pelo peso corporal do animal (VE/PC) (mg/g).

\subsubsection{Diâmetro de Cardiomiócitos}

O ventrículo esquerdo foi fixado em formaldeído $6 \%$ e após a inclusão em parafina foram realizados cortes histológicos de $5 \mu \mathrm{m}$ de espessura, corados com hematoxilina e eosina (HE) para visualização das estruturas celulares.

Três cortes de VE para cada animal foram selecionados, aleatoriamente, para visualização em microscópio óptico, utilizando objetiva de imersão com aumento de 40x. Para cada corte histológico foram determinados, aproximadamente, 20 campos visuais.

Os cardiomiócitos selecionados foram aqueles que apresentaram núcleo bem visível e membrana celular intacta. A imagem do cardiomiócito foi obtida na tela do computador e seu diâmetro transverso traçado manualmente, sendo que a linha traçada 
atravessou o centro do núcleo. O cálculo foi feito por um programa comercial (Quantimet 500, Cambridge Instruments).

\subsubsection{Fração Volume de Colágeno Cardíaco}

O coração foi cortado, fixado e incluso em parafina. Foram obtidos cortes histológicos de $5 \mu \mathrm{m}$ de espessura, corados com picrosirius red e montados em lâmina de vidro. Os cortes foram avaliados no sistema computadorizado de imagens (Leica Q500 iw e Leica DMLS, Leica Imaging Systems, Ltda., Cambridge, UK), utilizando-se lente com aumento de 20x.

Para quantificação do colágeno cardíaco, a fração de volume de colágeno (FVC) foi calculada pela razão percentual da área do tecido miocárdico corado positivamente para as fibras de colágeno (quantidade absoluta de colágeno), pela área total do tecido miocárdico. Foram examinados 20 campos visuais para cada amostra.

\subsection{Análises Bioquímicas e Moleculares}

\subsubsection{Atividade da Enzima Conversora de Angiotensina Cardíaca}

As amostras de tecido cardíaco foram homogeneizadas em tampão apropriado (para cada $100 \mathrm{mg}$ de tecido foram utilizados $1 \mathrm{~mL}$ de Tris-HCL, 0,1 M, contendo $50 \mathrm{mM}$ de $\mathrm{NaCL}$ ). $\mathrm{O}$ homogeneizado foi submetido à centrifugação a 3000 rpm, durante 15 minutos a $4^{\circ} \mathrm{C}$. O sobrenadante foi armazenado a $-80^{\circ} \mathrm{C}$, até o dia da dosagem enzimática.

Para o ensaio, foram utilizados $15 \mu \mathrm{l}$ de homogeneizado mantidos sob incubação com uma solução de Abz-FRK(Dnp)P-OH (Abz = ácido orthoaminobenzóico; Dnp = dinitrophenil) $15 \mu \mathrm{M}$ em tampão (Tris-HCL $1 \mathrm{mM}, \mathrm{NaCl} 50 \mathrm{mM}$ e $\left.\mathrm{ZnCl}_{2} 10 \mu \mathrm{M}\right)$ em um volume final de $200 \mu \mathrm{l}$. Em uma segunda etapa, a atividade enzimática foi determinada de forma contínua em fluorímetro $\left(\lambda_{\mathrm{em}}=420 \mathrm{~nm}\right)$ e $\left(\lambda_{\mathrm{ex}}\right.$ $=320 \mathrm{~nm}$ ), isto é, medindo-se a fluorescência por 60 minutos (uma leitura por minuto). Este método se baseia na utilização de um substrato fluorescente (Abz-FRK(Dnp)P$\mathrm{OH})$ que é clivado com alta afinidade pela ECA (Kcat/Km=45,4-1.s-1) (ARAUJO, MELO, CESARI, JULIANO \& CARMONA, 2000). Como controle negativo, a hidrólise do Abz-FRK(Dnp)P-OH foi abolida no homogeneizado de tecido por $0,5 \mu \mathrm{M}$ de Captopril. 
A partir da leitura das amostras, foi obtida uma curva de fluorescência por unidade de tempo e a inclinação desta curva resultou na atividade da ECA, convertida em $\mu \mathrm{mol}$ de substrato hidrolisado por minuto.

A atividade enzimática foi normalizada através do conteúdo de proteína de cada amostra, determinada por meio do método de BRADFORD, 1976. A atividade da ECA está expressa em uF.min ${ }^{-1} \cdot \mathrm{ml}^{-1} \cdot \mathrm{mg}^{-1}$ de proteína.

\subsubsection{Expressão de Proteínas Cardíacas}

Para as análises da expressão protéica dos receptores AT1 e AT2 foi utilizada a técnica de Western blotting, seguindo o seguinte protocolo:

\subsubsection{Preparação dos Homogeneizados dos Ventrículos}

Os ventrículos dos animais foram homogeneizados através de homogeneizador Polytron (PT-K Brinkman Instruments) em volumes ( $9 \mathrm{X}$ seu peso) com tampão de lise hipotônico, contendo $10 \mathrm{mM}$ TrisHCl e 5 mM EDTA, pH 7,4 na presença de uma mistura de inibidores de angiotensinases e proteases. O processo de homogeneização foi realizado três vezes, durante 15 segundos, com intervalos de 20 segundos, a $4^{\circ} \mathrm{C}$. O homogeneizado foi centrifugado a $12.5000 \mathrm{rpm}$ por 20 minutos a $4^{\circ} \mathrm{C}$. O sobrenadante foi transferido para tubos individuais. A concentração de proteína das amostras foi analisada por meio do método de Bradford, 1976 (Biorad-EUA). Após esse procedimento, cada amostra foi diluída em tampão Laemmli (LAEMMLI, 1970) na proporção de 1:4 e submetida a eletroforese em gel de poliacrilamida (SDS-PAGE 8\%) no aparelho para minigel (Mini-Protean). Em cada gel foi aplicado um marcador de peso molecular com valores pré-estabelecidos.

\subsubsection{Immunoblotting}

As proteínas foram transferidas eletricamente para uma membrana de nitrocelulose, por meio de um aparelho da Bio-Rad, durante cerca de uma hora sob 120 volts, em tampão de transferência contendo Tris (3,04 g para 1L de solução), glicina (14,4 g para 1L de solução), metanol (20\%) e SDS (10\%). Em seguida, realizou-se o bloqueio dos sítios antigênicos inespecíficos, por meio de uma mistura contendo PBS com o detergente tween 20 (PBS-T; 5\%) e leite desnatado (5\%) por três horas, em temperatura ambiente $\left(20-25^{\circ} \mathrm{C}\right)$ com agitação constante. A membrana foi lavada três vezes com solução tampão (PBS-T); incubada com o anticorpo primário para AT1 
(1:1000) ou AT2 (1:2000) diluído na solução PSB-T contendo $0,3 \%$ de BSA a $4^{\circ} \mathrm{C}$ overnight com agitação constante. Após a incubação com o anticorpo primário, a membrana foi lavada três vezes em solução de PBS-T. Em seguida, ela foi incubada com o anticorpo secundário (1:2000) em solução bloqueadora (PBS-T contendo 0,3\% de BSA), por uma hora e meia em temperatura ambiente, com agitação constante. Após a incubação com o anticorpo secundário, a membrana foi lavada três vezes em solução de PBS-T, a fim de remover o excesso de detergente. Por fim, a imunodetecção foi realizada por meio do método de quimioluminescência, de acordo com as instruções do fabricante (Enhancer Chemi-Luminescence, Amersham Biosciences, NJ-USA) que consistem na incubação das membranas com $1 \mathrm{ml}$ de cada um dos dois reagentes do kit por um minuto. A seguir as membranas foram expostas a filmes de raio-X.

Para analisar a intensidade das bandas nas auto-radiografias, as figuras obtidas por scaner foram analisadas por meio do programa de análise de densitometria óptica Scion Image, fornecido gratuitamente pela NIH (USA) via internet.

Esclarecemos que todos os anticorpos primários e secundários foram testados em diferentes titulações, assim como a solução bloqueadora e demais etapas metodológicas. Além disso, foram feitos controles negativo e positivo para cada anticorpo primário utilizado.

\subsubsection{Expressão Gênica Cardíaca}

A expressão gênica de colágeno tipo I, colágeno tipo III, aldosterona sintase (CYP11B2), receptores de mineralocorticóides (RM), 11ß-hidroxisteroide desidrogenase tipo 2 (11 $\beta$-HSD2), fator de crescimento transformador beta (TGF $\beta$ ) e osteopontina, foram determinadas pela técnica de reação de polimerase em cadeia (RTPCR). Foi utilizado como normalizador o gene da gliceraldeído-3-fosfato desidrogenase (GAPDH) que não sofre alterações com as condições experimentais.

As sequências de oligonucleotídeos utilizados nesse estudo estão descritas na tabela 2 . 
Tabela 2. Sequência dos oligonucleotídeos para os primers utilizados no RT-PCR.

\begin{tabular}{|c|c|c|c|}
\hline Gene & tipo & Sequência dos primers $\left(5^{`}-3^{\prime}\right)$ & Amplicon \\
\hline Col 1 $\alpha 1$ & $\begin{array}{l}\text { Sense } \\
\text { Anti-sense }\end{array}$ & $\begin{array}{l}\text { AGAGAGCATGACCGATGGA } \\
\text { GAGGTTGCCAGTCTGTTGG }\end{array}$ & $172 \mathrm{pb}$ \\
\hline $\operatorname{Col} 3 \alpha 1$ & $\begin{array}{l}\text { Sense } \\
\text { Anti-sense }\end{array}$ & $\begin{array}{l}\text { AAGGTCCACGAGGTGACAA } \\
\text { AGGGCCTGGACTACCAACT }\end{array}$ & 143 PB \\
\hline CYP11B2 & $\begin{array}{l}\text { Sense } \\
\text { Anti-sense }\end{array}$ & $\begin{array}{l}\text { GGATGTCCAGCAAAGTCTC } \\
\text { ATTAGTGCTGCCACAATGC }\end{array}$ & $324 \mathrm{pb}$ \\
\hline $\mathrm{RM}$ & $\begin{array}{l}\text { Sense } \\
\text { Anti-sense }\end{array}$ & $\begin{array}{l}\text { GCTTTGATGGTAGCTGCG } \\
\text { TGAGCACCAATCCGGTAG }\end{array}$ & $154 \mathrm{pb}$ \\
\hline $11 \beta$-HSD2 & $\begin{array}{l}\text { Sense } \\
\text { Anti-sense }\end{array}$ & $\begin{array}{l}\text { CCGGTTGTGACACTGGTTTTG } \\
\text { GGGGTATGGCATGTCTCCTG }\end{array}$ & $419 \mathrm{pb}$ \\
\hline TGF $\beta$ & $\begin{array}{l}\text { Sense } \\
\text { Anti-sense }\end{array}$ & $\begin{array}{l}\text { GGCGGTGCTCGCTTTGTA } \\
\text { GCGGGTGACTTCTTTGGC }\end{array}$ & $106 \mathrm{pb}$ \\
\hline OTPN & $\begin{array}{l}\text { Sense } \\
\text { Anti-sense }\end{array}$ & $\begin{array}{l}\text { GTCCTTCACTGCCAGCACAC } \\
\text { GAACTCGCCTGACTGTCGAT }\end{array}$ & $450 \mathrm{pb}$ \\
\hline$\overline{\text { GAPDH }}$ & $\begin{array}{l}\text { Sense } \\
\text { Anti-sense }\end{array}$ & $\begin{array}{l}\text { ATGGGTGTGAACCACGAGAA } \\
\text { CGAGTACTGGTGTCAGGTA }\end{array}$ & $141 \mathrm{pb}$ \\
\hline
\end{tabular}

\subsubsection{Extração do RNA Total}

As amostras de cada tecido, pesando $100 \mathrm{mg}$, foram homogeneizadas em 1 mL de TRIZOL®Reagent (Invitrogen) e a extração seguida conforme instruções do fabricante. O RNA precipitado foi lavado com etanol 75\% para eliminar resíduos de fenol e sal, e solubilizado em água tratada com dietil-pirocarbonato (DEPC).

Posteriormente, foi realizada a leitura espectrofotométrica das soluções nos comprimentos de onda 260 e 280 nm para determinação da concentração de RNA total em cada amostra extraída e de uma estimativa do seu grau de pureza a partir da relação $\mathrm{A}_{260} / \mathrm{A}_{280}$.

A integridade foi verificada através de eletroforese em gel de agarose $1 \%$, contendo $0.5 \mu \mathrm{g} / \mathrm{mL}$ de brometo de etídeo. O gel imerso em tampão TAE $1 \mathrm{X}$ ( $40 \mathrm{~nm}$ Tris-acetato, 2 mM EDTA) e a eletroforese realizada a 100 Volts por aproximadamente 40 minutos. A quantidade de amostra foi avaliada pela análise da intensidade das bandas correspondentes às subunidades do RNA ribossomal 28S e 18S, onde a relação 28S/18S 
deverá ser aproximadamente dois. Amostras que apresentaram algum grau de degradação foram descartadas.

\subsubsection{Síntese de cDNA}

Foram utilizados $2 \mu \mathrm{g}$ de RNA total, extraídos a partir do tecido cardíaco dos ratos. As amostras foram incubadas com $0.5 \mu \mathrm{g} / \mathrm{mL}$ de oligo dT12-18 a $65^{\circ} \mathrm{C}$ por cinco minutos, para obtenção da primeira fita de cDNA. A transcrição reversa das amostras foi realizada em volume total de $20 \mu \mathrm{l}$ contendo 3U de RNAsin (Promega, Madison, USA), 10mM de dNTPs, 0.1 M de DTT, 1X tampão de enzima, e 2.5U de SuperScript Reverse Transciptase II (Invitrogen, Brasil). Após incubação por 1 hora a $42^{\circ} \mathrm{C}$, a temperatura foi elevada a $95^{\circ} \mathrm{C}$ por cinco minutos. $\mathrm{O}$ cDNA obtido foi estocado em freezer $-20{ }^{\circ} \mathrm{C}$.

\subsubsection{Transcrição Reversa (RT-PCR)}

A amplificação dos segmentos de cDNA foi realizada nas seguintes condições: $5-7 \mu 1$ de produto da reação de transcrição reversa (cDNA), 2,5 $\mu 1$ do tampão de reação 10x (Tris- $\mathrm{HCl} 20 \mathrm{mM}(\mathrm{pH} 8,4), \mathrm{KCl} 50 \mathrm{mM}$ ), $0,75 \mu \mathrm{l}$ de $\mathrm{MgCl}_{2} 50 \mathrm{mM}, 2 \mu 1$ da mistura de dNTP 2,5mM (dATP, dTTP, dCTP e dGTP), 0,5 $\mu$ le cada primer $(12,5 \mu \mathrm{M}$ concentração final) e $0,25 \mu 1$ da enzima Taq DNA polimerase Platinum (Gibco) (2,5 unidades da enzima) e $\mathrm{H}_{2} \mathrm{O}$ estéril (q.s.p. $25 \mu \mathrm{l}$ ).

As reações de PCR foram realizadas em termociclador MiniCycler MJ Research, seguindo as condições especificadas para cada par de primers. Os passos da reação de anelamento e amplificação foram os seguintes: 1) reação de denaturação e ativação da Taq, $94^{\circ} \mathrm{C}, 5 \mathrm{~min}$, um ciclo; 2) reação de denaturação, $94^{\circ} \mathrm{C}, 1 \mathrm{~min}, 35$ ciclos; 3) reação de anelamento, $55^{\circ} \mathrm{C}, 1 \mathrm{~min}, 35$ ciclos; 4) reação de extensão, $72^{\circ} \mathrm{C}, 30$ s, 35 ciclos; 5) reação de extensão final, $72^{\circ} \mathrm{C}, 10 \mathrm{~min}, 35$ ciclos; 6) resfriamento, $4^{\circ} \mathrm{C}$, tempo indeterminado.

\subsubsection{Avaliação Eletroforética dos Produtos de Amplificação}

Para a análise de formação dos produtos de PCR, alíquotas de $10 \mu \mathrm{l}$ dos produtos de reação foram submetidas à eletroforese em gel de agarose a 3\%, em tampão 
TAE 1x. O marcador de peso molecular utilizado foi o DNA "Ladder" de 100 pb (Gibco-BRL).

As bandas foram visualizadas por meio da incidência de radiação ultravioleta, em uma câmara escura equipada com um transluminador e as imagens, adquiridas pelo programa Chemilmager 5500 (Alpha Innotech, CA, USA).

As imagens foram salvas, a intensidade das bandas obtidas e analisadas utilizando o programa de análise de densitometria óptica Scion Image, fornecido gratuitamente pela NIH (USA) via internet.

\subsection{Análise Estatística}

Os dados obtidos neste estudo estão apresentados na forma de média \pm desvio padrão. A análise estatística foi realizada com a utilização do software STATISTIC BASIC por meio de análise de variância de dois fatores (ANOVA twoway). Para melhor compreensão dos resultados, os grupos foram analisados em três etapas, sendo primeiramente comparados os grupos controle com os grupos tratados com EA (treinamento físico e EA como variáveis independentes). Em um segundo momento, os grupos tratados com EA foram comparados com os grupos tratados com Losartan (treinamento físico e Losartan como variáveis independentes) e em um terceiro momento, foram comparados os grupos tratados com EA com os grupos tratados com Epironolactona (treinamento físico e Espironolactona como variáveis independentes). Para análise da pressão arterial pré e pós-tratamento experimental foi realizada ANOVA para medidas repetidas. Quando F significante foi aplicado teste post-hoc de Duncan de múltiplas comparações. Para análise da frequência cardíaca pré e pós-tratamento foi realizado Teste t de Student pareado. Foi aceito como valores significantes um $\mathrm{p} \leq 0.05$.

\section{RESULTADOS}

\subsection{Pressão Arterial}

Como observamos na FIGURA 2A, no início do protocolo experimental os animais não apresentavam diferenças nos valores de PA entre os grupos avaliados. Após o período experimental, os animais tratados com EA, assim como os submetidos ao treinamento físico de natação, não apresentaram diferenças significantes na PA em relação ao período pré-tratamento. 
Observaram-se resultados semelhantes, quando os animais foram tratados com Losartan (FIGURA 2B) ou com Espironolactona (FIGURA 2C). Não foram observadas diferenças significantes na PA entre os grupos estudados nos períodos pré e pós-tratamento.
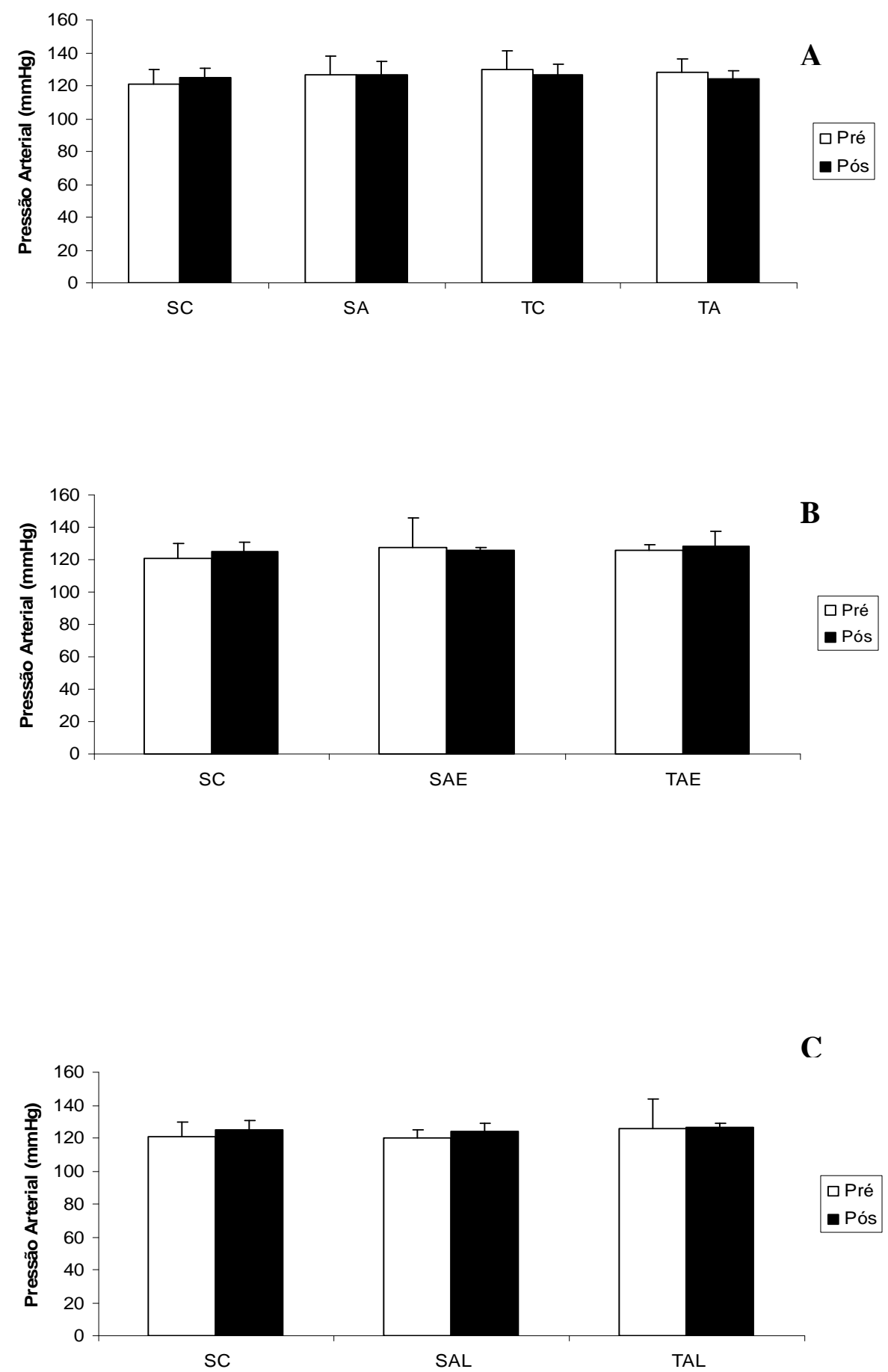
FIGURA 2 - Pressão arterial (mmHg). Efeitos da administração de EA (A) associado ao Losartan (B) ou a Espironolactona (C) sobre a pressão arterial pré e pós tratamento experimental em animais sedentários e treinados. Sedentário controle ( $\mathrm{SC}, \mathrm{n}=7)$, $\underline{\text { sedentário tratado com anabolizante }(\mathrm{SA}, \mathrm{n}=7) \text {, treinado controle }(\mathrm{TC}, \mathrm{n}=7) \text {, treinado }}$ tratado com anabolizante (TA, n=7), sedentário tratado com anabolizante e Losartan (SAL, n=7), treinado tratado com anabolizante e Losartan (TAL, $\mathrm{n}=7$ ), sedentário tratado com anabolizante e Espironolactona (SAE, $n=7$ ) e treinado tratado com anabolizante e Espironolactona (TAE, n=7). Os resultados são apresentados como média \pm DP.

\subsection{Frequência Cardíaca}

Como já esperado, não foram observadas diferenças significantes na FCrep entre os grupos sedentários analisados pré e pós-tratamento experimental.

Conforme se observa na FIGURA 3, o treinamento físico de natação utilizado nesse estudo reduziu a FCrep no grupo treinado controle, quando comparado pré e pós-treinamento físico. Entretanto, quando a administração de EA foi associada ao treinamento de natação (TA), não foi observada redução da FCrep.

Como resultados muito interessantes encontrados nesse estudo, destacam-se os diferentes efeitos observados quando o Losartan ou Espironolactona são associados ao EA. Os animais que realizaram o treinamento físico e foram tratados com EA e Losartan (TAL) não apresentaram redução da FCrep. Por outro lado, o grupo que recebeu Espironolactona apresentou redução da FC de repouso, após o período de tratamento.

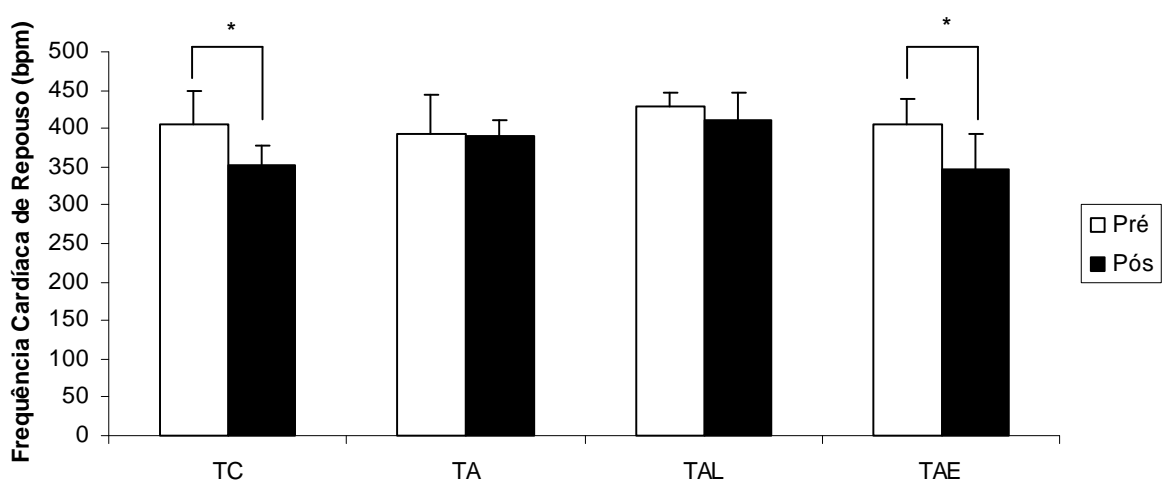


FIGURA 3 - Frequência cardíaca de repouso pré e pós treinamento físico (bpm). Efeitos da administração de EA associado ao treinamento físico de natação, Losartan ou Espironolactona sobre a frequência cardíaca de repouso pré e pós protocolo experimental. Treinado controle $(\mathrm{TC}, \mathrm{n}=7$ ), treinado tratado com anabolizante (TA, $\underline{\mathrm{n}=7 \text { ), treinado tratado com anabolizante e Losartan (TAL, } \mathrm{n}=7 \text { ) e treinado tratado com }}$ anabolizante e Espironolactona (TAE, $\mathrm{n}=7$ ). Os resultados são apresentados como $\underline{\text { média } \pm \text { DP. }(*) \text { Diferença significante entre os períodos pré e pós treinamento de }}$ natação no mesmo grupo, $\mathrm{p}<0,05$.

\subsection{Função Ventricular}

Conforme descrito na Tabela 3, o tratamento com EA não alterou a função ventricular no grupo sedentário (SA). No entanto, quando a administração de EA foi associada ao treinamento físico de natação (TA), houve redução do pico de velocidade da onda E e da relação E/A, o que sugere uma possível disfunção diastólica nesse grupo, em relação aos outros grupos analisados.

TABELA 3 - Índices de função ventricular sistólica e diastólica obtidos pelo exame ecocardiográfico nos grupos Sedentário controle (SC), Sedentário anabolizante (SA), Treinado controle (TC) e Treinado anabolizante (TA). Média \pm Desvio Padrão. Dados analisados pela análise de variância de 2 -caminhos com post-hoc de Duncan. $* p<0,05$ vs SC, SA, e TC.

\begin{tabular}{ccccc}
\hline Medida & SC & SA & TC & TA \\
\hline Função Sistólica & & & & \\
FEj (\%) & $81,05 \pm 4,38$ & $79,03 \pm 5,17$ & $78,55 \pm 2,95$ & $79,02 \pm 3,76$ \\
FEn (\%) & $44,30 \pm 3,44$ & $42,39 \pm 4,09$ & $40,23 \pm 2,74$ & $40,77 \pm 3,78$ \\
Função Diastólica & & & & \\
Pico E (m/s) & $0,61 \pm 0,07$ & $0,56 \pm 0,06$ & $0,62 \pm 0,06$ & $\mathbf{0 , 4 2 \pm 0 , 1 0 *}$ \\
Pico A (m/s) & $0,43 \pm 0,08$ & $0,40 \pm 0,05$ & $0,40 \pm 0,09$ & $0,38 \pm 0,04$ \\
Relação E/A & $1,53 \pm 0,08$ & $1,34 \pm 0,12$ & $1,68 \pm 0,23$ & $\mathbf{1 , 0 7 \pm 0 , 2 5 *}$ \\
TRIV (ms) & $25,2 \pm 1,7$ & $24,2 \pm 2,5$ & $30,6 \pm 2,8$ & $23,5 \pm 2,3$ \\
\hline
\end{tabular}

Quando os animais que receberam EA e realizaram o treinamento físico foram tratados com Losartan (TAL) ou com Espironolactona (TAE), observou-se que os efeitos deletérios sobre função diastólica foram inibidos (TABELA 4). 
TABELA 4 - Índices de função ventricular sistólica e diastólica obtidos pelo exame ecocardiográfico nos grupos Treinado anabolizante (TA), Treinado anabolizante Losartan (TAL) e Treinado anabolizante Espironolactona (TAE). Média \pm Desvio Padrão. Dados analisados pela análise de variância de 2-caminhos com post-hoc de Duncan. $\ddagger \mathrm{p}<0,05$ vs TA.

\begin{tabular}{rccc}
\hline Medida & TA & TAL & TAE \\
\hline Função Sistólica & & & \\
FEj (\%) & $79,02 \pm 3,76$ & $82,12 \pm 2,74$ & $78,66 \pm 3,03$ \\
FEn (\%) & $40,77 \pm 3,78$ & $42,08 \pm 2,76$ & $40,42 \pm 3,71$ \\
Função Diastólica & & & \\
Pico E (m/s) & $0,42 \pm 0,10$ & $\mathbf{0 , 5 9 \pm 0 , 0 7}$ & $\mathbf{0 , 5 7 \pm 0 , 0 7}$ \\
Pico A (m/s) & $0,38 \pm 0,04$ & $0,404 \pm 0,09$ & $0,417 \pm 0,05$ \\
Relação E/A & $1,07 \pm 0,25$ & $\mathbf{1 , 3 9 \pm 0 , 1 2} \neq$ & $\mathbf{1 , 4 6 \pm 0 , 1 4}$ \\
TRIV (ms) & $23,5 \pm 2,3$ & $30 \pm 1,15$ & $31,50 \pm 1$ \\
\hline
\end{tabular}

\subsection{Hipertrofia Cardíaca}

Na FIGURA 4A, podemos observar os efeitos do EA, do treinamento de natação e da associação de ambos sobre a HC. O grupo que apenas realizou o treinamento físico (TC) apresentou $\mathrm{HC}$ em relação ao grupo sedentário controle. $\mathrm{O}$ tratamento com EA induziu a $\mathrm{HC}$ no grupo sedentário quando comparado ao grupo controle. No entanto, quando o EA foi associado ao treinamento físico, a HC, avaliada pelo índice de hipertrofia, foi ainda mais pronunciada em relação aos grupos SA e TC.

Resultados referentes à espessura do septo interventricular e parede posterior do VE calculados por ecocardiograma são demonstrados na FIGURA 4B. Podemos observar aumento do septo e da parede posterior nos grupos SA e TC em relação ao grupo sedentário controle. Assim como os resultados de HC, o grupo tratado com EA, que realizou o treinamento físico, apresentou um amento ainda mais pronunciado do septo e da parede posterior quando comparados ao grupo TC, confirmando os resultados observados de HC. 

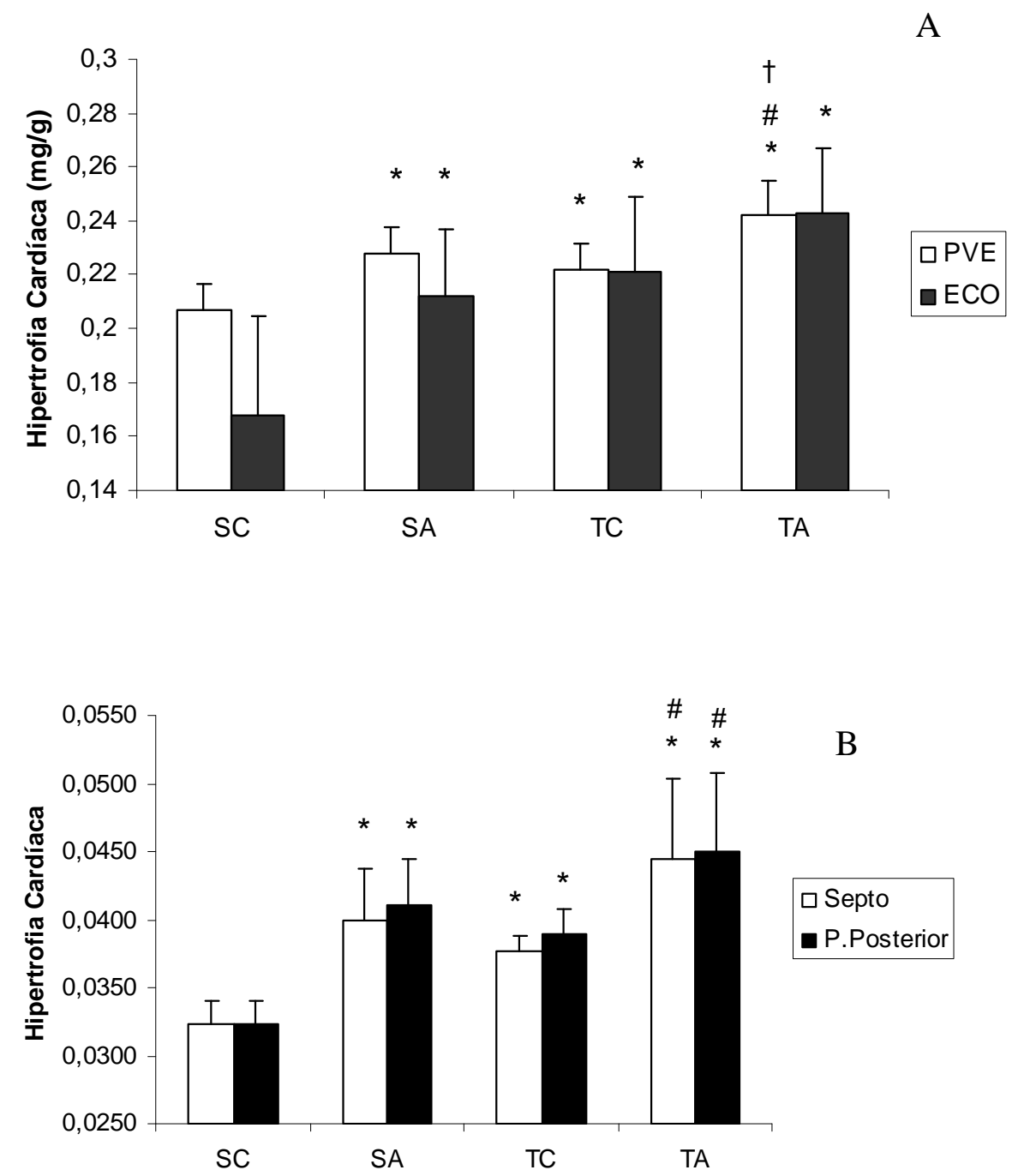

FIGURA 4 - Hipertrofia cardíaca $(\mathbf{m g} / \mathbf{g})$. Efeitos na administração de EA e a sua associação ao treinamento físico sobre a $\mathrm{HC}$ avaliada pelo índice de $\mathrm{HC}$ (peso do VE/ massa corporal) e por ecocardiograma (LVM=[(DDVE+SIV+PP) $\left.\left.{ }^{3}-(\mathrm{DDVE})^{3}\right] \times 1,047\right)$ (3A) e sobre a espessura do septo e parede posterior do ventrículo esquerdo avaliado por ecocardiograma (3B). Sedentário controle $(\mathrm{SC}, \mathrm{n}=7)$, sedentário tratado com anabolizante ( $\mathrm{SA}, \mathrm{n}=7$ ), treinado controle ( $\mathrm{TC}, \mathrm{n}=7$ ), treinado tratado com anabolizante (TA, n=7). Os resultados são apresentados como média \pm DP.(*) Diferença significante em relação ao grupo SC. (\#) Diferença significante em relação ao grupo TC. (†) Diferença significante em relação ao grupo $S A, p<0,05$.

A FIGURA 5A mostra os efeitos da administração do Losartan sobre a HC dos grupos tratados com EA. Como podemos observar, os grupos que receberam o 
Losartan, tanto sedentário (SAL) como treinado (TAL), apresentaram inibição da HC em relação aos grupos que receberam apenas EA (SA e TA).

Por outro lado, quando os animais foram tratados com Espironolactona a HC não foi inibida em nenhum dos grupos estudados (SAE e TAE), conforme pode ser observado na FIGURA 5B.
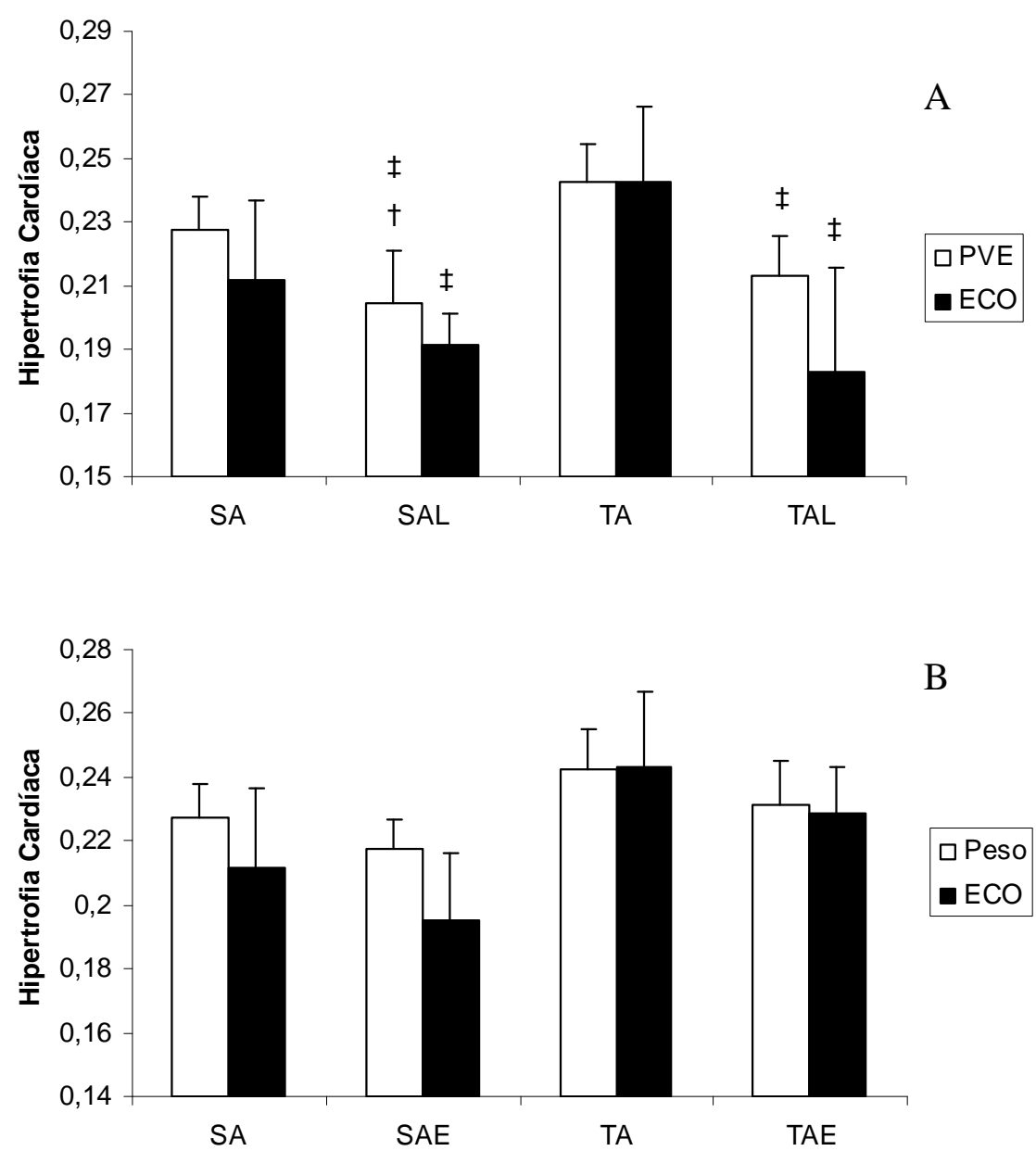

FIGURA 5 - Hipertrofia cardíaca (mg/g). Efeitos do EA associado ao treinamento físico e ao Losartan (A) ou a Espironolactona (B) sobre a HC avaliada pelo índice de $\underline{\mathrm{HC}}$ (peso do VE/ massa corporal) e por ecocardiograma (LVM=[(DDVE+SIV+PP) ${ }^{3}-$ $\left.\left.(\text { DDVE })^{3}\right] \times 1,047\right)$. Sedentário tratado com anabolizante (SA, n=7), sedentário tratado com anabolizante e Losartan (SAL, $\mathrm{n}=7$ ), sedentário tratado com anabolizante e Espironolactona (SAE, $n=7)$, treinado tratado com anabolizante (TA, $n=7$ ), treinado tratado com anabolizante e Losartan (TAL, $\mathrm{n}=7$ ), treinado tratado com anabolizante e Espironolactona (TAE, $\mathrm{n}=7$ ). Os resultados são apresentados como média \pm DP. $(\dagger)$ Diferença significante em relação ao grupo SA. ( $\ddagger$ ) Diferença significante em relação ao grupo TA, $\mathrm{p}<0,05$. 


\section{5}

Diâmetro de Cardiomiócitos

Conforme observado na FIGURA 6A, a administração de EA levou ao aumento no diâmetro de cardiomiócitos no grupo sedentário quando comparado ao grupo controle. Ambos os grupos que realizaram o treinamento físico apresentaram aumento no diâmetro dos cardiomiócitos em relação ao grupo SC. No entanto, o aumento observado nesses grupos foi ainda mais pronunciado quando comparado ao grupo SA.

Na FIGURA 6B podemos observar os efeitos do Losartan sobre o diâmetro dos cardiomiócitos. O grupo sedentário tratado com EA e Losartan não apresentou diferença significante em relação ao grupo SA. Por outro lado, quando o Losartan foi administrado no grupo que realizou o treinamento físico e recebeu EA, o aumento no diâmetro dos cardiomiócitos foi inibido, sendo significativamente menor em relação ao grupo TA. Por outro lado, a administração da Espironolactona não alterou o diâmetro dos cardimiócitos em nenhum dos grupos analisados (FIGURA 6C).
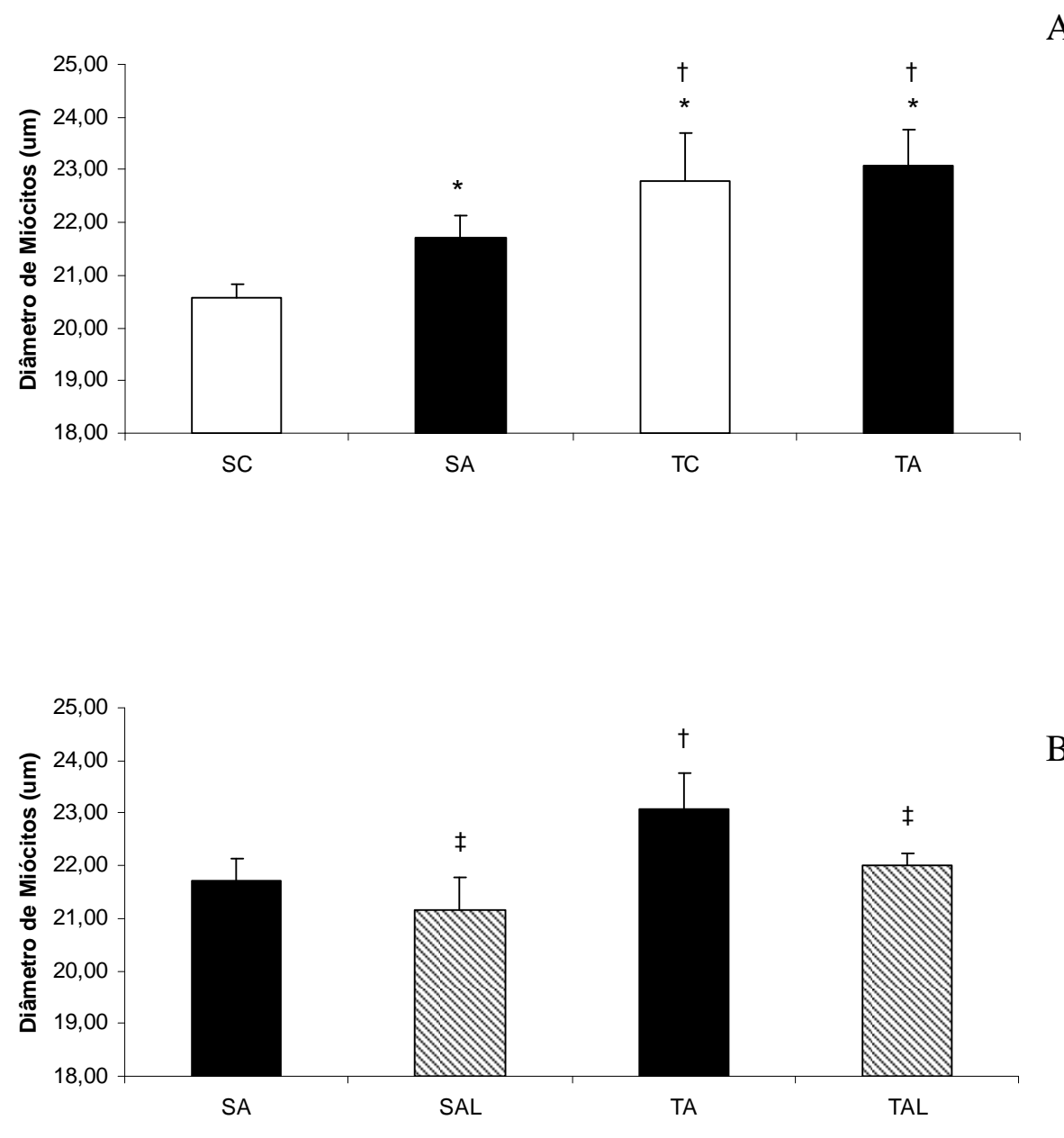


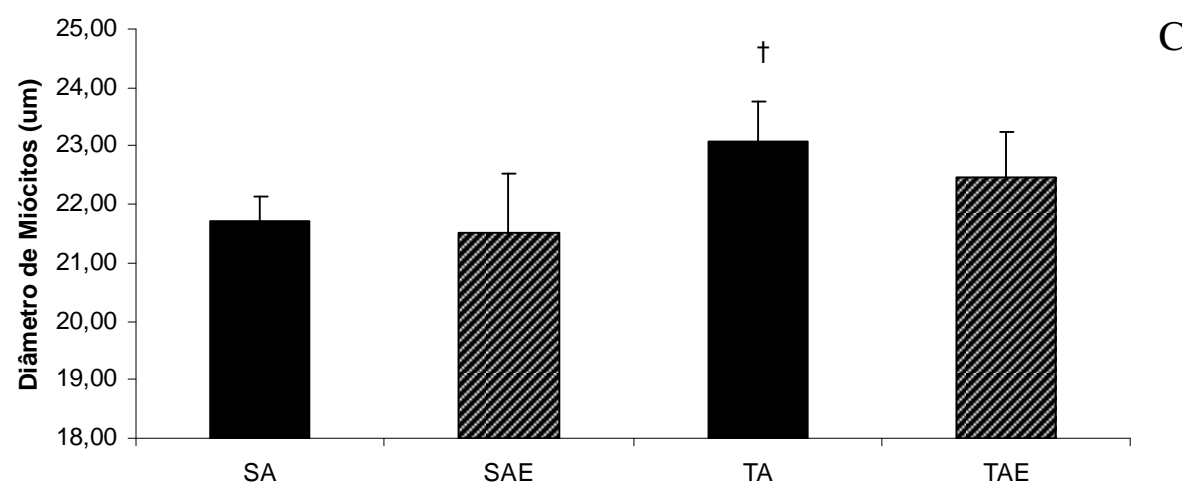

FIGURA 6 - Diâmetro dos cardiomiócitos $(\mu \mathrm{M})$. Efeitos da administração de EA e a associação ao treinamento físico (5A) ao Losartan (5B) e a Espironolactona (5C) sobre o diâmetro dos cardiomiócitos. Sedentário controle ( $\mathrm{SC}, \mathrm{n}=7$ ), sedentário tratado com anabolizante (SA, $\mathrm{n}=7$ ), sedentário tratado com anabolizante e Losartan ( $\mathrm{SAL}, \mathrm{n}=7$ ), $\underline{\text { sedentário tratado com anabolizante e Espironolactona (SAE, } \mathrm{n}=7 \text { ), treinado controle }}$ (TC, $\mathrm{n}=7$ ), treinado tratado com anabolizante (TA, n=7), treinado tratado com anabolizante e Losartan (TAL, $\mathrm{n}=7$ ) e treinado tratado com anabolizante $\mathrm{e}$ Espironolactona (TAE, $\mathrm{n}=7$ ). Os resultados são apresentados como média \pm DP. $(*)$ Diferença significante em relação ao grupo SC. (\#) Diferença significante em relação ao grupo TC. $(\dagger)$ Diferença significante em relação ao grupo SA. (†) Diferença significante em relação ao grupo TA, $\mathrm{p}<0,05$.

\subsection{Colágeno Cardíaco}

Conforme podemos observar na FIGURA 7A, os grupos tratados com EA, tanto sedentário como treinado, apresentaram um aumento significante da FVC quando comparados aos grupos controle. Resultados semelhantes também foram observados quando analisada a expressão do colágeno cardíaco (FIGURA 7B), em que os grupos SA e TA apresentaram aumento significante da expressão do colágeno tipo III. 

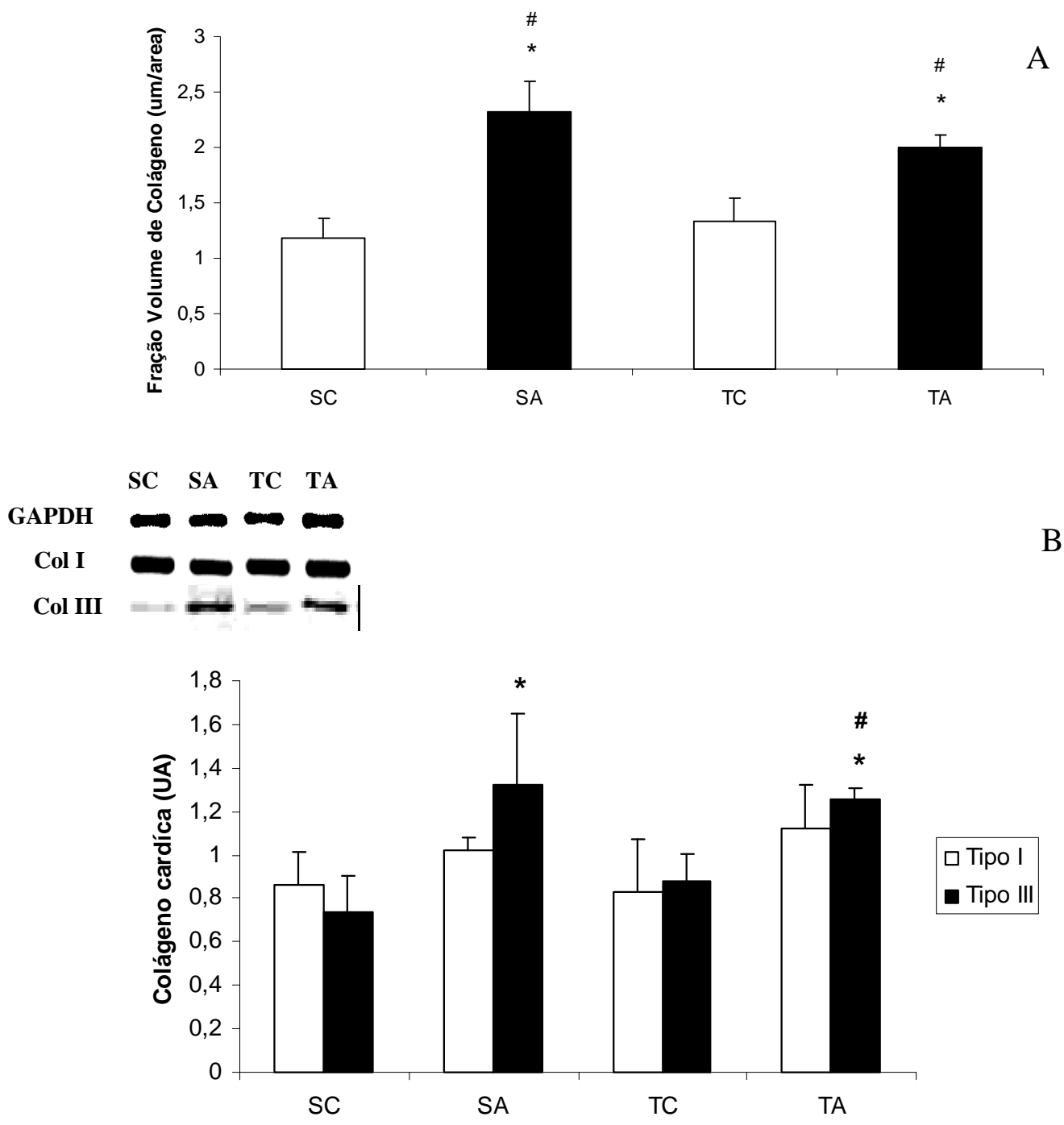

FIGURA 7 - Colágeno cardíaco. Efeitos da administração de EA e a associação ao $\underline{\text { treinamento físico sobre o colágeno intersticial cardíaco analisado pela FVC ( } \mu \mathrm{m} / a ́ r e a)}$ (A) e a expressão de colágeno cardíaco tipo I e Tipo III analisado por meio de PCR (UA) (B). Sedentário controle ( $\mathrm{SC}, \mathrm{n}=7$ ), sedentário tratado com anabolizante (SA,

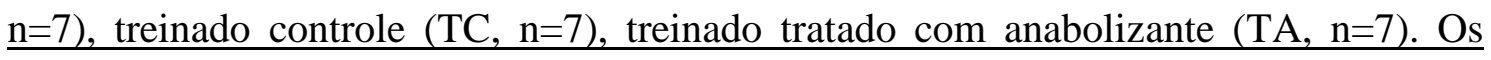
resultados são apresentados como média \pm DP. (*) Diferença significante em relação ao grupo SC. (\#) Diferença significante em relação ao grupo TC, $\mathrm{p}<0,05$.

Quando o Losartan foi associado à administração de EA, observamos redução da FVC nos grupos SAL e TAL em relação aos grupos tratados com EA (FIGURA 8A). O tratamento com Losartan também foi efetivo em inibir o aumento da expressão de colágeno tipo III nos grupos SAL e TAL em relação aos respectivos 
grupos tratados com EA (FIGURA 8B), além da diminuição do colágeno tipo I no grupo TAL quando comparado ao grupo TA.
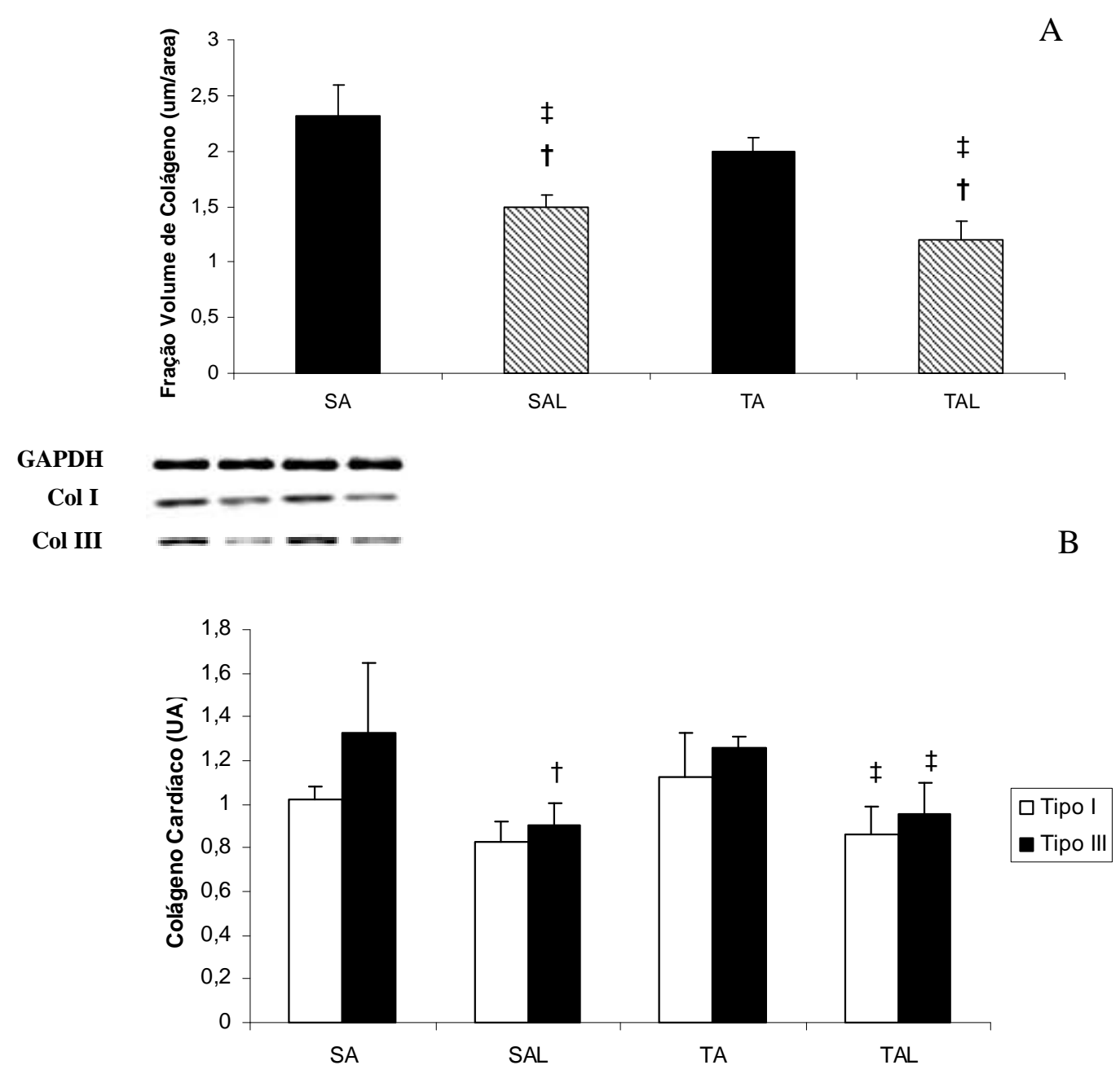

FIGURA 8-Colágeno Cardíaco. Efeitos da administração de EA, treinamento físico e $\underline{\text { Losartan sobre o colágeno intersticial cardíaco analisado pela FVC ( } \mu \mathrm{m} / a ́ r e a)(A) \text { e a }}$ expressão de colágeno cardíaco tipo I e Tipo III analisado por meio de PCR (UA) (B). Sedentário tratado com anabolizante $(\mathrm{SA}, \mathrm{n}=7)$, sedentário tratado com anabolizante e Losartan (SAL, $\mathrm{n}=7$ ), treinado tratado com anabolizante (TA, $\mathrm{n}=7$ ), treinado tratado com anabolizante e Losartan (TAL, $\mathrm{n}=7$ ). Os resultados são apresentados como média \pm DP. $(\dagger)$ Diferença significante em relação ao grupo SA. (†) Diferença significante em relação ao grupo TA, $\mathrm{p}<0,05$.

Assim como no tratamento com Losartan, quando os animais foram tratados com Espironolactona, observamos uma inibição da FVC nos grupos SAE e TAE em 
relação aos grupos tratados com EA (FIGURA 9A). As expressões do colágeno tipo III e tipo I também foram inibidas nos grupos tratados com Espironolactona, revertendo os efeitos induzidos pelo EA (FIGURA 9B).
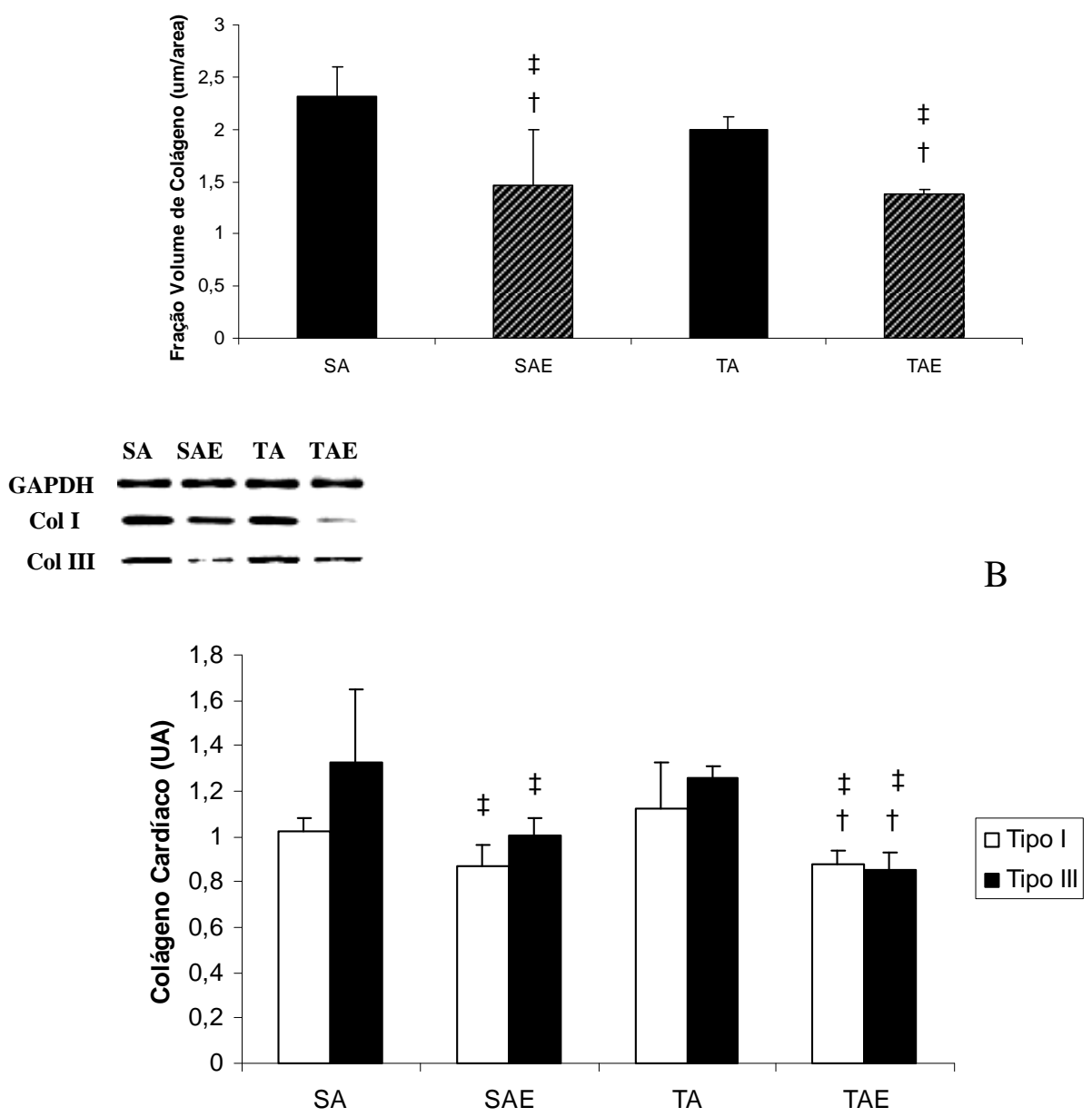

FIGURA 9-Colágeno cardíaco. Efeitos da administração de EA, treinamento físico e Espironolactona sobre o colágeno intersticial cardíaco analisado pela FVC ( $\mu \mathrm{m} / \mathrm{área})$ (A) e a expressão de colágeno cardíaco tipo I e Tipo III analisado por meio de PCR (UA) (B). Sedentário tratado com anabolizante (SA, n=7), sedentário tratado com anabolizante e Espironolactona (SAE, $n=7$ ), treinado tratado com anabolizante (TA, $\underline{\mathrm{n}=7 \text { ), treinado tratado com anabolizante e Espironolactona (TAE, } \mathrm{n}=7 \text { ). Os resultados }}$ $\underline{\text { são apresentados como média } \pm \text { DP. }(\dagger) \text { Diferença significante em relação ao grupo SA. }}$ (\$) Diferença significante em relação ao grupo TA, $p<0,05$.

\subsection{Sistema Renina Angiotensina Aldosterona Cardíaco}

6.7.1 Atividade Cardíaca da Enzima Conversora de Angiotensina Cardíaca 
Foi observado que os grupos tratados com EA, independente do treinamento físico, apresentaram aumento na atividade da ECA quando comparados aos grupos controle (FIGURA 10A). Por outro lado, quando a administração de EA foi associada ao Losartan (FIGURA 10B) ou a Espironolactona (FIGURA 10C) houve inibição no aumento da atividade da ECA induzido pelo EA.
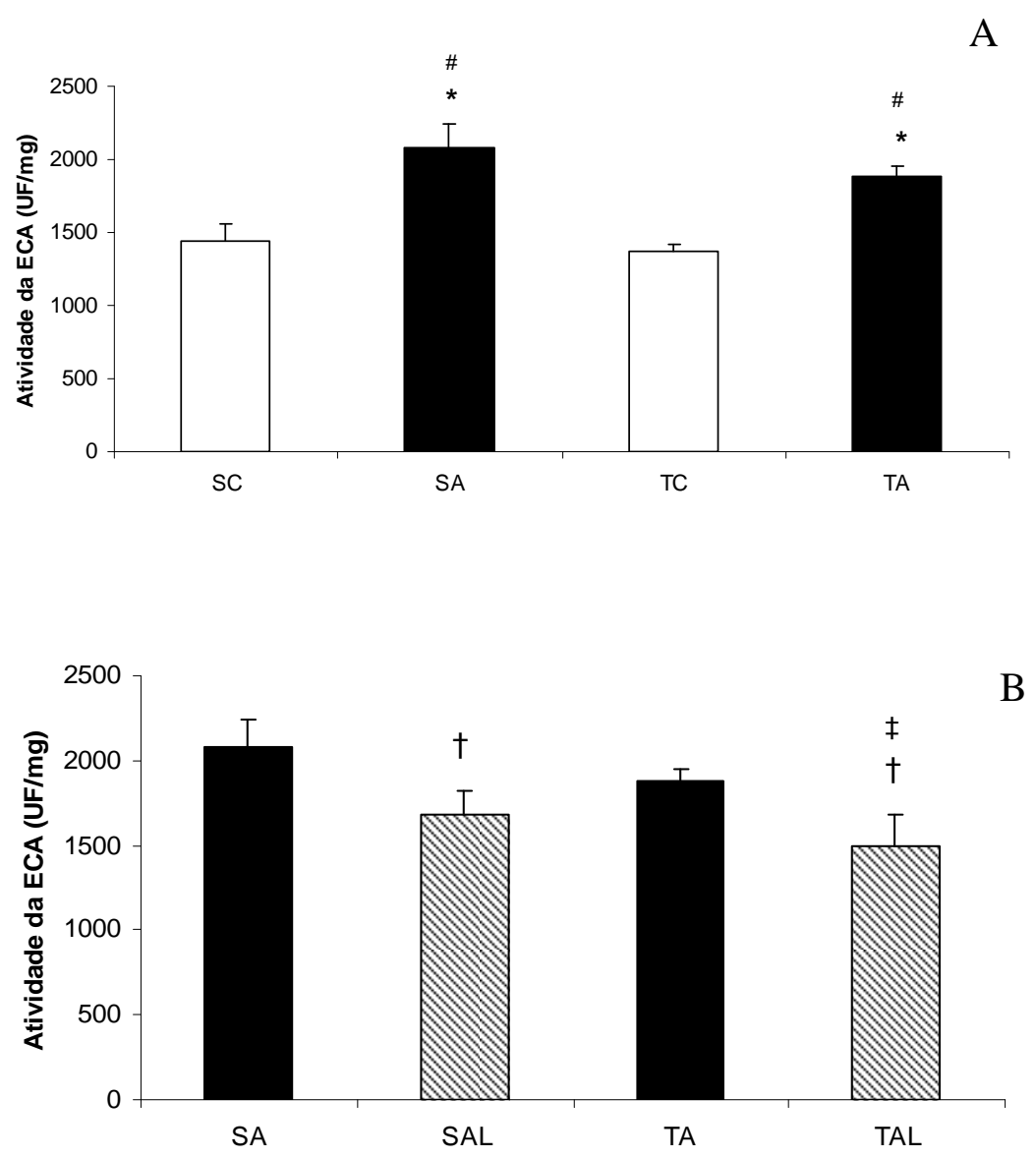


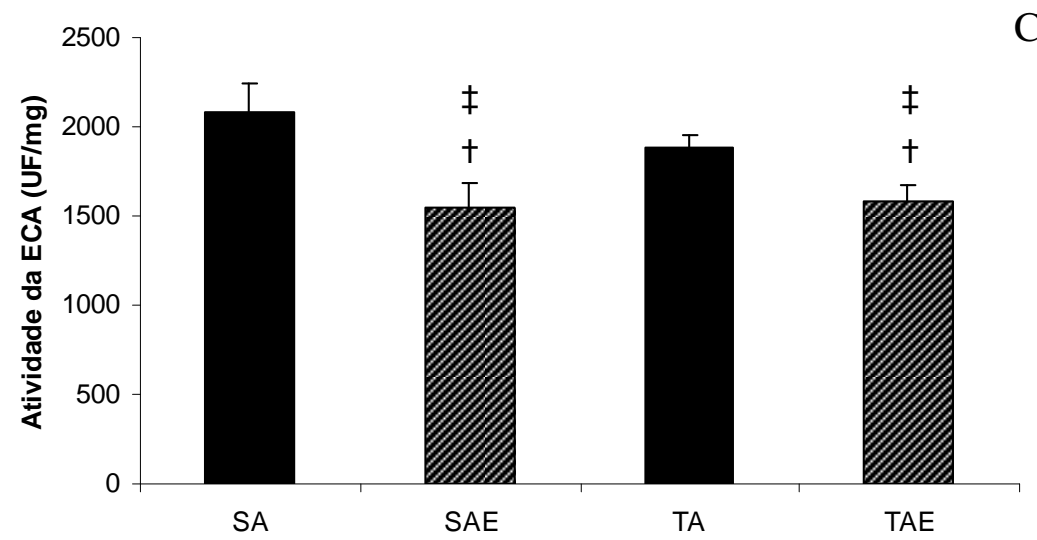

FIGURA 10 - Atividade da ECA cardíaca (UF/mg). Efeitos da administração de EA e a associação ao treinamento físico (A) ao Losartan (B) e a Espironolactona (C) sobre a atividade da ECA cardíaca. Sedentário controle ( $\mathrm{SC}, \mathrm{n}=7$ ), sedentário tratado com anabolizante (SA, n=7), sedentário tratado com anabolizante e Losartan (SAL, n=7), $\underline{\text { sedentário tratado com anabolizante e Espironolactona ( } \mathrm{SAE}, \mathrm{n}=7) \text {, treinado controle }}$ (TC, $\mathrm{n}=7$ ), treinado tratado com anabolizante (TA, $\mathrm{n}=7$ ), treinado tratado com anabolizante e Losartan (TAL, $n=7$ ) e treinado tratado com anabolizante e Espironolactona (TAE, $\mathrm{n}=7$ ). Os resultados são apresentados como média \pm DP. (*) Diferença significante em relação ao grupo SC. (\#) Diferença significante em relação ao grupo TC. $(\dagger)$ Diferença significante em relação ao grupo SA. (†) Diferença significante em relação ao grupo TA, $\mathrm{p}<0,05$.

\subsubsection{Expressão dos Receptores AT1}

As figuras abaixo ilustram os dados encontrados sobre a expressão cardíaca dos receptores AT1 (FIGURA 11). Os grupos tratados com EA apresentaram um aumento dos receptores AT1 em relação aos grupos controle (FIGURA 11A). Quando os animais que receberam EA foram tratados com Losartan (FIGURA 11B) ou com Espironolactona (FIGURA 11C), não houveram reduções na expressão dos receptores AT1. 

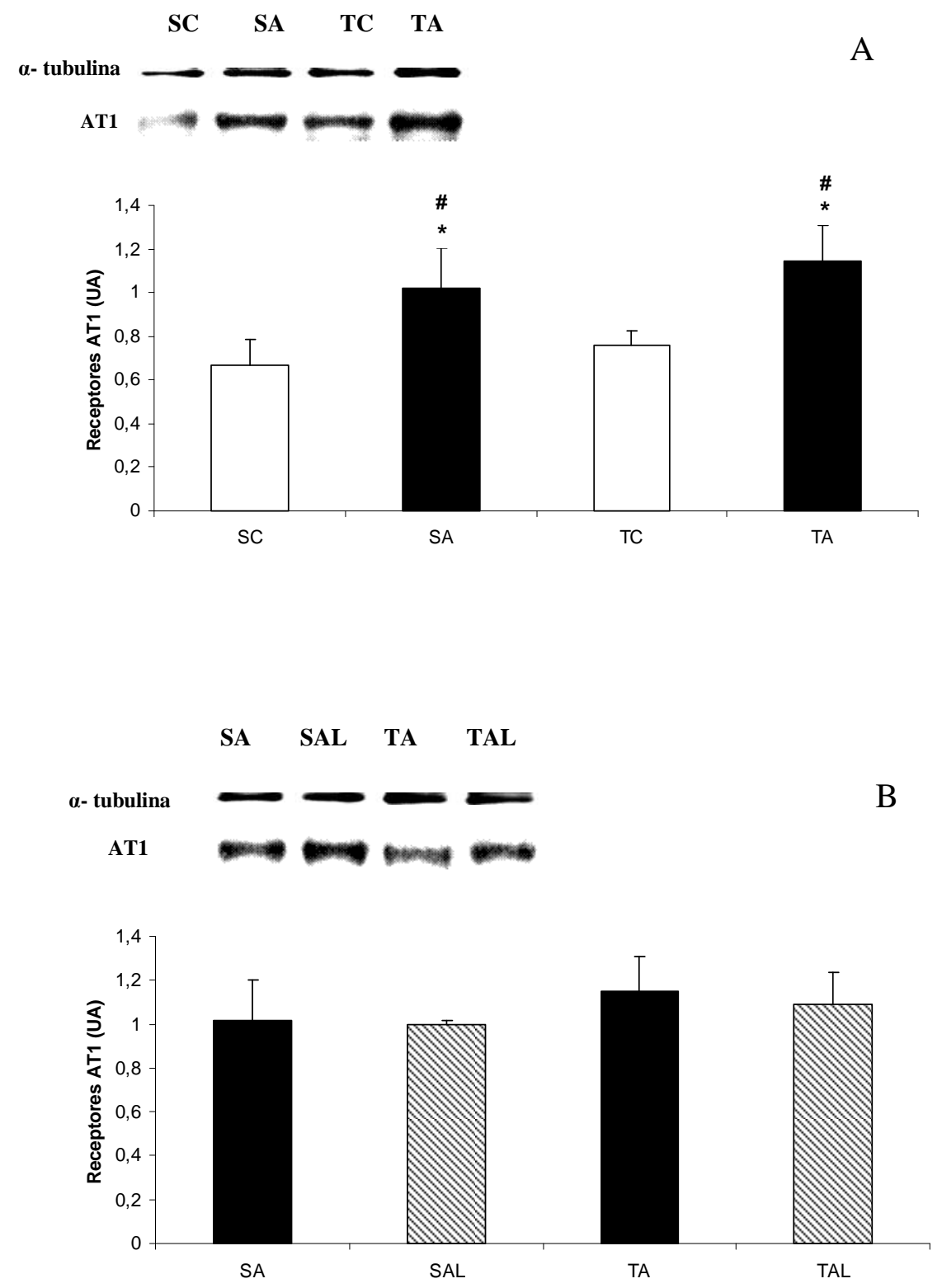


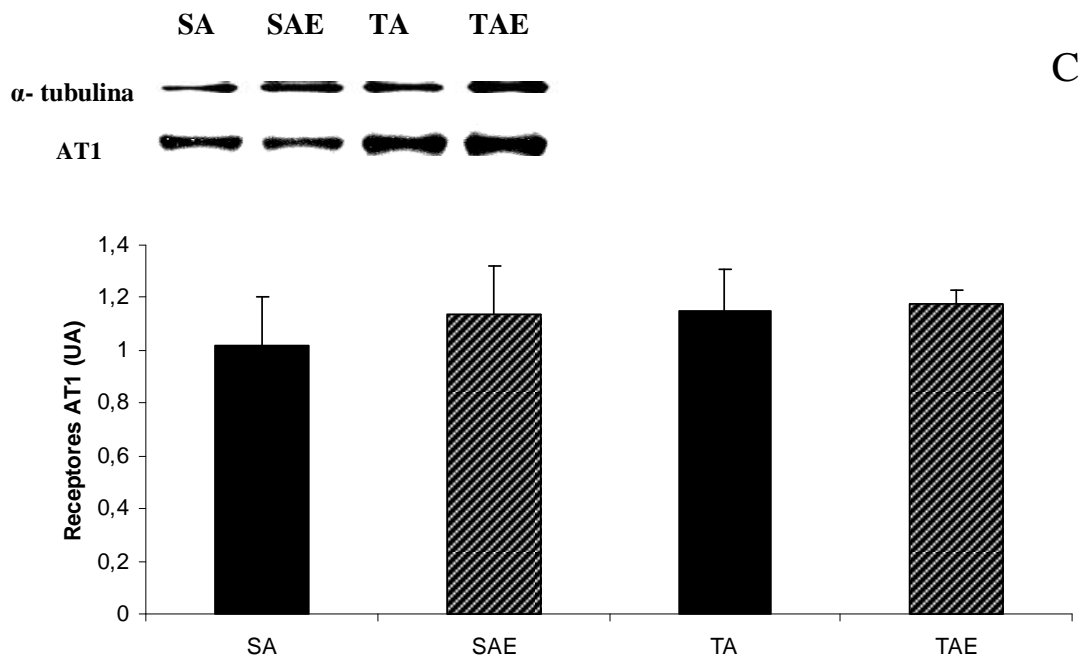

FIGURA 11 - Expressão dos receptores AT1 no coracão (UA). Efeitos da administração de EA e a associação ao treinamento físico (A) ao Losartan (B) e a Espironolactona (C) sobre a expressão dos receptores AT1 cardíacos. Sedentário controle ( $\mathrm{SC}, \mathrm{n}=7)$, sedentário tratado com anabolizante $(\mathrm{SA}, \mathrm{n}=7)$, sedentário tratado com anabolizante e Losartan (SAL, n=7), sedentário tratado com anabolizante e Espironolactona $(\mathrm{SAE}, \mathrm{n}=7)$, treinado controle $(\mathrm{TC}, \mathrm{n}=7)$, treinado tratado com anabolizante (TA, $n=7$ ), treinado tratado com anabolizante e Losartan (TAL, n=7) e treinado tratado com anabolizante e Espironolactona (TAE, $n=7$ ). Os resultados são apresentados como média \pm DP. (*) Diferença significante em relação ao grupo SC. (\#) Diferença significante em relação ao grupo TC, $\mathrm{p}<0,05$.

\subsubsection{Expressão dos Receptores AT2}

Conforme pode ser observado na FIGURA 12A, a administração de EA, independentemente do treinamento físico, aumentou a expressão dos receptores AT2 no tecido cardíaco dos animais. Quando o Losartan foi administrado nos animais tratados com EA (FIGURA 12B), não houveram diferenças significantes na expressão dos receptores AT2. Entretanto, foi observada uma tendência à diminuição $(p<0,07)$ em relação aos grupos que apenas receberam EA. O tratamento com Espironolactona (FIGURA 12C) não inibiu o aumento na expressão dos receptores AT2 no tecido cardíaco. 


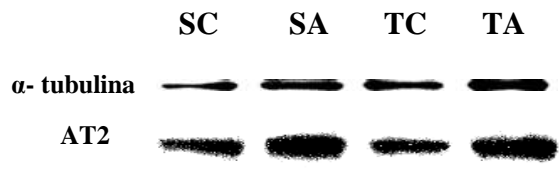

A
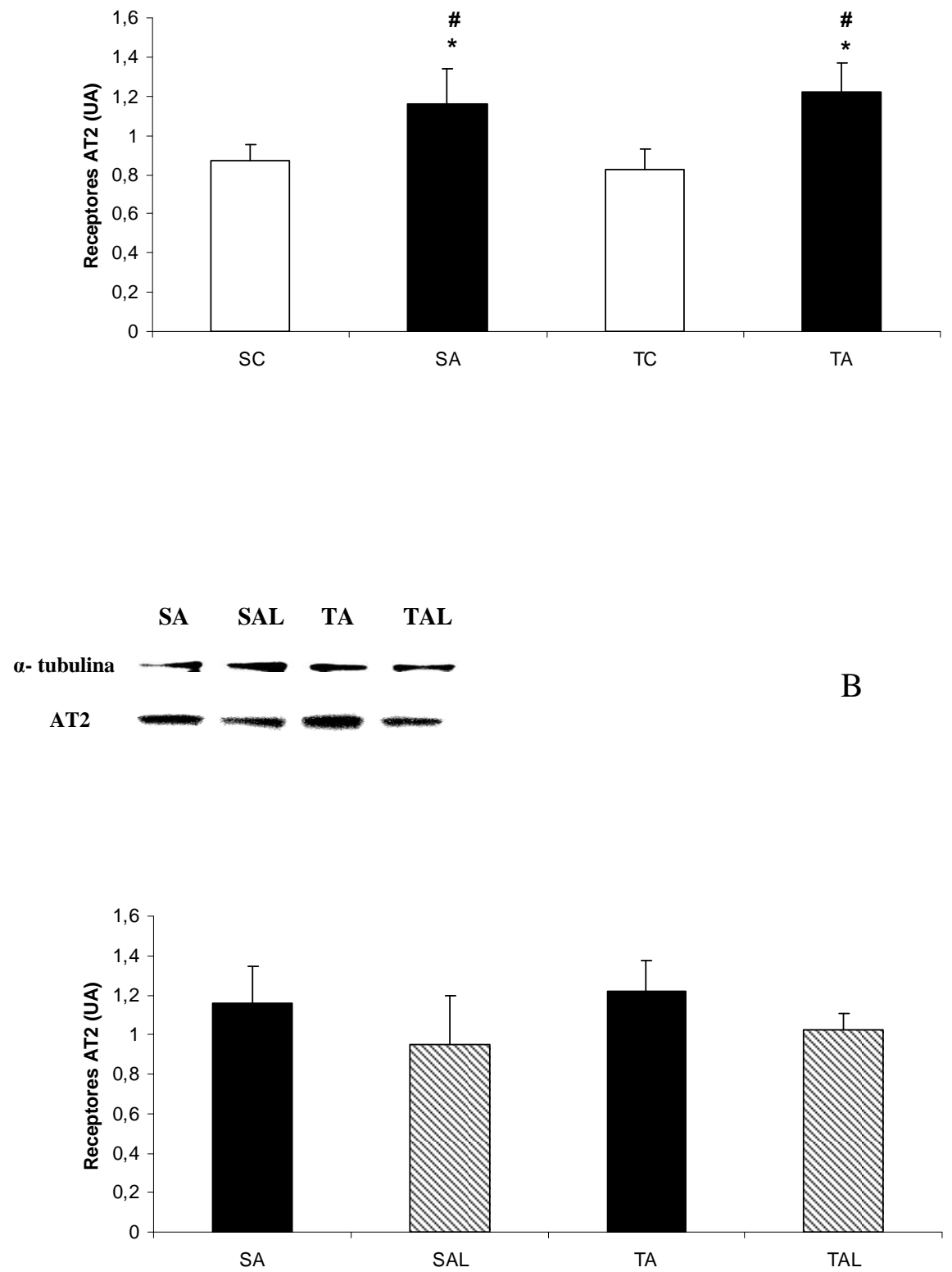


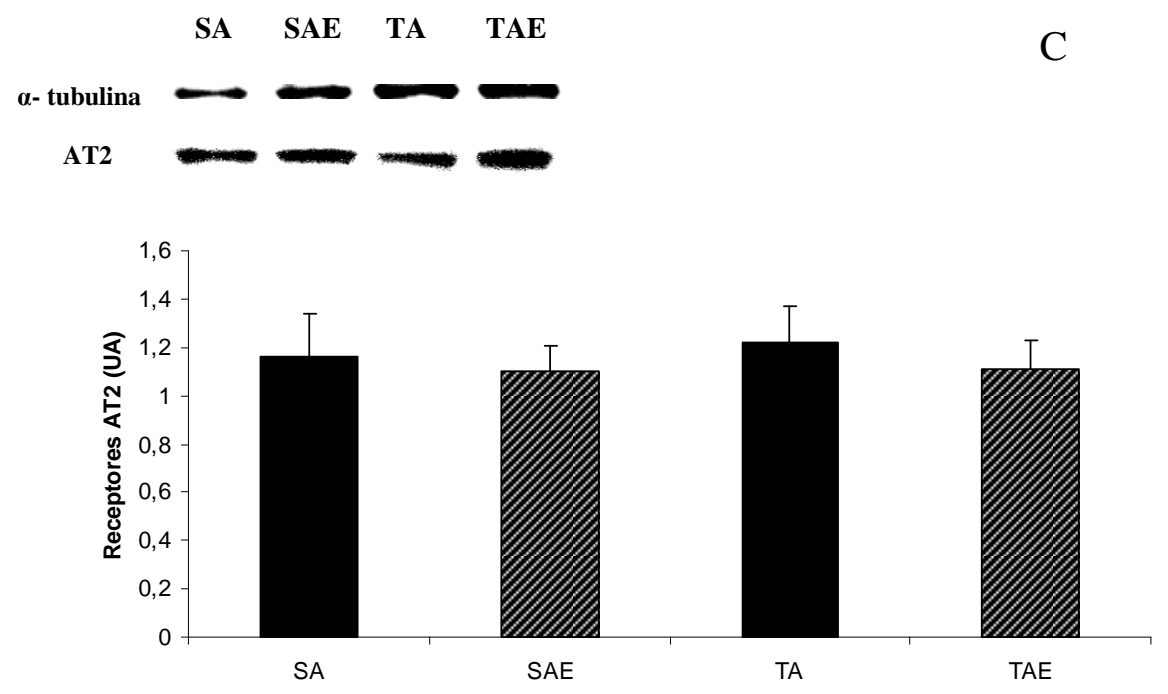

FIGURA 12 - Expressão dos receptores AT2 no coracão (UA). Efeitos da administração de EA e a associação ao treinamento físico (A) ao Losartan (B) ou a Espironolactona (C) sobre a expressão dos receptores AT2 cardíacos. Sedentário controle ( $\mathrm{SC}, \mathrm{n}=7$ ), sedentário tratado com anabolizante $(\mathrm{SA}, \mathrm{n}=7$ ), sedentário tratado com anabolizante e Losartan (SAL, n=7), sedentário tratado com anabolizante e Espironolactona (SAE, $\mathrm{n}=7$ ), treinado controle $(\mathrm{TC}, \mathrm{n}=7)$, treinado tratado com anabolizante (TA, $n=7$ ), treinado tratado com anabolizante e Losartan (TAL, n=7) e treinado tratado com anabolizante e Espironolactona (TAE, $n=7$ ). Os resultados são apresentados como média \pm DP. (*) Diferença significante em relação ao grupo SC. (\#) Diferença significante em relação ao grupo TC, $\mathrm{p}<0,05$.

6.7.4 Expressão do Gene da Enzima Aldosterona Sintase (CYP11B2) Cardíaca

Foi observada uma tendência de aumento na expressão do gene CYP11B2 $(\mathrm{p}<0,09)$ no grupo sedentário tratado com EA quando comparado ao grupo sedentário controle. Entretanto, houve um aumento significante em relação ao grupo treinado controle. Quando o EA foi associado ao treinamento físico, observou-se aumento na expressão do gene CYP11B2 comparado a ambos os grupos controle (FIGURA 13A).

O tratamento com Losartan (FIGURA 13B) ou com Espironolactona (FIGURA 13C) diminuíram a expressão do gene CYP11B2 nos grupos sedentários quando comparados aos grupos SA e TA. Observou-se ainda, diminuição nos grupos TAL e TAE comparados ao grupo TA. 


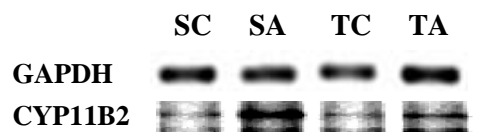

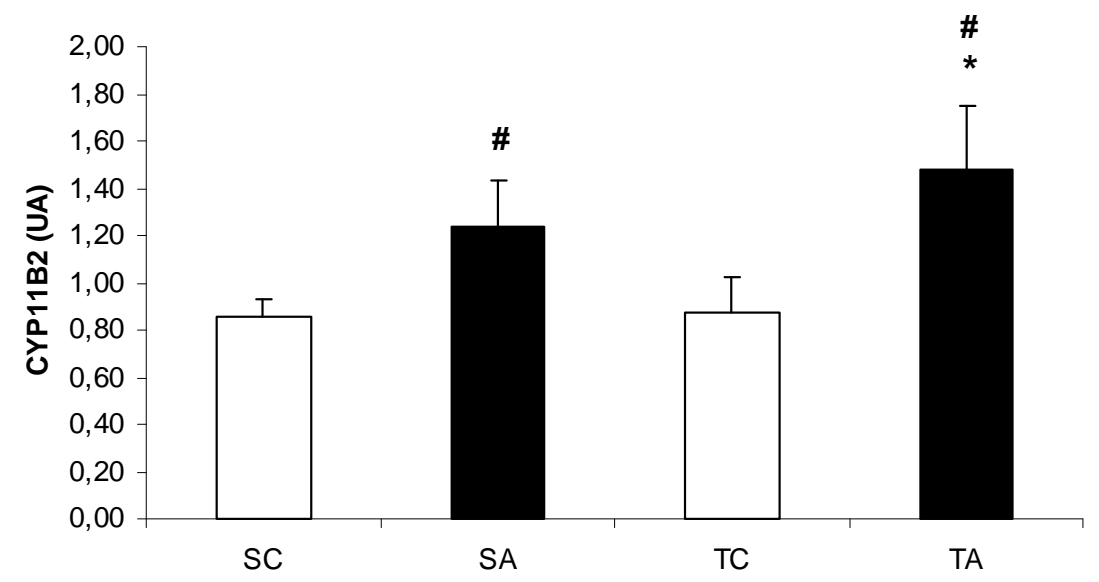

SA SAL TA TAL
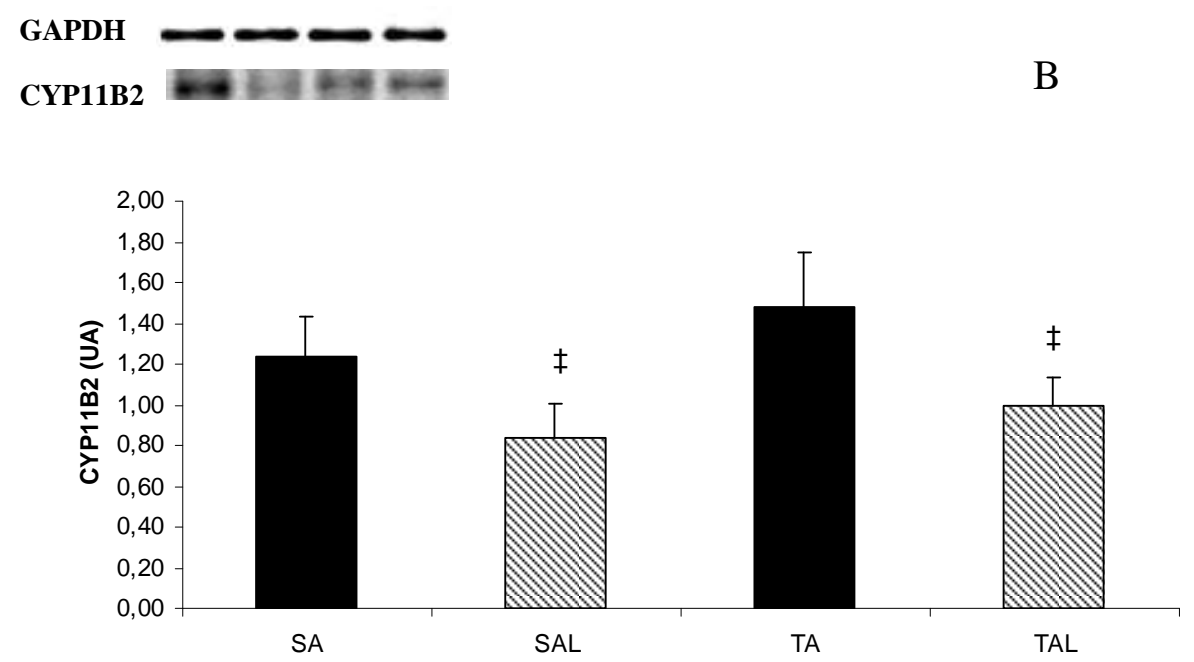


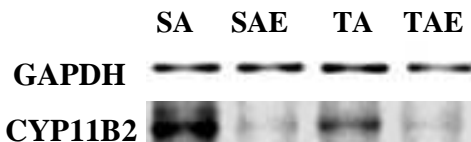

$\mathrm{C}$

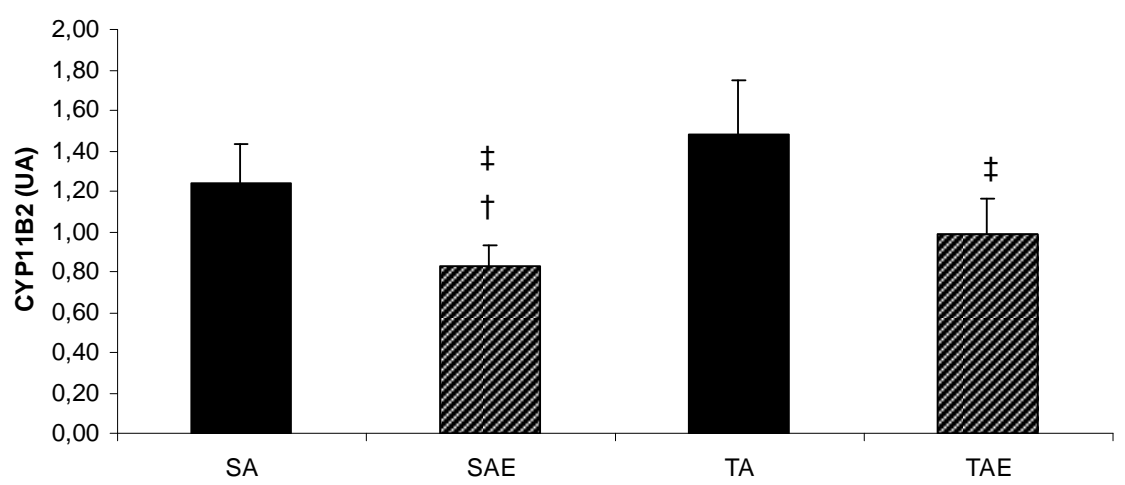

FIGURA 13 - Expressão do gene CYP11B2 no coração (UA). Efeitos da administração de EA e a associação ao treinamento físico (A) ao Losartan (B) e a Espironolactona (C) sobre a expressão do gene CYP11B2 no coração. Sedentário controle ( $\mathrm{SC}, \mathrm{n}=7)$, sedentário tratado com anabolizante $(\mathrm{SA}, \mathrm{n}=7)$, sedentário tratado com anabolizante e Losartan (SAL, $\mathrm{n}=7$ ), sedentário tratado com anabolizante e Espironolactona (SAE, $\mathrm{n}=7$ ), treinado controle $(\mathrm{TC}, \mathrm{n}=7)$, treinado tratado com anabolizante (TA, $n=7$ ), treinado tratado com anabolizante e Losartan (TAL, n=7) e treinado tratado com anabolizante e Espironolactona (TAE, n=7). Os resultados são apresentados como média \pm DP. (*) Diferença significante em relação ao grupo SC. (\#) Diferença significante em relação ao grupo TC. $(\dagger)$ Diferença significante em relação ao grupo SA. ( $\ddagger$ Diferença significante em relação ao grupo TA, $\mathrm{p}<0,05$.

6.7.5 Expressão dos Receptores de Mineralocorticóides Cardíacos

Conforme observado abaixo, o tratamento com EA (FIGURA 14A), Losartan (FIGURA 14B) ou Espironolactona (FIGURA 14C) não alterou a expressão dos RM no coração dos animais estudados. 

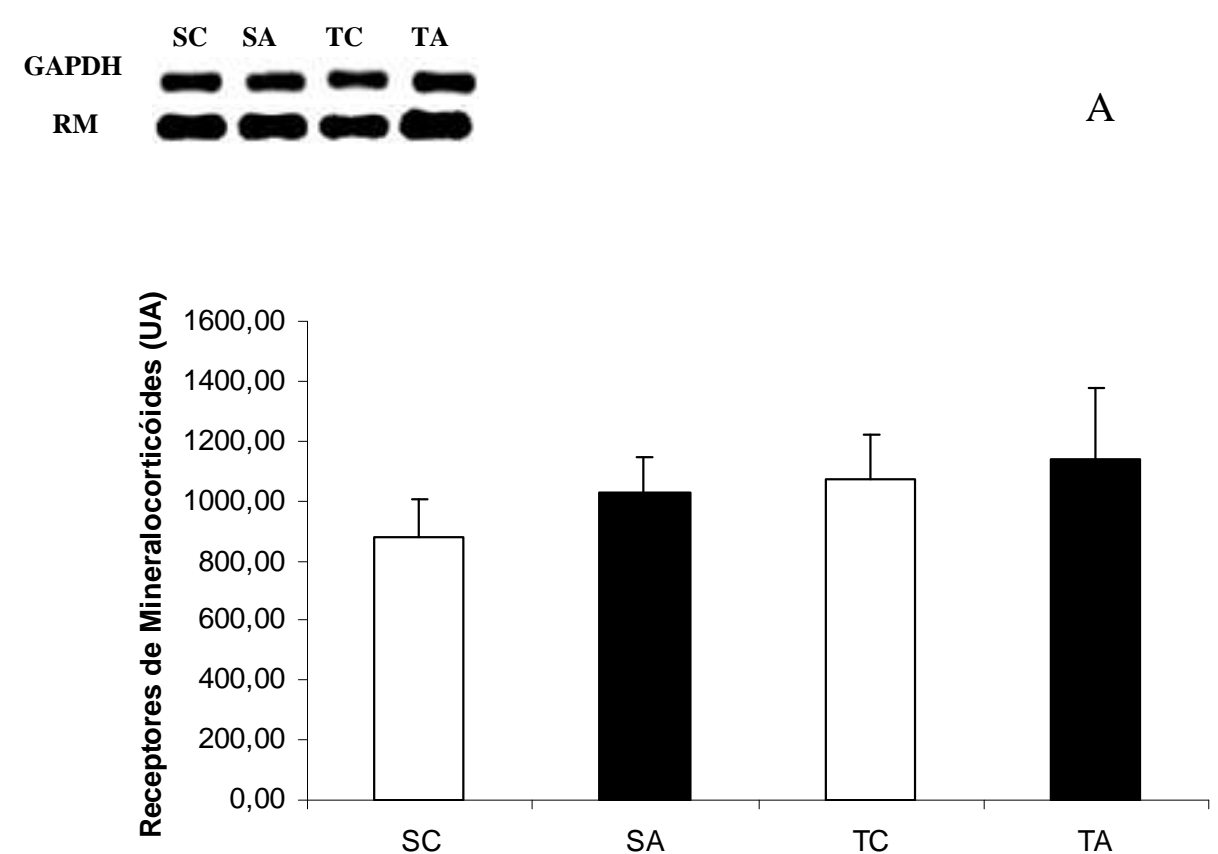

SA SAL TA TAL
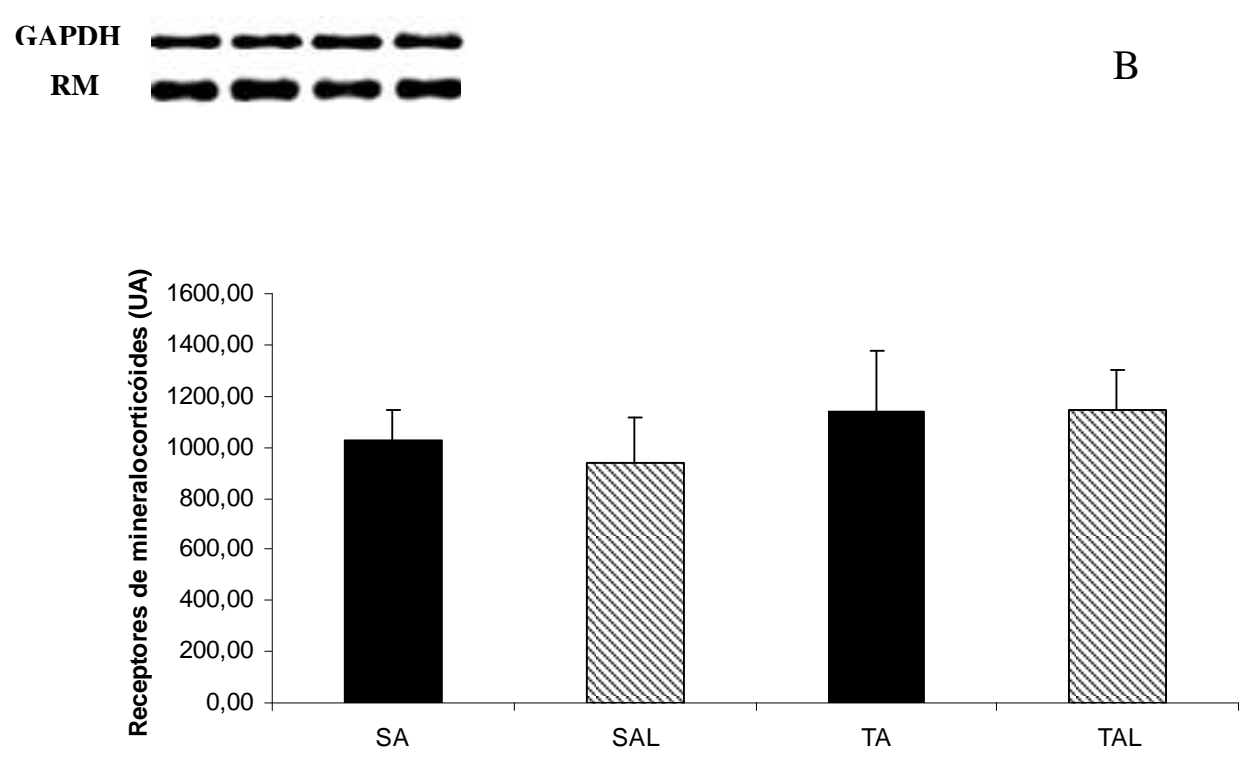


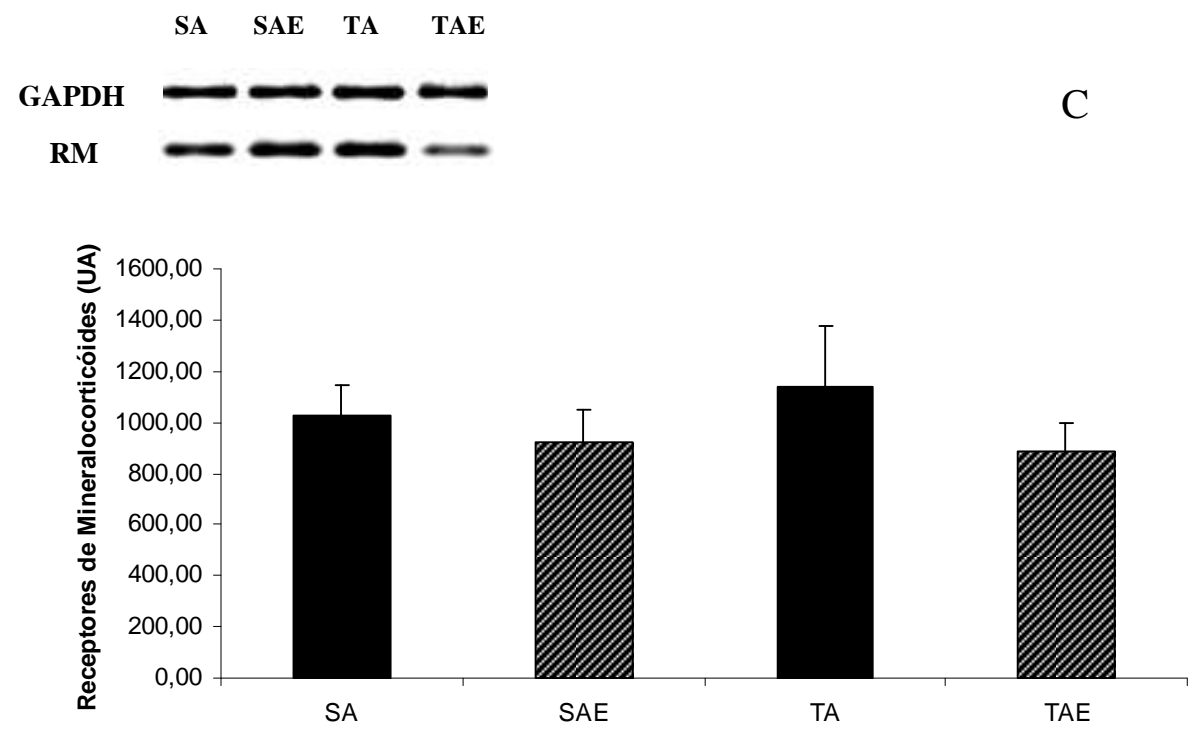

FIGURA 14 - Expressão dos receptores de mineralocorticóides no coracão (UA).

Efeitos da administração de EA e a associação ao treinamento físico (A) ao Losartan (B) e a Espironolactona (C) sobre a expressão dos receptores de mineralocorticóides cardíacos. Sedentário controle ( $\mathrm{SC}, \mathrm{n}=7)$, sedentário tratado com anabolizante (SA, $\underline{\mathrm{n}=7 \text { ), sedentário tratado com anabolizante e Losartan (SAL, } \mathrm{n}=7 \text { ), sedentário tratado }}$ com anabolizante e Espironolactona ( $\mathrm{SAE}, \mathrm{n}=7$ ), treinado controle ( $\mathrm{TC}, \mathrm{n}=7$ ), treinado tratado com anabolizante (TA, n=7), treinado tratado com anabolizante e Losartan (TAL, n=7) e treinado tratado com anabolizante e Espironolactona (TAE, n=7). Os resultados são apresentados como média \pm DP, $\mathrm{p}<0,05$.

6.7.6 Expressão da Enzima 11 $\beta$ Hidroxisteróide Desidrogenase tipo 2 (11 $\beta$ HSD2)

Ambos os grupos tratados com EA apresentaram aumento significante na expressão da enzima 11ßHSD2 no tecido cardíaco, sendo observada ainda uma tendência de aumento no grupo TA, em relação ao grupo SA (FIGURA 15A). Um resultado muito interessante verificado, foi a redução na expressão da 11ßHSD2 no grupo que apenas realizou o treinamento físico quando comparado ao grupo controle.

O tratamento dos animais com Losartan (FIGURA 15B) parece não ter inibido o aumento induzido pelo EA no grupo SAL comparado ao grupo SA. No entanto, ambos os grupos SAL e TAL apresentaram menor expressão da enzima $11 \beta \mathrm{HSD} 2$ em relação ao grupo TA.

Os grupos que foram tratados com Espironolactona tiveram inibição na expressão da enzima 11ßHSD2 em comparação ao grupo TA, sendo essa, observada também quando comparado o grupo SAE ao SA (FIGURA 15C). 


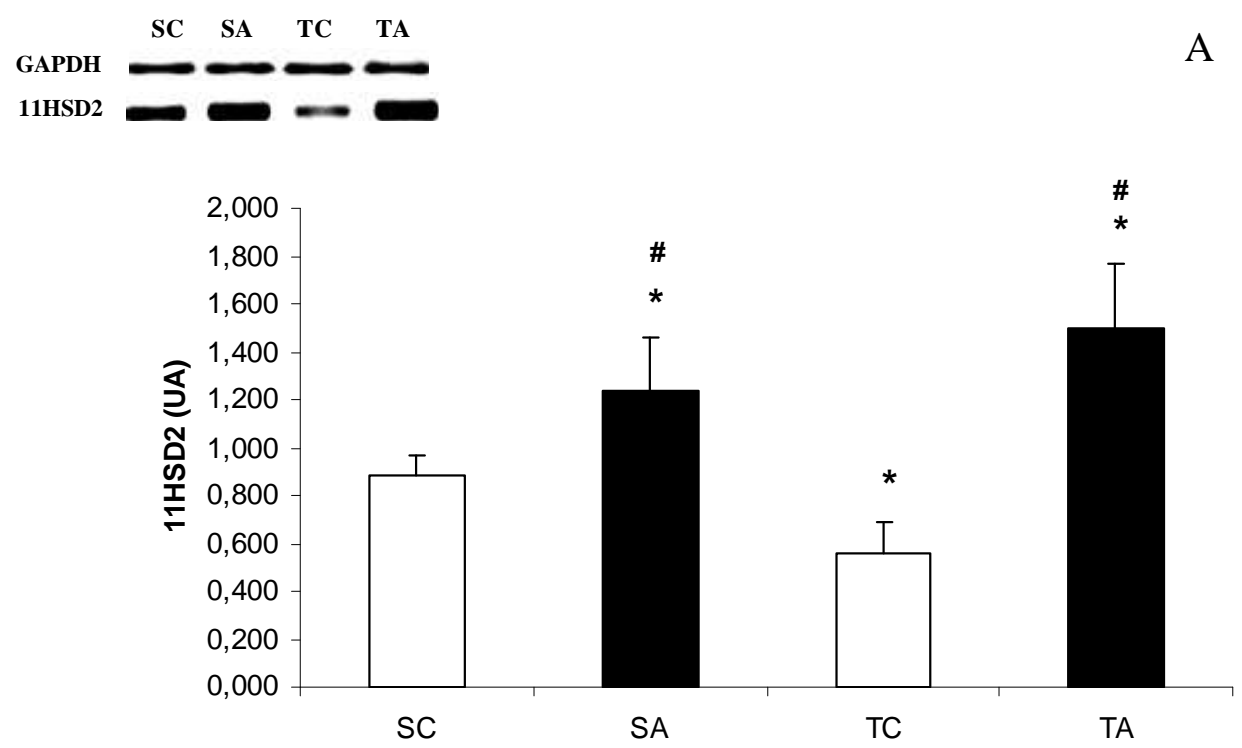

$\underset{\text { GAPDH }}{\text { 11HSD2 }} \underset{-}{-}$

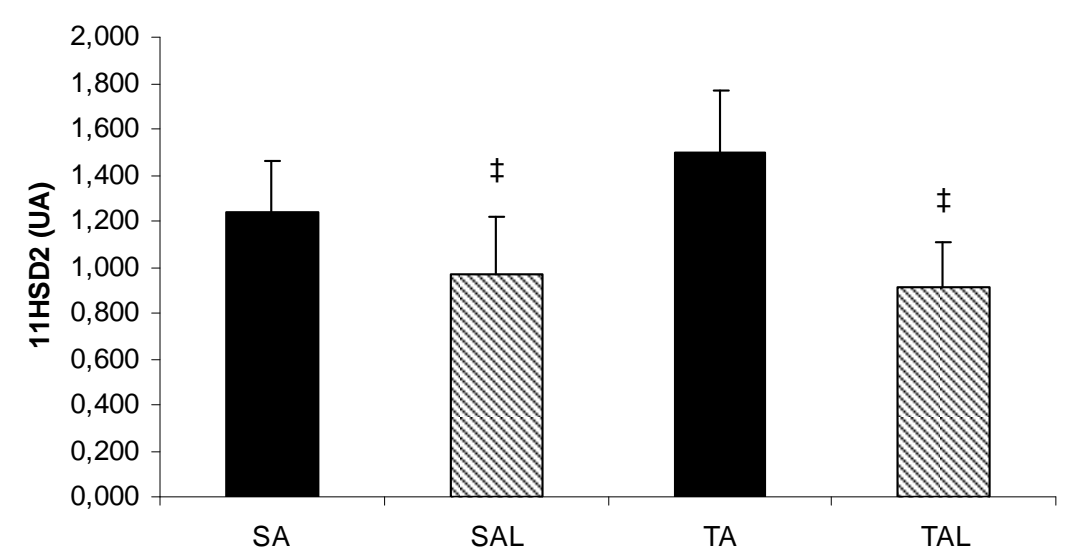




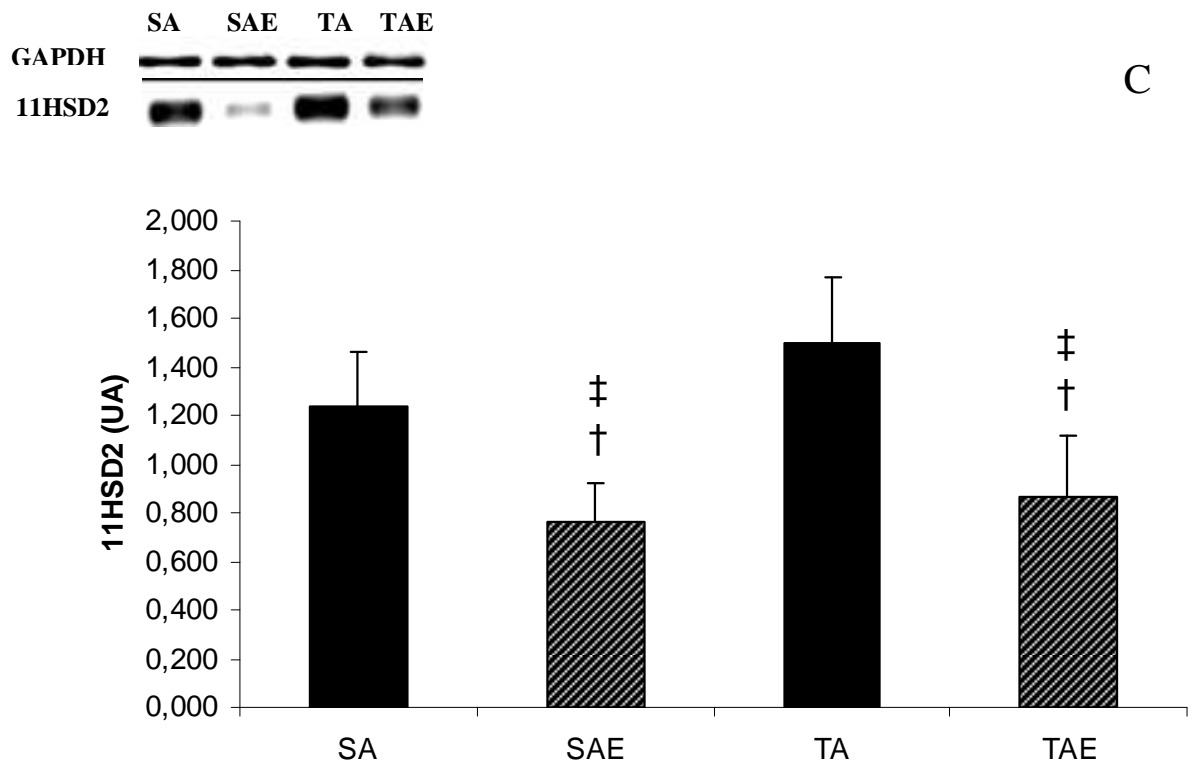

FIGURA 15 - Expressão da enzima 11ß Hidroxisteróide Desidrogenase tipo 2 no coração (UA). Efeitos da administração de EA e a associação ao treinamento físico (A) ao Losartan (B) e a Espironolactona (C) sobre a expressão da enzima 11 ßHSD2 cardíaca. Sedentário controle ( $\mathrm{SC}, \mathrm{n}=7$ ), sedentário tratado com anabolizante ( $\mathrm{SA}, \mathrm{n}=7$ ), sedentário tratado com anabolizante e Losartan ( $\mathrm{SAL}, \mathrm{n}=7$ ), sedentário tratado com anabolizante e Espironolactona ( $\mathrm{SAE}, \mathrm{n}=7$ ), treinado controle $(\mathrm{TC}, \mathrm{n}=7)$, treinado tratado com anabolizante (TA, n=7), treinado tratado com anabolizante e Losartan (TAL, n=7) e treinado tratado com anabolizante e Espironolactona (TAE, n=7). Os resultados são apresentados como média \pm DP. (*) Diferença significante em relação ao grupo SC. (\#) Diferença significante em relação ao grupo TC. (†) Diferença significante em relação ao grupo SA. (†) Diferença significante em relação ao grupo TA, $p<0,05$.

\subsection{Fatores Inflamatórios}

6.8.1 Expressão de TGF $\beta$

Como podemos observar na FIGURA 16A, o tratamento com EA, independente do treinamento físico, levou ao aumento do TGF $\beta$ quando comparado aos grupos controle. O tratamento com Losartan (FIGURA 16B) ou Espironolactona (FIURA 16C) inibiu o aumento do TGF $\beta$ induzido pelo EA nos grupos sedentários e treinados quando comparados ao grupo TA. 


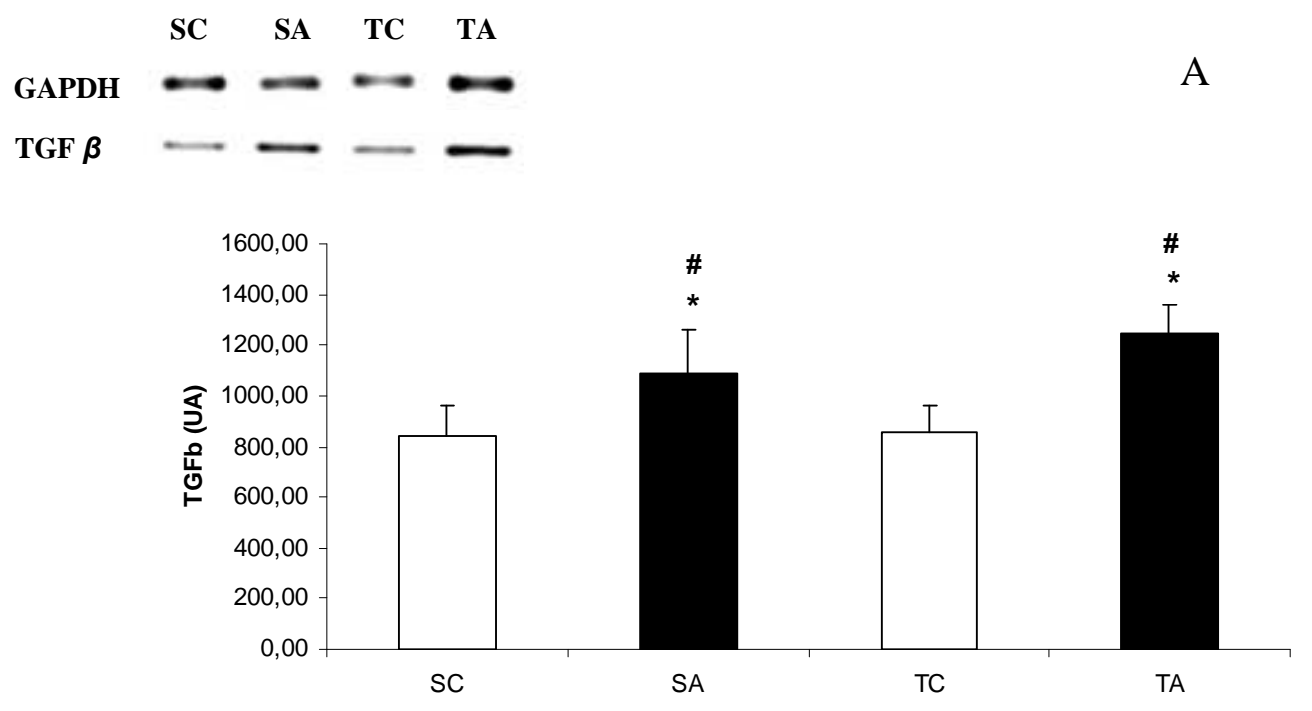

SA SAL TA TAL
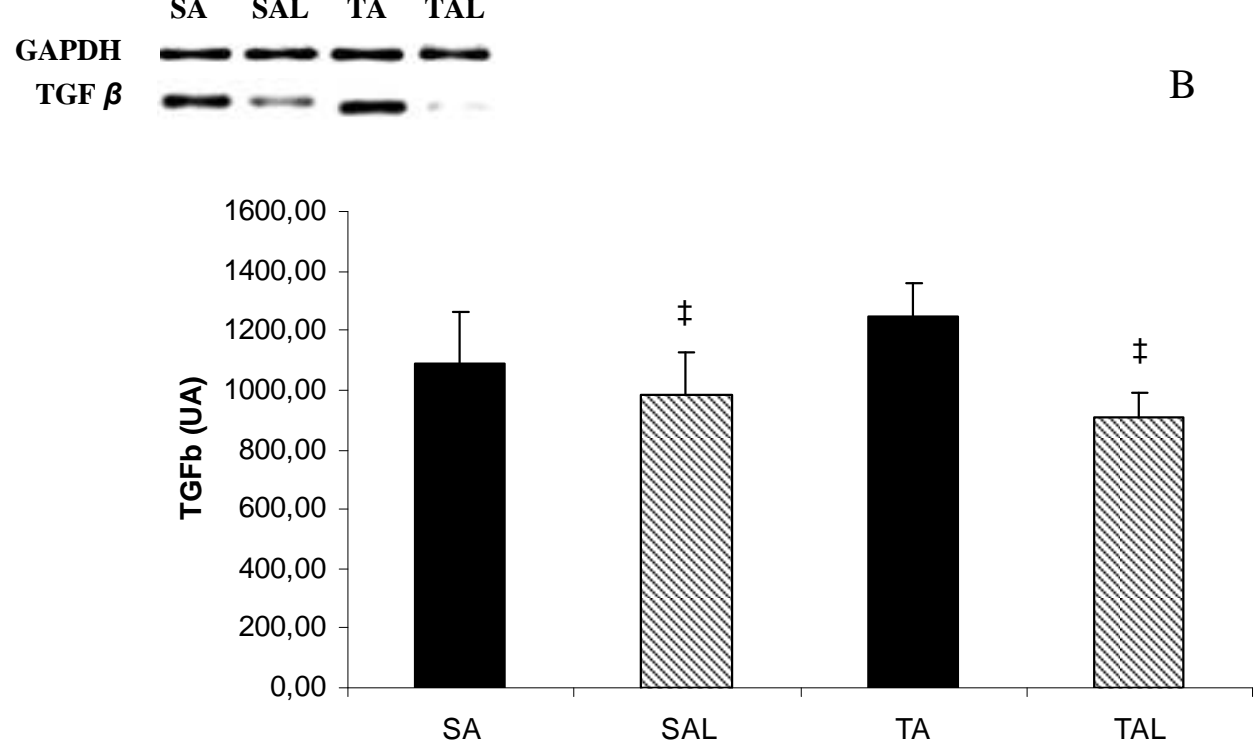


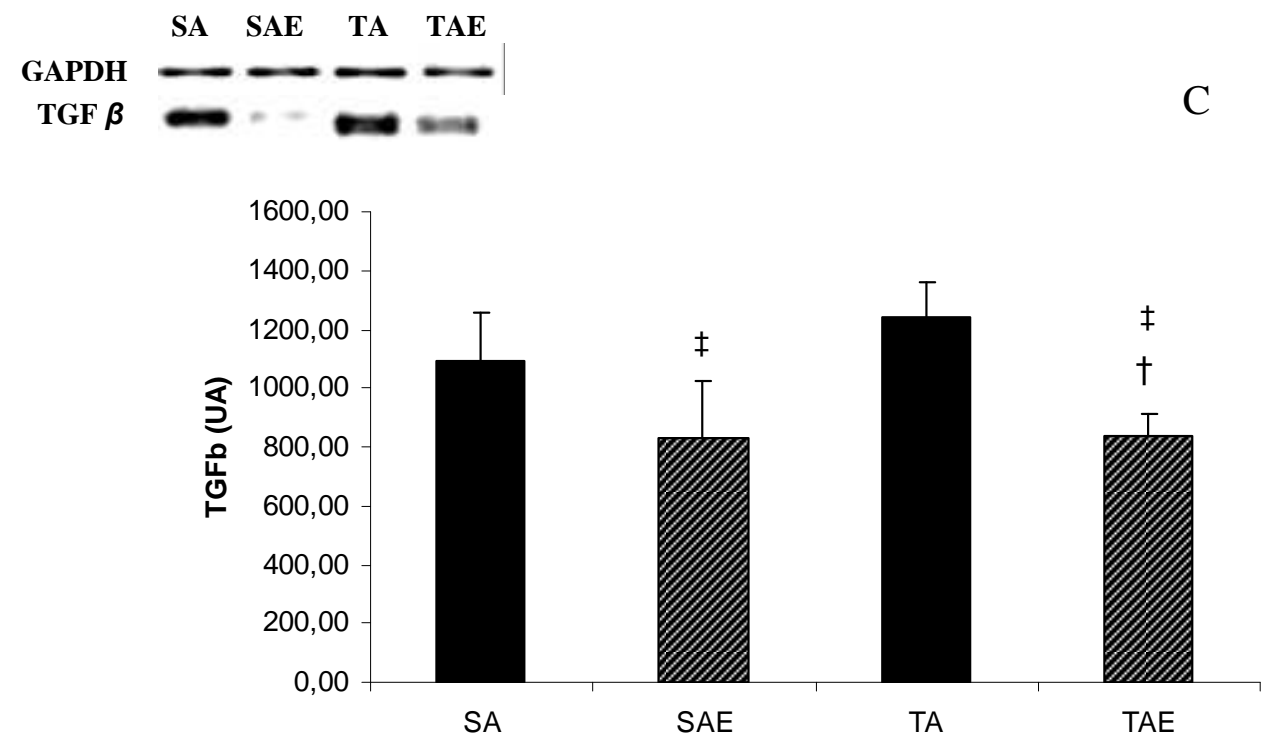

FIGURA 16 - Expressão de TGF $\boldsymbol{\beta}$ (UA). Efeitos da administração de EA e a associação ao treinamento físico (A) ao Losartan (B) e a Espironolactona (C) sobre a expressão de TGF $\beta$ cardíaco. Sedentário controle ( $\mathrm{SC}, \mathrm{n}=7$ ), sedentário tratado com anabolizante (SA, n=7), sedentário tratado com anabolizante e Losartan (SAL, n=7), $\underline{\text { sedentário tratado com anabolizante e Espironolactona (SAE, } \mathrm{n}=7 \text { ), treinado controle }}$ (TC, $\mathrm{n}=7$ ), treinado tratado com anabolizante (TA, $\mathrm{n}=7$ ), treinado tratado com anabolizante e Losartan (TAL, $\mathrm{n}=7$ ) e treinado tratado com anabolizante $\mathrm{e}$ Espironolactona (TAE, $\mathrm{n}=7$ ). Os resultados são apresentados como média \pm DP. (*) Diferença significante em relação ao grupo SC. (\#) Diferença significante em relação ao grupo TC. $(\dagger)$ Diferença significante em relação ao grupo SA. (†) Diferença significante em relação ao grupo TA, $\mathrm{p}<0,05$.

\subsubsection{Expressão de Osteopontina}

O tratamento dos animais com EA induziu aumento na expressão de osteopontina cardíaca em relação aos grupos controle. No entanto, quando o treinamento físico foi associado ao EA, observamos um aumento ainda mais pronunciado quando comparado ao grupo sedentário tratado com EA (FIGURA 17A).

Assim como os resultados encontrados anteriormente, a associação de Losartan (FIGURA 17B) ou Espironolactona (FIGURA 17C) a administração de EA inibiu o aumento na expressão de osteopontina nos grupos sedentários e treinados. 


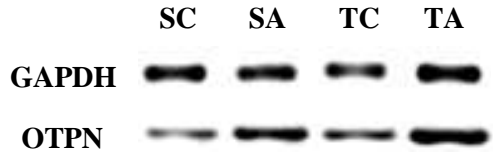

A

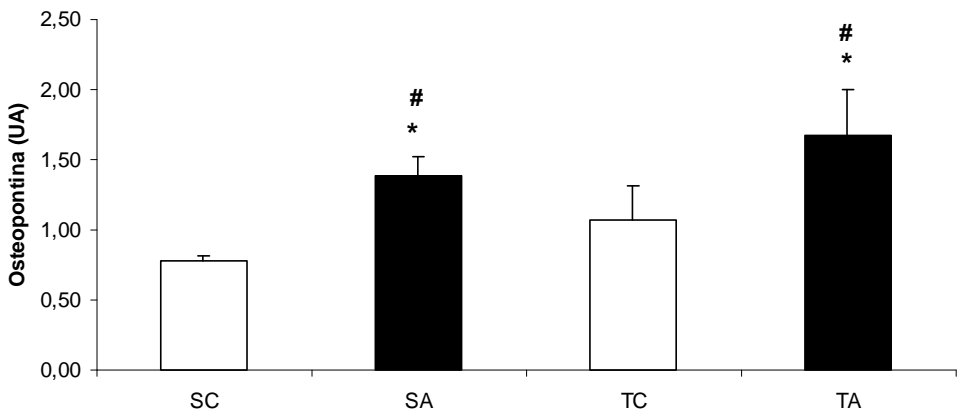

SA SAL TA TAL

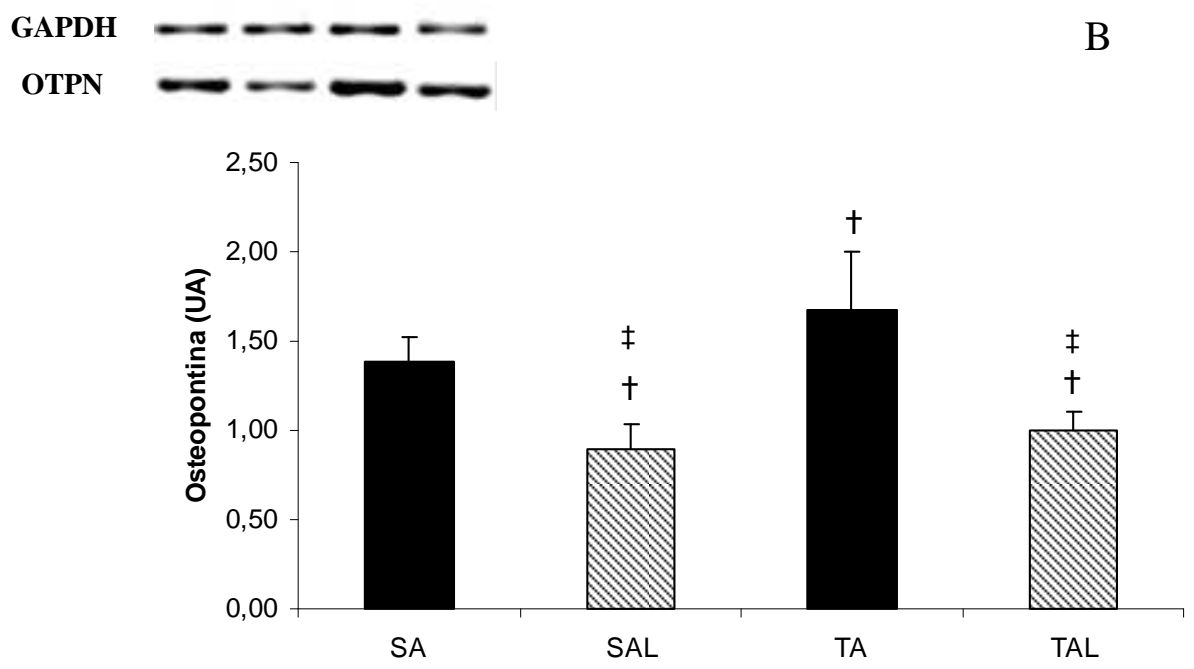




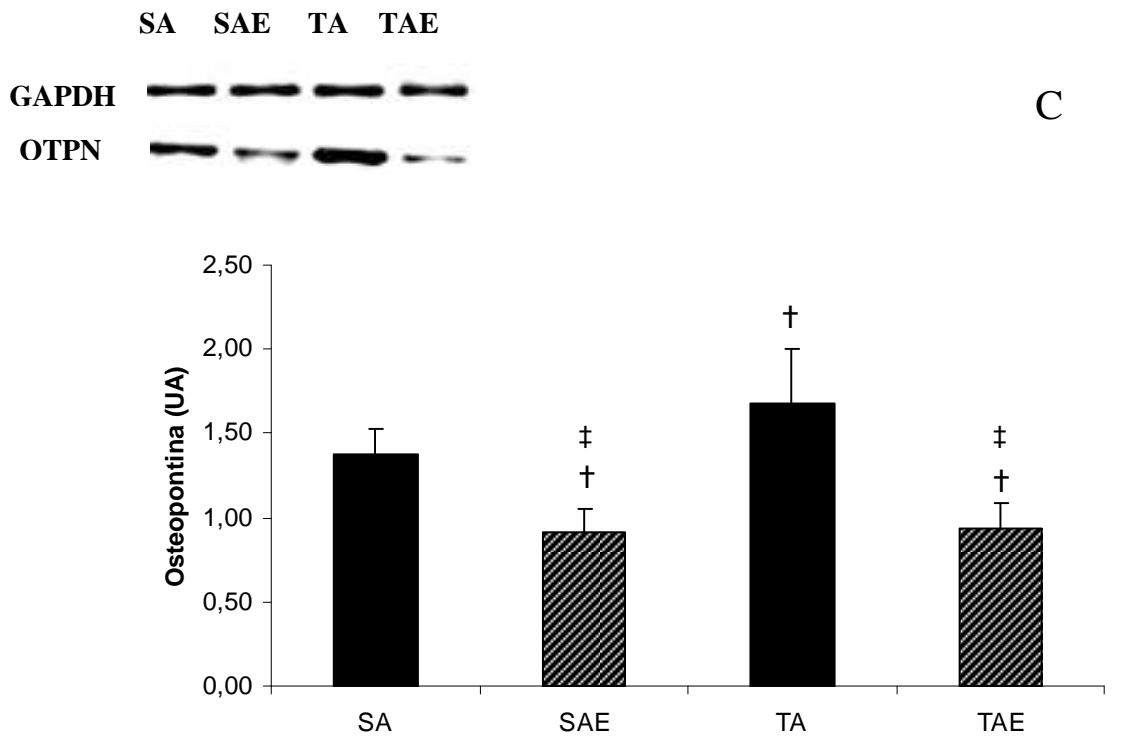

FIGURA 17 - Expressão de Osteopontina (UA). Efeitos da administração de EA e a associação ao treinamento físico (A) ao Losartan (B) e a Espironolactona (C) sobre a expressão de osteopontina cardíaca. Sedentário controle ( $\mathrm{SC}, \mathrm{n}=7$ ), sedentário tratado com anabolizante (SA, n=7), sedentário tratado com anabolizante e Losartan (SAL, $\underline{\mathrm{n}=7) \text {, sedentário tratado com anabolizante e Espironolactona (SAE, } \mathrm{n}=7 \text { ), treinado }}$ controle ( $\mathrm{TC}, \mathrm{n}=7$ ), treinado tratado com anabolizante (TA, $\mathrm{n}=7$ ), treinado tratado com anabolizante e Losartan (TAL, $\mathrm{n}=7$ ) e treinado tratado com anabolizante $\mathrm{e}$ Espironolactona (TAE, $\mathrm{n}=7$ ). Os resultados são apresentados como média \pm DP. (*) Diferença significante em relação ao grupo SC. (\#) Diferença significante em relação ao grupo TC. $(\dagger)$ Diferença significante em relação ao grupo SA. ( $\ddagger$ ) Diferença significante em relação ao grupo TA, $\mathrm{p}<0,05$.

7

\section{DISCUSSÃO}

Os principais resultados encontrados nesse estudo mostram a participação do SRA aldosterona sobre a HC cardíaca induzida pela administração do EA e sua associação ao treinamento físico de natação em ratos, visto que, tanto o bloqueio dos receptores AT1 com Losartan, como dos RM com Espironolactona, foram efetivos em reverter os efeitos deletérios induzidos pelo EA. Foram demonstrados, pela primeira vez, os aumentos da aldosterona sintase e da enzima 11ßHSD2, induzidos pelo EA, sugerindo o importante papel da aldosterona sobre os efeitos deletérios ao coração.

Os resultados observados em relação aos valores de PA revelam que os tratamentos realizados não levaram a alterações nesses animais. O treinamento físico já 
é bem demonstrado na literatura por não alterar a PA em animais normotensos (KRIEGER, BRUM \& NEGRÃO, 1998). Por outro lado, os efeitos dos EA sobre a PA ainda são muito controversos. Estudos têm observado aumento da PA em usuários de EA (HARTEGENS \& KUIPERS, 2004) e em ratos tratados com EA (BEUTEL et al., 2004). No entanto, outros pesquisadores observaram resultados semelhantes aos nossos, em que atletas que receberam doses suprafisiológicas de EA por 16 semanas, (URHAUSEN et al., 2004) ou ratos treinados por natação e tratados com EA (ROCHA et al., 2007), não apresentaram alterações de PA. As discrepâncias nos resultados encontrados podem ocorrer devido aos diferentes regimes de tratamento, EA e protocolos utilizados.

Podemos observar ainda que ambos os tratamentos, Losartan ou Espironolactona, não alteraram a PA dos animais, o que sugere que os resultados observados com esses antagonistas possam ter ocorrido por seus efeitos cardíacos, sem alterações em sua regulação sistêmica. Quando se propõe estudar os efeitos locais de determinados sistemas por meio de intervenções farmacológicas, deve-se ter cuidado para que a PA não seja alterada. Essa precaução deve ser ainda maior quando estes estão diretamente envolvidos com sua regulação, como é o caso do SRA aldosterona, uma vez que qualquer alteração poderia ocasionar resultados provenientes de uma alteração pressórica. Por isso, as doses utilizadas do antagonista de receptores AT1, Losartan, e do antagonista dos RM, Espironolactona, foram já bem demonstradas na literatura, por serem eficazes em inibir os efeitos locais sem consequências hemodinâmicas (LI et al., 1997; WEBER \& BRILLA, 1991).

Como já era previsto, os animais que apenas realizaram o treinamento físico de natação (TC) apresentaram redução da FCrep após o protocolo experimental, mostrando que o treinamento físico aplicado foi eficaz em promover adaptações aeróbias sobre o sistema cardiovascular, sendo essa uma das principais alterações promovidas pelo treinamento (NEGRÃO, MOREIRA, BRUM, DENADAI \& KRIEGER 1992). A redução da FCrep pode ser induzida por diferentes mecanismos, dependendo do tipo de treinamento realizado.

MEDEIROS et al. (2004) observaram que ratos treinados por natação apresentavam menor FCrep, principalmente devido ao aumento do tônus parassimpático, o que leva a concluir que as adaptações induzidas pelo treinamento físico sobre a FC, nesse estudo, possam ter ocorrido pelo aumento do tônus parassimpática. 
Quando o EA foi associado ao treinamento de natação não foram observadas alterações sobre a FCrep, o que sugere um possível efeito do EA sobre as adaptações induzidas pelo treinamento. Esses efeitos podem ter ocorrido devido às ações dos EA sobre a modulação autonômica - alguns estudos têm demonstrado aumento das respostas taquicárdicas e diminuição das bradicárdicas (BEUTEL et al., 2005; PEREIRA-JUNIOR et al., 2006).

Outro fator que pode ter contribuído para os efeitos dos EA sobre a FCrep seria a maior ativação do SRA aldosterona, no qual a angiotensina II tem um importante papel sobre a modulação autonômica, aumentando o tônus simpático e diminuindo o parassimpático (PHILLIPS, 1987), além de estar associada ao aumento do colágeno intersticial e consequente prejuízo da função diastólica, cujos efeitos serão melhores discutidos mais à frente nesse estudo.

Resultados muito interessantes foram observados quando os animais treinados que receberam EA foram tratados com antagonistas dos receptores AT1 ou dos RM, em que apenas o grupo em que foi administrado a Espironolactona apresentou redução da FCrep após o período de treinamento.

Os antagonistas dos RM têm sido bem descritos na literatura por serem eficientes em reverter os efeitos deletérios induzidos pela aldosterona sobre o sistema cardiovascular em condições patológicas (BRILLA et al., 1993; FRACCAROLLO et al., 2005). No entanto, os efeitos desses antagonistas associados ao EA são desconhecidos, sendo sugerida pela primeira vez, sua eficácia em reverter os efeitos induzidos pelo EA sobre a FCrep após o treinamento físico. Uma possível explicação para esses resultados estaria relacionada às ações do EA sobre o aumento da aldosterona cardíaca, que pode ter levado a maior atividade simpática, inibindo os efeitos do treinamento físico sobre a FCrep, uma vez que a administração de Espironolactona parece ter revertido esses efeitos.

Uma segunda hipótese estaria relacionada às alterações estruturais cardíacas induzidas pela aldosterona, em que tem sido mostrado que a aldosterona tem importante papel na fibrose cardíaca e prejuízo da função ventricular, revertido por antagonistas dos RM (LIJNEN \& PETROV, 1999).

Por outro lado, o tratamento com Losartan parece não ter revertido os efeitos induzidos pelo EA sobre a FCrep. Esses resultados podem ter ocorrido devido aos efeitos dos receptores AT1 sobre as adaptações induzidas pelo treinamento, sendo descrito que esses receptores têm importante participação nessas adaptações, exercendo 
papel fundamental na HC e hipertrofia de cardiomiócitos (ZHU et al., 2003; SARKAR et al., 2004). Com isso, podemos sugerir que o fato de não ser observada diminuição na FCrep nesse grupo, pode ter ocorrido pela inibição dos efeitos do treinamento físico sobre a estrutura cardíaca, resultando na falta de adaptações autonômicas sobre a FCrep.

Além dos efeitos sobre a redução na FCrep, observamos ainda maior HC no grupo treinado controle em relação ao grupo sedentário controle. A HC, nesse grupo, parece ter ocorrido pelo aumento no diâmetro dos cardiomiócitos induzido pelo treinamento, visto que não foram observadas alterações no colágeno cardíaco. Os efeitos do exercício físico sobre a $\mathrm{HC}$ já são muito bem descritos na literatura - o exercício físico provoca respostas benéficas e adaptativas ao sistema cardiovascular, levando ao aumento da massa cardíaca sem prejuízos funcionais (LORELL \& CARABELLO, 2000). A HC induzida pelo treinamento físico aeróbio é desencadeada por estímulos mecânicos decorrentes da sobrecarga de volume, levando à maior síntese de proteínas contráteis e aumento do sarcoplasma, o que acarreta em aumento no diâmetro dos cardiomiócitos (HEINEKE \& MOLKENTIN, 2006; WEBER \& BRILLA, 1991).

Por outro lado, diferentemente do que ocorre com o treinamento físico, a $\mathrm{HC}$ encontrada no grupo sedentário anabolizante parece estar relacionada ao aumento do colágeno cardíaco, sendo observado aumento na fração volume de colágeno e colágeno tipo III quando comparados ao grupo sedentário controle. Resultados semelhantes foram mostrados em trabalhos anteriores, feitos por nosso grupo, em que a administração de EA parece ter sido responsável pelo aumento de áreas fibróticas no coração dos animais, tendo sido encontradas regiões de colágeno reparativo semelhantes às observadas em situações de morte celular, o que sugere que o EA pode levar à necrose tecidual, ocasionando alterações estruturais similares às observadas nos estágios iniciais de insuficiência cardíaca (LIPS et al., 2003).

O tratamento com EA parece também estar associado ao aumento no diâmetro dos cardiomiócitos, apesar desse ser significativamente menor em relação ao observado nos grupos que realizaram o treinamento físico de natação. $\mathrm{O}$ aumento dos cardiomiócito induzido pelo EA pode ocorrer devido aos seus efeitos diretos sobre a síntese protéica muscular (KOCHAKIAN \& WELBER, 1993), ou ainda, por aumentar vias patológicas, aumentando a expressão de genes usualmente encontrados na vida fetal, como a miosina de cadeia pesada e a $\alpha$ actina esquelética (SANTOS et al., 2000). Assim, não podemos descartar a hipótese de que o aumento dos cardiomiócitos induzido 
pelo EA no grupo sedentário pode ter ocorrido por vias patológicas. No entanto, são necessários mais estudos para se compreender os efeitos do EA sobre a hipertrofia dos cardiomiócitos e os mecanismos pelos quais esta ocorre.

Quando a administração de EA foi associada ao treinamento físico de natação, a HC observada foi ainda mais pronunciada em relação aos grupos SA e TC. A maior HC encontrada nesse grupo pode ter ocorrido tanto pelo aumento no diâmetro dos cardiomiócitos, como pelo aumento do colágeno cardíaco, observado pela FVC e colágeno tipo III. Esses resultados sugerem um efeito somatório do treinamento físico e do EA nesse grupo. Observamos ainda menor pico de velocidade da onda E e relação E/A no grupo TA em relação aos demais, sugerindo que a associação do EA ao treinamento físico pode levar a prejuízo da função diastólica, mostrando que, quando o EA é associado ao treinamento físico os efeitos cardiovasculares podem ser ainda mais deletérios, revertendo a HC fisiológica induzido pelo treinamento aeróbio para uma HC patológica. Estudos têm mostrado os efeitos dos EA sobre a função diastólica, quando associados ao exercício físico.

KRIEG et al., 2007, observaram por ecocardiograma em usuários de EA a diminuição no pico de velocidade durante a fase inicial de enchimento diastólico. Também foi observado prejuízo da função diastólica em levantadores de peso que utilizavam EA comparados aos que não utilizavam (PEARSON et al., 1986; DE PICCOLI et al., 1991). Prejuízos na função diastólica podem estar relacionados ao aumento do colágeno intersticial, visto que o tecido conectivo é responsável por distribuir as forças de trabalho sobre o coração, exercendo importante influência sobre a complacência ventricular (WEBER \& BRILLA, 1991).

Apesar de muitos estudos já terem mostrado os efeitos dos EA sobre a HC, fibrose e função ventricular (KRIEG et al., 2007, BEUTEL et al., 2005; ROCHA et al., 2007), pouco se sabe sobre os reais mecanismos responsáveis por esses efeitos, ficando sugerida a ação direta dos EA por meio de receptores androgênicos (KOCHAKIAN \& WELBER, 1993), ou ainda por afetar enzimas específicas, fluxo de íons e a matriz estrutural no miocárdio (MELCHERT \& WELDER, 1995). Em trabalho anterior realizado por nosso grupo, foi demonstrada, pela primeira vez, a participação do SRA aldosterona sobre o aumento do colágeno intersticial associado ao EA, quando o aumento na expressão do colágeno tipo III foi diretamente correlacionado a maior atividade da ECA cardíaca (ROCHA et al., 2007). 
Por meio dos receptores AT1, a angiotensina II tem sido considerada um dos principais estimulantes da proliferação de fibroblastos (BURLEW \& WEBER, 2000). Ela aumentaria a secreção de proteínas da matriz extracelular (KOMURO, 2001), a liberação de fatores inflamatórios, (BOOZ \& BAKER, 1995), ou ainda diminuiria a expressão das metaloproteinases 1 (MMP-1), responsáveis pela degradação do colágeno (CHEN et al., 2004).

O bloqueio dos receptores AT1, com Losartan, foi eficaz em restaurar a atividade da colagênese, diminuindo o efeito pró-fibrótico da angiotensina II (CHEN et al., 2004; KAWANO et al., 2005). Em condições patológicas, modelos de infarto, sobrecarga de volume e estenose aórtica, o tratamento com Losartan foi eficaz em inibir a HC (MIL et al., 1997; DENT et al., 2006, GONÇALVES et al., 2005).

Resultados semelhantes foram encontrados no presente estudo, em que o tratamento com Losartan inibiu o aumento do colágeno intersticial induzido pelo EA no grupo sedentário. $\mathrm{O}$ que pode explicar, em parte, a menor $\mathrm{HC}$ encontrada nesse grupo. Isso sugere que os receptores AT1 têm importante papel na fibrose cardíaca induzida pelo EA. Quando o Losartan foi administrado no grupo treinado tratado com EA, também foi observada menor HC, inibição no aumento da fração volume de colágeno e redução na expressão de colágeno tipo I e III, em relação aos grupos tratados com EA. A redução do colágeno cardíaco observado nesse grupo pode ter sido responsável pelos efeitos benéficos do Losartan sobre a função diastólica, eficaz em reverter os efeitos deletérios induzidos pela associação do EA ao treinamento físico.

Entretanto, um resultado muito interessante foi observado em relação ao diâmetro dos cardiomiócitos, em que o grupo TAL apresentou menor diâmetro em relação ao grupo TA, sugerindo que o bloqueio dos receptores AT1 pode, além de bloquear os efeitos dos EA, fazer o mesmo com os efeitos do treinamento físico sobre os cardiomiócitos. Os efeitos do SRA local sobre a HC induzida pelo treinamento aeróbio também foram observados em outro estudo, em que ratos treinados em um sistema de natação e tratados com Losartan apresentaram inibição da HC (OLIVEIRA, SASAKI, CERENCIO, BARAUNA, KRIEGER, 2009). As ações da angiotensina II sobre o aumento no diâmetro dos cardiomiócitos cardíacos são desencadeadas pela interação com os receptores AT1, que ativam uma variedade de vias de sinalização intracelular, aumentando a expressão de genes relacionados à hipertrofia (ZHU et al., 2003; SARKAR et al., 2004). Além das ações da angiotensina II, os receptores AT1 podem ter um importante papel na $\mathrm{HC}$ induzida pelo treinamento físico, por atuar 
diretamente como um sensor de estresse mecânico, ativando vias de sinalização celular responsáveis pela hipertrofia dos cardiomiócitos (BARAUNA, MAGALHÃES, KRIEGER, OLIVEIRA, 2008).

Recentemente tem sido proposto que algumas das ações atribuídas a angiotensina II, principalmente sobre a $\mathrm{HC}$ e aumento do colágeno intersticial, podem estar diretamente relacionadas à síntese e liberação de aldosterona cardíaca (BURLA et al., 2006), associada a respostas inflamatórias, levando a lesão tecidual (STRUTHERS, 2004), síntese de colágeno e remodelamento (SANTOS et al., 2000; ROBERT et al., 1995), independentemente de alterações hemodinâmicas, sugerindo os efeitos locais da aldosterona (BRILLA et al., 1990).

Buscando entender um pouco mais a participação da aldosterona sobre a $\mathrm{HC}$ e síntese de colágeno induzidas pelo EA e sua associação ao treinamento físico, os animais foram tratados com Espironolactona. Não houve inibição da HC nos grupos tratados (SAE e TAE), comparados aos grupos que receberam EA. No entanto, foi observada menor fração volume de colágeno e expressão dos colágenos tipo I e III nesses grupos. Assim como o tratamento com Losartan, a Espironolactona também inibiu a disfunção diastólica induzida pela associação do EA ao treinamento físico, que pode ter sido associada ao menor colágeno cardíaco.

A HC observada no grupo TAE pode ter ocorrido pelos efeitos do treinamento físico, em que diferentemente do Losartan, a Espironolactona não inibiu o aumento no diâmetro dos cardiomiócitos, sugerindo assim o papel importante da aldosterona sobre a síntese de colágeno cardíaco, não influenciando os efeitos do treinamento físico.

Esses resultados podem ser confirmados por estudos em que o bloqueio dos RM com Espironolactona, mesmo em baixas doses, foi capaz de reverter a fibrose cardíaca, sem produzir efeitos sobre a HC (NEHME et al., 2006). Em outro, a administração de antagonistas dos RM não tiveram efeitos sobre o índice de HC, mas foi efetivo em reduzir o colágeno do miocárdio em ratos idosos e hipertensos (YONG \& FUNDER, 2004).

Conforme observado até aqui, o SRA aldosterona parece ter importante papel nos efeitos deletérios induzidos pelo EA e sua associação ao treinamento físico sobre a $\mathrm{HC}$ e colágeno intersticial, visto que ambos os tratamentos com Losartan ou Espironolactona reverteram os efeitos deletérios sobre o miocárdio. Sendo assim, o próximo passo do estudo foi procurar entender um pouco mais a modulação cardíaca desse sistema. 
A atividade da ECA cardíaca foi aumentada nos grupos tratados com EA em relação aos grupos controle, confirmando os dados anteriores do nosso grupo, em que a atividade da ECA no coração também foi aumentada pelo EA (ROCHA et al., 2007). Uma vez que a atividade da ECA cardíaca pode refletir as concentrações de angiotensina II no coração (DZAU, BERNSTEIN, CELERMAJER \& WEBER, 2001; ROCHA et al., 2007), podemos sugerir que o tratamento com EA pode ter aumentado as concentrações de angiotensina II no tecido cardíaco.

Assim como a atividade da ECA, o tratamento com EA também aumentou a expressão dos receptores AT1 e AT2 no tecido cardíaco. Esses resultados mostram que a administração de EA leva à maior ativação do SRA cardíaco, o que pode ter sido responsável, parcialmente, pelos efeitos deletérios observados anteriormente.

Em condições patológicas, a expressão dos receptores AT1 tem se mostrado aumentada no tecido cardíaco, sendo responsável pela hipertrofia e proliferação celular (MATSUBARA et al., 1998; UNGER et al., 1999). Por outro lado, os receptores AT2 parecem ter efeitos opostos aos receptores AT1. Entretanto, seu verdadeiro papel ainda é muito controverso (PAUL et al., 2006). Tem sido sugerida sua participação na modulação da matriz extracelular, em que foi observado que a administração de um antagonista desses receptores levou ao aumento na síntese de fibronectina, comprovando sua importância na restauração da normalidade do sistema cardiovascular (GASPARO et al., 2000). Esses dados podem explicar o aumento na expressão dos receptores AT2 encontrados nesse estudo, que pode ter ocorrido como uma tentativa de contrabalançar os efeitos deletérios induzidos pelo EA e a maior ativação do SRA cardíaco.

Ambos os tratamentos com Losartan ou com Espironolactona inibiram o aumento na atividade da ECA cardíaca induzida pelo EA, o que consequentemente pode ter diminuído as concentrações de angiotensina II. Isso explica, em parte, os efeitos benéficos sobre o colágeno e função cardíaca. Além dos efeitos inibindo as ações da angiotensina II, os benefícios do Losartan podem ainda estar associados à maior ativação dos receptores AT2 pela angiotensina II, o qual teria efeitos opostos aos receptores AT1. No entanto, esses mecanismos ainda são muito controversos.

Os efeitos da Espironolactona sobre a atividade da ECA também têm sido demonstrados na literatura. Animais tratados com aldosterona apresentaram aumento na expressão da ECA cardíaca, que foi inibida com a administração de Espironolactona 
(FRACCAROLLO et al., 2005), confirmando os resultados observados no presente estudo.

Por outro lado, dados da literatura mostram que o tratamento com Losartan (MIL et al., 1997) ou com Espironolactona (HARADA et al., 2001) reduziram a expressão dos receptores AT1 cardíacos. Entretanto, no presente estudo, os tratamentos com Losartan ou Espironolactona não inibiram o aumento na expressão dos receptores AT1 induzido pelo EA, sugerindo a influência direta do EA sobre a modulação desses receptores.

Poucos trabalhos têm mostrado a influência dos hormônios esteróides sobre a expressão dos receptores AT1, sendo verificado um aumento de quase $300 \% \mathrm{em}$ animais tratados com glicocorticóides (DELLA BRUNA et al., 1995). No entanto, os efeitos dos EA sobre a expressão dos receptores AT1 ainda são desconhecidos, e outros estudos são necessários para entendermos os verdadeiros mecanismos.

Como citado anteriormente, dentre os principais efeitos relacionados à angiotensina II, está sua ação sobre o aumento na síntese e liberação da aldosterona, que pode ser responsável pela fibrose cardíaca associada a angiotensina II. Com isso, o próximo passo foi avaliar a expressão do gene CYP11B2 no tecido cardíaco.

Os grupos tratados com EA apresentaram aumento na expressão do gene CYP11B2 em relação aos grupos controle. O aumento na expressão desse gene está diretamente relacionado ao aumento nas concentrações de aldosterona cardíaca (YOSHIMURA et al., 2002), o que leva a sugerir que o tratamento com EA aumentou a síntese de aldosterona cardíaca nesses animais, a qual pode ter importante papel na fibrose cardíaca observada nesses grupos (ROBERT et al., 1995).

O tratamento dos animais com Losartan ou com Espironolactona inibiu o aumento na expressão do gene CYP11B2, o que consequentemente pode ter reduzido a síntese de aldosterona cardíaca e ser responsável pela menor fibrose observada. Alguns estudos têm descrito os efeitos do bloqueio do SRA aldosterona sobre a expressão do gene CYP11B2, em que animais tratados com inibidores da ECA apresentaram redução da aldosterona cardíaca e menor expressão do gene CYP11B2 (WEHLING, 2005). Em outro trabalho, o tratamento com Losartan reduziu as concentrações da enzima Aldosintase em animais infartados (SILVESTRE et al., 1999).

A aldosterona age na maioria dos casos por meio dos RM (FRIMM \& KOIKE, 2003). No entanto, a interação da aldosterona com o RM é modulada por diferentes fatores, entre eles, a enzima 11 $\beta$-HSD2, responsável pela inativação da corticosterona, 
permitindo, assim, a maior ação da aldosterona sobre os receptores (FRIMM \& KOIKE, 2003). A expressão dessa enzima pode ser modulada por diversos fatores, como alguns tipos de patologias ou até mesmo o tecido analisado (STRUTHERS, 2004), sendo mostrado que o aumento na expressão da 11ß-HSD2 está diretamente relacionada a maior fibrose cardíaca (QIN et al., 2003).

No presente estudo, não foram observadas diferenças na expressão dos RM cardíacos em nenhum dos grupos analisados. No entanto, os grupos tratados com EA apresentaram um aumento na expressão da 11ß-HSD2 cardíaca. Com isso, demonstramos, pela primeira vez, que o EA pode alterar a seletividade dos RM, aumentando a expressão da enzima $11 \beta$-HSD2 e permitindo, assim, a maior ação da aldosterona sobre os RM, que pode ser responsável pelos efeitos deletérios induzidos pelo EA.

Um resultado muito interessante encontrado nesse estudo mostra o efeito do treinamento físico sobre a expressão da 11ß-HSD2. Apenas o grupo TC apresentou diminuição na expressão dessa enzima, sugerindo que o treinamento físico aeróbio pode alterar a seletividade desses receptores a aldosterona, além de permitir a maior interação dos RM com os glicocorticóide, inibindo os efeitos deletérios da aldosterona sobre o coração. Os glicocorticóides podem atuar como antagonistas dos RM (QIN et al., 2003), mostrando que baixa expressão da 11ß-HSD2, mesmo com os níveis de aldosterona elevados, pode prevenir seus efeitos colaterais, principalmente pela ligação da corticosterona aos RM (NAGATA et al., 2006).

Ambos os tratamentos com antagonistas dos receptores AT1 e dos RM foram eficazes em inibir o aumento na expressão da 11ß-HSD2 induzida pelo EA. O que pode ter contribuído para a menor fibrose cardíaca nesses grupos, visto que, como discutido anteriormente, a diminuição na expressão da 11ß-HSD2 está relacionada à menor fibrose cardíaca.

Tanto a angiotensina II, como a aldosterona, podem exercer efeitos sobre a HC e aumento do colágeno por meio da liberação de fatores inflamatórios. Dentre eles, destacam-se o TGF $\beta$ e a osteopontina. Por meio dos receptores AT1, a angiotensina II desencadeia uma cascata de sinalização intracelular, estimulando a liberação de TGF $\beta$ pelos cardiomiócitos, que, por sua vez, atua tanto nos cardiomiócitos, levando à necrose tecidual, como nos fibroblastos, aumentando a expressão de proteínas relacionadas a fibrose (BOOZ \& BAKER, 1995). O TGF $\beta$ também tem sido destacado por ser 
liberado pelas ações da aldosterona, induzindo o aumento na expressão de fatores de crescimento do tecido conectivo (SATOH et al., 2002).

Os efeitos colaterais induzidos pela aldosterona são, ainda, associados à maior liberação de osteopontina, que tem sido colocada em destaque por ter importante papel sobre a $\mathrm{HC}$ e fibrose intersticial. Trabalhos apresentam ações inibidas da aldosterona em camundongos geneticamente modificados, com deficiência para osteopontina (SAM et al., 2004).

Observamos aumento na expressão de TGF $\beta$ e osteopontina nos grupos tratados com EA em relação aos grupos controle. Um resultado muito interessante observado, foi o aumento ainda mais pronunciado na expressão de osteopontina quando o EA foi associado ao treinamento físico de natação. $\mathrm{O}$ aumento na expressão dos fatores inflamatórios pode ter importante participação na fibrose cardíaca induzida pelo EA, sendo que o maior aumento da osteopontina no grupo TA pode explicar os efeitos mais pronunciados observados nesse grupo.

A administração de Losartan ou Espironolactona foi eficaz em inibir os aumentos dos fatores inflamatórios quando comparados aos grupos tratados com EA. Ela mostra que tanto a ativação dos receptores AT1, quanto a dos RM, participam no aumento da expressão desses fatores. Resultados semelhantes têm sido observados em estudo cujo bloqueio da angiotensina II e da aldosterona inibiram a expressão de osteopontina em ratos infartados (ZHANG et al., 2008), confirmando os resultados observados nesse trabalho. Mais estudos são necessários para compreender seus mecanismos.

Os resultados observados mostram que a administração de EA aumenta a ativação do SRA aldosterona, o que parece estar diretamente relacionado aos efeitos colaterais produzidos sobre o tecido cardíaco, visto que, o bloqueio dos receptores AT1 e dos RM inibiram esses efeitos. Uma possível hipótese dos mecanismos pelos quais os EA atuam sobre o SRA aldosterona estaria relacionada à afinidade dos EA aos RM, devido à sua estrutura similar a aldosterona (MELCHERT \& WELBER, 1995). Os EA, por meio dos RM, ativariam o SRA aldosterona, visto que um mecanismo inverso tem sido proposto na modulação desse sistema, em que a maior ativação dos RM parece aumentar a atividade da ECA e a expressão dos receptores AT1 (FRACCAROLLO et al., 2005).

O EA pode ainda agir sobre os RM por alterar a expressão da enzima $11 \beta$ HSD2, influenciando na modulação dos RM, conforme foi observado no presente 
estudo. Essa alteração permitirá a maior ação da aldosterona sobre os receptores, o que está relacionada aos efeitos deletérios da aldosterona sobre o tecido cardíaco. No entanto, mais estudos são necessários para se entender os reais mecanismos pelos quais os EA aumentam o SRA aldosterona cardíaco.

Resultados muito interessantes verificados nesse estudo, foram os efeitos similares observados com o tratamento do Losartan ou Espironolactona sobre a regulação do SRA aldosterona e seus efeitos deletérios sobre o tecido cardíaco, em que ambos se mostraram eficientes em inibir esses efeitos. Recentemente, foi sugerido um mecanismo que pode ajudar a entender melhor esses resultados, sendo proposto um “cross-talking" entre os RM e os receptores AT1 (LEMARIÉ et al., 2008). Essa hipótese tem sido sugerida por trabalhos que mostram que a infusão de angiotensina II e aldosterona aumentaram a proliferação de células musculares lisas, sendo que nas situações em que apenas um dos dois foi administrado, esses resultados não foram observados. No mesmo estudo, os autores mostraram ainda que a administração de antagonistas dos receptores AT1 ou dos RM inibiram os efeitos induzidos pela associação da angiotensina II e da aldosterona, sugerindo uma interação entre os dois receptores, desencadeando cascatas de sinalização intracelular especificas, que não são ativas pelas ações de apenas um dos dois (MIN, MOGI, LI, IWANAMI, IWAI \& HORIUCHI, 2005).

Com isso, podemos sugerir que os efeitos cardíacos observados nesse estudo podem ter ocorrido por um "cross-talking" entre os receptores AT1 e RM, visto que o bloqueio de ambos os receptores foram eficientes em inibir esses efeitos, sendo que se observou também que o tratamento com EA pode ter aumentado as concentrações de angiotensina II e de aldosterona.

\section{CONCLUSÃO}

Podemos concluir que o SRA aldosterona participa dos efeitos deletérios induzidos pelo EA e sua associação ao treinamento físico de natação sobre a $\mathrm{HC}$ e síntese de colágeno, visto que tanto o bloqueio dos receptores AT1 como dos RM foram efetivos em inibir esses efeitos. Mostrando pela primeira vez, os efeitos do EA e sua associação ao treinamento físico sobre a aldosterona cardíaca, observada pelo aumento na expressão do gene da Aldo-sintase (CYP11B2) e da enzima 11ßHSD2. 
ABBOTT, A. What price the Olympian ideal? Nature, London, v. 407, p. 124-7, 2000.

AlARANTA, A.; AlARANTA, H.; HOLMILA, J.; PALMU, P.; PIETILA, K.; HELENIUS, I. Self-reported attitudes of elite athletes towards doping: differences between type of sport. International journal of Sports Medicine, Stuttgart, v.27, n.10, p.842-6, 2006.

ARAUJO, M. C.; MELO, R. L.; CESARI, M. H.; JULIANO, L.; CARMONA, A. K. Peptidase specificity characterization of $\mathrm{C}$ - and $\mathrm{N}$ - terminal catalytic sites of angiotensin I-converting enzyme. Biochemistry, Washington, v.39, n.29, p.8519-8525, 2000

BADER, M. Role of the local renin-angiotensin system in cardiac damage: a minireview focussing on transgenic animal models. Journal of molecular and cellular cardiology, London, v.34, p.1455-62, 2002.

BADER, M.; PETERS, J.; BALTATU, O.; MULLER, D.; LUFT, F. C.; GANTEN, D. Tissue renin-angiotensin systems: new insights from experimental animal models in hypertension research. Journal of Mollecular Medicine, New York, v. 79, n.2-3, p. 76$102,2001$.

BAHRKE, M.S.; YESALIS, C.E. Abuse of anabolic-androgenic steroids and related substances in sport and exercise. Current opinion in pharmacology, Oxford, v.4, p.61420, 2004.

BAMMAN, M.M.; SHIPP, J.R.; JIANG, J.; GOWER, B.A.; HUNTER, G.R.; GOODMAN, A.; MCLAFFERTY, C.L.; URBAN, R.J. Mechanical load increases muscle IGF-1 and androgen receptor mRNA concentrations in humans. American journal of physiology. Endocrinology and metabolism, Bethesda, v.280, p. 383-90, 2001.

BARAUNA, V. G.; MAGAlHÃES, F. C.; KRIGER, J. E.; OLIVEIRA, E. M. AT1 receptor participates in the cardiaca hypertrophy induced by resistance training in rats. 
American journal of physiology. Regulatory, integrative and comparative physiology, Bethesda, v.295, n.2, p. 381-387, 2008.

BEUTEL, A.; BERGAMASCHI, C.T.; CAMPOS, R.R. Effects of chronic anabolic steroid treatment on tonic and reflex cardiovascular control in male rats. Journal of Steroid Biochemistry \& Molecular Biology, Oxford, v.93, n.1, p.43-48, 2005.

BIANCO, AC.; RABELO, R. Introdução a fisiologia endócrina. In: AIRES, M.M. Fisiologia, $2^{\text {a }}$ edição, Rio de Janeiro, Guanabara Koogan, 1999, cáp.65,p.741-65

BIRGNER, C.; HOGBERG, A.M.S.K.; ALSIO, J.; LINDBLOM, J.; SCHIOTH, H.B.; BERGSTROM, L. The anabolic androgenic steroid nandrolone decanoate affects mRNA expression of dopaminergic but not serotonergic receptors. Brain Research, Amsterdam, v.13, p.221-28, 2008.

BONVALET, J.P.; ALFAIDY, N.; FARMAN, N.; LOMBES, M. Aldosterone: intracellular receptors in human heart. European heart journal, London, v.16, p.92-97, 1995.

BOOZ, G.W.; BAKER, K.M. Molecular signalling mechanisms controlling growth and function of cardiac fibroblast. Cardiovascular Research,_London, v.30, p.537-43, 1995.

BRADFORD, M.M. A rapid and sensitive method for the quantitation of microgram quantities of protein utilizing the principle of protein-dye binding. Analytical Biochemistry, New York, v.72, p.248-54, 1976.

BRICOUT, V.; GERMAIN, P.; SERRURIER, B.; GUEZENNEC, C. Changes in testosterone muscle receptors: effects of na androgen treatment on physically-trained rat. Cellular and molecular biology, Noisy-le-Grand, v.40, p.291-94, 1994.

BRILLA, C.G.; MATSUBARA, L.S.; WEBER, K.T. Anti-aldosterone treatment and the prevention of myocardial fibrosis in primary and secondary hyperaldosteronism. Journal of molecular and cellular cardiology, London, v.25, p.563-75, 1993. 
BRILLA, C.G.; PICK, R.; TAN, L.B.; JANICKI, J.S.; WEBER, K.T. Remodelling of the rat right and left ventricles in experimental hypertension. Circulation Research, Baltimore, v.67, p.1355-64, 1990.

BROWN, N.J. Eplereone. Cardiovascular protection. Circulation, Dallas, v.102, p.102$38,2003$.

BUCKLEY, W.E.; YESALIS, C.E.; FRIEDL, K.E.; ANDERSON, W.A.; STREIT, A.L.; WRIGHT, J.E. Estimated prevalence of anabolic steroid use among male high school seniors. JAMA: the journal of the American Medical Association, Chicago, v.260, p. 3441-45, 1988.

BURLA, A.K.; NEVES, M.F.; OIGMAN, W.; MANDARIM-DE-LACERDA, C.A. Eplerenone offsets cardiac and adverse remodeling in spontaneously hypertensive rats. International Journal of Cardiology, Amsterdam, v.114, n.1, p.1-7, 2006.

BURLEW, B.S.; WEBER, K.T. Connective tissue and the heart. Functional significance and regulatory mechanism. Cardiology clinics, Amsterdan, v.18, n.3, p.435-42, 2000.

CALFEE, R.; FADALE, P. Popular ergogenic drugs and supplements in yong athletes. Pediatrics, Springfield, v.177, n.3, p.577-89, 2006.

CAREY, R.M.; SIRAGY, H.M. Newly recognized components of rennin-angiotensin system: potential roles in cardiovascular and renal regulation. Endocrinology Review, Milan, v.24,n.3, p.261-71, 2003.

CATLIN, D.H.; FITCH, K.D.; LIUNGOVIST, A. Medice and science in the fight against doping in sport. Journal Of Internal Medice, New Jersey, v.264, n.2, p.99-114, 2008 .

CATLIN, D.H.; SEKERA, M.H.; AHRENS, B.D.; STARCEVIC, B.; CHANG, Y.C.; HATTON, C.K. Tetrahydrogestrinone: discovery, synthesis, and detection in urine. Rapid Communication in Mass Spectrometry, London, v.18, p. 1245-49, 2004. 
CELOTTI, F.; CESI, P.N. Anabolic Steroids: A review of their effects on the muscle, of their possible mechanisms of action and of their use in athletics. The Journal of

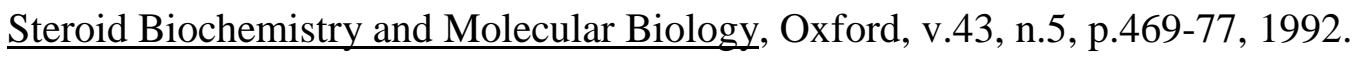

CHEN, K.; MEHTA, J.L.; LI, D.; JOSEPH, L.; JOSEPH, J. Transforming growth factor beta receptor endoglin is expressed in cardiac fibroblasts and modulates profibrogenic actions of angiotensin II. Circulation research, Baltimore, v.95, n.12, p.1167-73, 2004.

COBEA (Colégio Brasileiro de Experimentação Animal) Princípios éticos na experimentação animal, 1991. disponível na internet $\underline{\text { HTP://www.cobea.org.br> }}$ Acesso em julho 2007.

COHN, J.N.; FERRARI, R.; SHARPE, N. Cardiac remodeling - concepts and clinical implications: a consensus paper from an international fórum on cardiac remodeling. Journal of the American College of Cardiology, New York, v.35, n.3, p.569-582, 2000.

CRABOS, M.; ROTH, M.; HAHN, A.W.A.; EME. P. Characterization of angiotensin II receptors in cultured adult rat cardiac fibroblasts. The Journal of clinical investigation, New Haven,v.93, p.2372-78, 1994.

CREUTZBERG, E.C.; WOUTERS, E.F.; MOSTERT, R.; PLUYMERS, R.J.; SCHOOLS, A.M. A role for anabolic steroids in the rehabilitation of patients with COPD? A double-blind, placebo-controlled, randomized trial. Chest, Chicago, v.124, n.5, p.1733-42, 2003.

DAL PIZZOL, T.S.; BRANCO, M.M.N.; CARVALHO, R.M.A.; PASQUALOTTI, A.; MACIEL, E.M.; MIGOTT, A.M.B. Uso não-médico de medicamentos psicoativos entre escolares do ensino fundamental e médio no sul do Brasil. Caderno de Saúde Pública, Rio de Janeiro, v.22, n.1, p.109-15, 2006.

DANSER, A.H.; SCHALEKAMP, M.A. Is there na internal cardiac renin-angiotensin system? Heart, London, v.76, n.3 Suppl 3, p.28-32, 1996. 
DE MARCHI, S.F.; ALLEMANN, Y.; SEILER, C. Relaxation in hypertrophic cardiomyopathy and hypertensive heart disease: Relations between hypertrophy and diastolic function. Heart, London, v.83, n.6. p.678-84, 2000.

DE PICCOLI, B.; GIADA, F.; BENETTIN, A.; SARTORI, F.; PICCOLO, E. Anabolic steroid use in body builders: An echocardiographic study of left ventricle morphology and function. International journal of sports medicine, Stuttgart, v.12, n.4, p.408-12, 1991.

DELLA BRUNA, R.; RIES, S.; HIMMELSTOSS, C.; KURTZ, A. Expression of cardiac angiotensin II AT1 receptor genes in rat hearts is regulated by steroids but not by angiotensin II Journal of hypertension, London, v.13, p.763-69, 1995.

DENT, M.R.; AROUTIOUNOVA, N.; DHALLA, N.S.; TAPPIA, P.S. Losartan attenuates phospholipase $\mathrm{C}$ isozyme gene expression in hypertrophied hearts due to volume overload. Journal of cellular and molecular medicine, London, v.10, p.470-79, 2006.

DICKERMAN, R.D.; SCHALLER, F.; PRATHER, I.; MCCONATHY, W.J. Sudden cardiac death in a 20-year-old bodybuilder using anabolic steroids. Cardiology, Basel, v.86, n.2, p.172-73, 1995.

DOURAKIS, S.P.; TOLIS, G. Sex hormonal preparations and the liver. The European Journal of Contraception \& Reproductive health care, Carnforth, v.3, n.1, p.7-16, 1998.

DU TOIT. E.F.; ROSSOUW, E.; VAN ROOYEN, J.; LOCHNER, A. Proposed mechanisms for the anabolic steroid-induced increase in myocardial susceptibility to ischaemia/reperfusion injury. Cardivascular Journal of Southern Africa, Durbanvilli, v.16, n.1, p.21-8, 2005.

DZAU, V.; BERNSTEIN, K.; CELERMAJER, D.; WEBER, M. The relevance of tissue angiotensin-converting enzyme manifestations in mechanistic and endpoint data. American Journal Cardiology, Bethesda, v.88, p.1L-20L, 2001. 
ENGELI, S.; NEGREL, R.; SHARMA, A. Physiology and pathophysiology of the adipose tissue rennin-angiotensin system. Hypertension, Dallas, v.35, n.6, p. 1270-7, 2000.

FISCHER, J.; STOLL, M.; UNGER, T. Thrombospondin mRNA expression is increased in endothelial cells following stimulation of AT2-receptors. vascular research , Basel, v.33,p.26-29, 1996.

FRACCAROLLO, D.; GALUPPO, P.; SCHMIDT, I.; ERTL, G.; BAUERSACHAS, J. Additive amelioration of left ventricular remodeling and molecular alterations by combined aldosterone and angiotensin receptor blockade after myocardial infarction. Cardiovascular Research, London, v.67, p.97-105, 2005.

FRIMM, C.; KOIKE, M.K. Ações fisiológicas da aldosterona, Hipertensão, São Paulo, v.6, n.2, p46-49, 2003.

FUNDER, J.W. Rales, Ephesus and redox. Journal of Steroid Biochemistry \& Molecular Biology, Oxford, n.93, p.121-25, 2005.

FUNDER, J.W.; MCMAHON, E.G. Transgenic model of aldosteronedriven cardiac hypertrophy and heart failure. Circulation Research, Baltimore, v.93, p.69-76, 2003.

FUNDER, J.W.; PEARCE, P.T.; SMITH, R.; SMITH, A.I. Mineralocorticoid action: target tissue specificity is enzyme, not receptor, mediated. Science, New York, v. 242, p.583-585, 1988.

GASPARO, M.; CATT, K.J.; INAGAMI, J.W.; UNGER, Y.H. International Union of Pharmacology. XXIII. The Angiotensin II Receptors. Pharmacological reviews, Baltimore, V.52, N.3, p.415-472, 2000.

GEORGIEVA, K. N,; BOYADJIEV, N. P. Effecta of nandrolone decanoato on VO2max, running economy and endurance in rats. Medicine Science and Sport Exercise, Madison, v.36, n.8, p.1336-1341, 2004. 
GONÇALVES, G.; ZORNOFF, L.A.M.; RIBEIRO, H.B.; OKOSHI, M.P.; CORDARO, F.R.S.; OKOSHI, K.; PADOVANI, C.R.; ARAGON, F.F.; CICOGNA, A.C. O bloqueio do sistema renina-angiotensina atenua a remodelação cardiaca de ratos submetidos a estenose aórtica. Arquivos Brasileiros de Cardiologia, Rio de janeiro, n.84, p.304-08, 2005.

GUO, D.F.; UNO, S.; INAGAMI, T. Steroid hormones upregulate rat angiotensin II type 1A receptor gene: Role of glucocorticoid responsive elements in rat angiotensin II type 1A promoter. The Journal of steroid biochemistry and molecular biology, Oxford, v.53, p.69-73, 1995.

HARTGENS, F.; KUIPERS, H. Effects of androgenic-anabolic steroids in athletes. Sports Medicine, Auckland, v38, p.513-54, 2004.

HATAKEYAMA, H.; MIYAMORI, I.; FUJITA, T.; TAKEDA, Y.; TAKEDA, R.; YAMAMOTO, H. Vascular aldosterone. Biosynthesis and a link to angiotensin IIinduced hypertrophy of vascular smooth muscle cells. The Journal of biological chemistry, Baltimore, v.269, p.24316-20, 1994.

HEINEKE, J.; MOLKENTIN, J.D. Regulation of cardiac hypertrophy by intracellular signaling pathways. Nature reviews. Molecular Cell Biology, London, v.7, n.8, p.589600, 2006.

HICKSON, R.C.; CZERWINSKI, S.M; FALDUTO, M.T.; YOUNG, A.P. Glucocorticoid antagonism by exercise and androgenic-anabolic steroids. Medicine Science and Sport Exercise, Madison, v.22, p.331-40, 1990.

IEMITSU, M.; MIYAUCHI, T.; MAEDA, S.; SAKAI, S.; KOBAYASHI, T.; FUJII, N.; MIYAZAKI, H.; MATSUDA, M.; YAMAGUCHI, I. Physiological and pathological cardiac hypertrophy induce different molecular phenotypes in the rat. American journal of physiology. Regulatory, integrative and comparative physiology, Bethesda, v.281, n.6, p.2029-36, 2001. 
IGLARZ, M.; TOUYZ, R.M.; VIEL, E.V.; AMIRI, F.; SCHIFFRIN, E.L. Involvement of oxidative stress in the profibrotic action of aldosterone. American journal of hypertension., New York, v.17, p.597-603, 2004.

IRIART, J.A.B.; ANDRADE, T.M. Musculação, uso de esteróides anabolizantes e percepção de risco entre jovens fisiculturistas de um bairro popular de salvador, Bahia, Brasil. Caderno de Saúde Publica, Rio de Janeiro, v.18, n.5, p.1379-87, 2002.

KAGIYAMA, S.; MATSUMURA, K.; FUKUHARA, M.; SAKAGAMI, K.; FUJII, K.; IIDA, M. Aldosterone-and-Salt-Induced Cardiac Fibrosis Is Independent from Angiotensin II Type 1a Receptor Signaling in Mice. Hypertension research, Toyonaka, v.30, p.979-89, 2007.

KAM, P.C.; YARROW, M. Anabolic steroid abuse: physiological and anaesthetic considerations. Anaesthesia, London, v.60, n.7, p.685-92, 2005.

KAWANO, H.; TODA, G.; NAKAMIZO, R.; KOIDE, Y.; SETO, S.; YANO, K. Valsartan decrease type I collagen synthesis in patients with hypertrophic cardiomyopathy. Circulation journal, Kyoto, v.69, p.1244-48, 2005.

KICMAN, A. T. Pharmacology of anabolic steroids. Brazilian Journal of Pharmacology, São Paulo, v. 154, n.3, p.502-521, 2008.

KOCHAKIAN, C.D. History, chemistry and pharmacodynamics of anabolic-androgenic steroids. Wiener medizinische Wochenschrift, Wien , v.143, p. 359-63, 1993.

KOCHAKIAN, C.D.; WELBER, A.A. Anabolic-androgenic steroids: in cell culture. $\underline{\text { In }}$ vitro cellular \& developmental biology, Columbia, v.29A, n.6, p.433-38, 1993.

KOMURO, I. Molecular mechanism of cardiac hypertrophy and development. Japanese circulation journal, Kyoto, v.65, n.5, p.353-58, 2001. 
KRIEG, A.; SCHARHG, J.; ALBERTS, T.; KINDERMAN, W.; URHAUSE, A. Cardiac Tissue Doppler in Steroid Users. International journal of sports medicine, Stuttgart, v.28, n.8, p.638-43, 2007.

KRIEGER, E.M.; BRUM, P.C.; NEGÃO, C.E. Role of arterial baroreceptor function on cardiovascular adjustments to acute and chronic dynamic exercise. Biological Research, Santiago, v.31, n.3, p.273-9, 1998.

KUHN, C.M. Anabolic steroids. Recent Progress in Hormone Research, Durham, v.57, p.411-434, 2002.

LAM, E.Y.M.; FUNDER, J.W.; NIKOLIC-PATERSON, D.J.; FULLER, P.J.; YOUNG, M.J. Mineralocorticoid receptor blockade but not steroid withdrawal reverses renal fibrosis in deoxycorticosterone/salt rats. Endocrinology,_Springfield, v.147, p.3623-29, 2006.

LEA, W.B.; KWAK, E.S.; LUTHER, J.M.; FOWLER, S.M.; WANG, Z.; MA, J.; FOGO, A. B.; BROWN, N.J. Aldosterone antagonism or synthase inhibition reduces end-organ damage induced by treatment with angiotensin and high salt. Kidney International, Reston, v.75, n.9, p.936-944, 2009.

LE GROSS, T.; MACCONNELL, D.; MURRY, T.; EDAVETTAL, M.; RACEYBURNS, L.A.; SHEPHERD, R.E.; BURNS, A.H. The effects of 17 alphamethyltestosterone on myocardial function in vitro. Medicine Science of Sports Exercise, Madisom, v.32, p.897-903, 2000.

LEMARIÉ, C.A.; PARADIS, P.; SCHIFFRIN, E.L. New insights on signaling cascades induced by cross-talk between angiotensin II and aldosterone. Journal of Molecular Medicine, Heidelberg, v.86, n.6, p.673-678, 2008.

LEVY, B.I. How to explain the differences between renin angiotensin system modulators. American journal of hypertension, New York, v.18, n.9, p.1345S-1415S, 2005. 
LI, J.S.; SHARIFI, A.M.; SCHIFFRIN, E.L. Effect of AT1 angiotensin-receptor blockade on structure and function of small arteries in SHR. Journal of Cardiovascular Pharmacology, New York. v.30, n.1, p.75-83, 1997.

LIJNEN, P.; PETROV, V. Antagonism of the reninangiotensin-aldosterone system and collagen metabolism in cardiac fibroblasts. Methods and findings in experimental and clinical pharmacology, Barcelona, v.21, p.215-27, 1999.

LIPS, D.J.; DEWINDT, L.J.; DAVE, J.W.; KRAAIJ, V.; DOEVENDANS, P.A. Molecular determinants of myocardiol hypertrhphy and failure: alternative pathways for beneficial and maladaptive hypertrophy. European Heart Journal, London; v.24, n.10, p.883-96, 2003.

LITWIN, S.E.; KATZ, S.E.; MORGAN, J.P.; DOUGLAS, P.S. Serial echocardiographic assessment of left ventricular geometry and function after large myocardial infarction in the rat. Circulation, Dallas, v.89, n.1, p.345-54, 1994.

LOBO, A.P.T.; NAPPO, A.S.; SANCHEZ, Z.M.; CARLINI, E.A. O uso indevido de anabolizantes na cidade de São Paulo: um estudo qualitativo. Jornal Brasileiro de Psiquiatria, Rio de Janeiro, v.52, n.1, p.25-34, 2003.

LOMBARDI, R.; BETOCCHI, S, LOSI MA, TOCCHETTI CG, AVERSA M, MIRANDA M,D'ALESSANDRO G, CACACE A, CIAMPI Q, CHIARIELLO M. Myocardial collagen turnover in hypertrophic cardiomyopathy. Circulation, Dallas, v. 108, p.1455-60, 2003.

LOMBES, M.; OBLIN, M.E.; GASC, J.M.; BAULIEU, E.; FARMAN, N.; BONVALET, J.P._Immunohistochemical and biochemical evidence for a cardiovascular mineralocorticoid receptor. Circulation. Research, Baltimore, v.71, p503-10, 1992.

LORELL, B.H.; CARABELLO, B.A. Left ventricular hypertrophic: pathogenesis, detection, and prognosis. Circulation, Dallas, v.102, n.4, p.470-79, 2000. 
MARAVELIAS, C.; DONA, A.; STEFANIDOU, M.; SPILIOPOULOU, C. Adverse effects of anabolic steroids in athletes, A constant threat. Toxicology Letters, Amsterdam, v.158, n.3, p.167-75, 2005.

MATSUBARA, H. Pathophysiological role of angiotensin II type 2 receptor in cardiovascular and renal diseases. Circulation Research, Baltimore, v. 83, p.1182-91, 1998.

MATSUMINE, H.; HIRATO, K.; TAMADA, T.; YOSHIDA, M. Aromatization by skeletal muscle. Journal Clinic Endocrinology Metabolism, Toronto, v.63, p.717-20, 1986.

MEDEIROS, A.; OLIVEIRA, E.M.; GIANOLLA, R.; CASARINI, D.E.; NEGRÃO, C.E.; BRUM, P.C. Swimming training increases cardiac vagal activity and induces cardiac hypertrophy in rats. Brazilian journal of medical and biological research, São Paulo, v.37, p.1909-17, 2004.

MELCHERT, R.B.; WELDER, A.A.; Cardiovascular effects of androgenic-anabolic steroids. Medicine Science of Sports Exercise, Madison, v.27, p.1252-62, 1995.

MIL, J.G.; MILANEZ, M. C.; BUSATTO, V.C.W.; MORAES, A.C.; GOMES, M.G. Ativação da enzima conversora de angiotensina no coração após infarto do mocardio e sua repercussões no remodelamento ventricular. Arquivos Brasileiros de Cardiologia, Rio de Janeiro, v.69, p. 101-110, 1997.

MIN, L.J.; MOGI, M.; LI, J.M.; IWANAMI, J.; IWAI, M.; HORIUCHI, M. $\underline{\text { Aldosterone and angiotensin II synergistically induce mitogenic response in vascular }}$

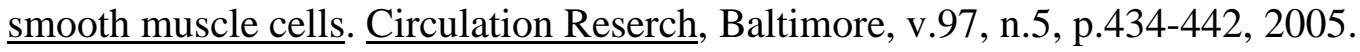

MIZUNO, Y.;YOSHIMURA, M.;YASUE,H.; SAKAMOTO, T.; OGAWA, H.; KUGIYAMA, K.; HARADA, E.; NAKAYAMA, M.; NAKAMURA, S.; ITO, T.; SHIMASAKI, Y.; SAITO, Y.; NAKAO, K. Aldosterone production is activated in failing ventricle in humans, Circulation, Dallas, v.103, p.72-77, 2001. 
MORIMOTO, S.; SIGMUND, C.D. Angiotensin mutant mice: a focus on the brain renin-angiotensin system. Neuropeptides, Basingstoke, v.36, n.2-3, p.194-200, 2002.

NAGATA, K.; OBATA, K.; XU, J.; ICHIHARA, S.; NODA, A.; KIMATA, H.; KATO, T.; IZAWA, H.; MUROHARA, T.; YOKOTA, M.; Mineralocorticoid receptor antagonism attenuates cardiac hypertrophy and failure in low-aldosterone hypertensioe rats. Hypertension, Dallas, v.47, p. 656-664, 2006.

NEGRÃO, C.E.; MOREIRA, E.D.; BRUM, P.C.; DENADAI, M.L.D.R.; KRIEGER, E.M. Vagal and sympathetic control of heart rate during exercise by sedentary and exercise-trained rats. Brazilian Journal of Medical and Biological Research, São Paulo, v.25, n.10, p.1045-52, 1992.

NEHME, J.; MERCIER, N.; LABAT, C.; BENETOS, A.; SAFAR, M.E.; DELCAYRE, C.; LACOLLEY, P. Differences Between Cardiac and Arterial Fibrosis and Stiffness in Aldosterone-Salt Rats: Effect of Eplerenone. Journal of the renin-angiotensinaldosterone system,_Birmingham, v.7, n.1, p. 31-39, 2006.

NIELSEN, A.H.; SCHAUSE, K.H.; POULSEN, K. Current topic: the uteroplacental renin-angiotensin system. Placenta, v.21, n.5-6, p.468-77,2000.

NIEMINEN, M.; RAMO, M.; VIITASALO, M.; HEIKKILA, P.; KARJALAINEN, J.; MANTYSAARI, M.; HEIKKILA, J. Serious cardiovascular side effects of large doses of anabolic steroids in weight lifters. European heart journal, London, v.17, n.10, p.1576-83, 1996.

NOMURA, M,; MOROHASHI, K.I.; KIRITA, S.; NONAKA, Y.; OKAMOTO, M.; NAWATA, H.; OMURA, T._Three forms of rat CYP11B genes: 11 beta-hydroxylase gene, aldosterone synthase gene, and a novel gene. Journal of Biochemical, Tokyo, v. 113, p.144-52, 1993. 
NOTO, A.R.; BAPTISTA, M.C.; FARIA, S.Y.; NAPPO, S.A.; GALURÓZ, J.C.; CARLINI, E.A. Drugs and health in Brazilian press: an analysis of articles published in newspapers and magazines. Caderno de Saúde Pública, Rio de Janeiro, v.19, n.1, p.6979, 2003.

NOTTIN, S.; NGUYEN. L, D.; TERBAH, M.; ROBERT, P. Cardiovascular effects of androgenic anabolic steroids in male bodybuilders determined by tissue Doppler imaging. American Journal of Cardiology, New Yorke, v.97, n.6, p.912-915, 2006.

OLIVEIRA, E.M.; SASAKI, M.S.; CERENCIO, M.; BARAUNA, V.G.; KRIEGER, J.E. Local renin-angiotensin system regulates LV hypertrophy induced by swimming training independent of circulating renin: a pharmacological study. Journal of the reninangiotensin-aldosterone system, Birmingham, v.10, n.1, p.15-23, 2009.

PARSSINEN, M.; KARILA, T.; KOVANEN, V.; SEPPALA, T. The effect of suprophysiological doses of anabolic androgenic steroids on collagen metabolism. International Journal of Sports Medicine, Stuttgart, v.21, n.6, p.406-11, 2000.

PARSSINEN. M.; SEPPALA, T. Steroid use and long-term health risks in former athletes. Sports medicine, Auckland, v.32, p. 83-94, 2002.

PAUL, M.; MEHR, A.P.; KREUTZ, R. Physiology of local renin-angiotensin systems. Physiological reviews, Washington, v.86, n.3, p.747-803, 2006.

PEARSON, A.C.; SCHIFF, M.; MROSEK, D.; LABOVITZ, A.J.; WILLIAMS, G.A. Left ventricular function in weightlifters. The American Journal of Cardiology, New York, v.58, n.13, p.1254-59, 1986.

PEREIRA JUNIOR, P.P.; CHAVES, E.A.; SOUZA, R.H.C.; MASUDA, M.O.; CARVALHO, A.C.C.; NASCIMENTO, J.H.M. Cardiac autonomic dysfunction in rats chronically treated with anabolic steroid. European journal of applied physiology, Berlim, v.96, n.5, p.487-94, 2006. 
PHILLIPS, M.I. Functions of angiotensin in the central nervous system. Annual review of physiology, Palo Alto, v. 49, p.413-35, 1987.

PONTES, M.R.N.; LEÃES, P.E. Remodelamento ventricular: dos mecanismos moleculares e celulares ao tratamento. Revista da Sociedade de Cardiologia do Rio Grande do Sul, Porto Alegre, v.3, p.1-7.

POPE JUNIOR, H.G.; KATZ, D.L. Affective and psychotic symptoms associated with anabolic steroid use. The American Journal of Psychiatry, Hanover, v.145, n.4, p.48790, 1988.

QIN， W.; RUDOLPH， A. E.; BOND， B. R.; ROCHA， R.; BLOMME， E. A.; GOELLNER, J. J.; FUNDER, J. W.; MCMAHON, E. G. Transgenic model of aldosterone-driven cardiac hypertrophy and heart failure. Circulation Researche, Baltimore, v.93, n.1, p.69-76, 2003.

ROBERT, V.; SILVESTRE, J.S.; CHARLEMAGNE, D.; SABRI, A.; TROUVE, P.; WASSEF, M.; SWYNGHEDAUW, B.; DELCAYRE, C._Biological determinants of aldosterone-induced cardiac fibrosis in rats. Hypertension, Dallas v.26, n.6, p.971-78, 1995.

ROCHA, F.L.; CARMO, E.C.; ROQUE, F.R.; HASHIMOTO, N.Y.; ROSSONI, L.V.; FRIMM, C.; ANEAS, I.; MEGRÃO, C.E.; KRIEGER, J.E.; OLIVEIRA, E.M. Anabolic steroids induce cardiac renin-angiotensin system and impair the beneficial effects of aerobic training in rats. American journal of physiology. Heart and circulatory physiology, Bethesda, v.293, n.6, p.H3575-83, 2007.

SAHN, D.J.; DEMARIA, A.; KISSLO, J.; WEYMAN, A. Recommendations regarding quantitation in M-mode echocardiography: results of survey of echocardiographic measurements. Circulation, Dallas, v.58, n.6, p.1072-83, 1978.

SAM, F.; XIE, Z.; OOI, H.; KERSTETTER, D.L.; COLUCCI, W.S.; SINGH, M.; SINGH, K. Mice lacking osteopontin exhibit increased left ventricular dilation and 
reduced fibrosis after aldosterone infusion. American journal of hypertension, New York, v.17, p.188-93, 2004.

SANTOS, R.A.S.; MOURA, C.R.F.; SILVA, A.C.S. Efeitos cardiovasculares e renais do sistema renina-angiotensina. Revista Brasileira de Hipertensão, Ribeirão Preto, v.3, p227-236, 2000.

SARKAR, S.; VELLAICHAMY, E.; YONG, D.; SEM, S. Influence of cytokines and growth factors in ang II-mediated collagen upregulation by fibroblasts in rats: role of myocytes. American journal of physiology. Heart and circulatory physiology, Bethesda; v.287, n.1, H107-H117, 2004.

SATOH, M.; NAKAMURA, M.; SAITOH, H.; SATOH, H.; AKATSU, T.; IWASAKA, J.; MASUDA, T.; HIRAMORI, K. Aldosterone synthase (CYP11B2) expression and myocardial fibrosis in the failing human heart. Clinical Science, London, v.102, n.4, p.381-86, 2002.

SCHILLER, N.B.; SHAH, P.M.; CRAWFORD, M.; DEMARIA, A.; DEVEREUX, R.; FEIGENBAUM, H.; GUTGESELL, H.; REICHEK, N.; SAHN, D.; SCHNITTGER, I.; ET AL. Recommendations for quantification of the left ventricle by two-dimensional echocardiopraphy. American Society of Echocardiography Committee on Standards, Subcommittee on Quantitation of Two-Dimensional Echocardiograms. Journal of the American Society of Echocardiography, New York, v.2, n.5, p. 358-67, 1989

SERNIA, C. A critical appraisal of the intrinsic pancreatic angiotensin-generating system. Journal of the Pancreas, New York, v.2, n.1, p.50-5, 2001.

SHAHIDI, N.Y. A Review of the Chemistry, Biological Action, and Clinical Applications of Anabolic-Androgenic Steroids. Clinical Therapeutics, Madison, v.23, n.9, p.1355-90, 2001

SHIBATA, H.; OGISHIMA, T.; MITANI, F.; SUZUKI, H.; MURUKAMI, M.; SARUTA, T.; ISHIMURA, Y. Endocrinology,_Springfield, v.128, n.5, p.2534-39, 1991. 
SILVESTRE, J.S.; HEYMES, C.; OUBÉNAÏSSA, A.; ROBERT, V.; FAISANT, B.A.; CARAYON, A.; SWYNGHEDAUW, B.; DELCAYRE, C. Activation of cardiac aldosterone production in rat myocardial infarction: effect of angiotensin II receptor blockade and role in cardiac fibrosis. Circulation, Dallas, v.99, p.2694-701, 1999.

SILVESTRE, J.S.; ROBERT, V.; HEYMES, C.; AUPETIT-FAISANT, B.; MOUAS, C.; MOALIC, J.M.; SWYNGHEDAUW, B.; DELCAYRE, C. Myocardial Production of Aldosterone and Corticosterone in the Rat. The Journal of biological chemistry, Baltimore, v.273, n.9, p.4883-91, 1998.

SJOQVIST, F.; GARLE, M.; RANE, A. Use of doping agents, particularly anabolic steroids, in sports and society. Lancet, Londres, v.371 p.1872-82, 2008.

STANNARD, J.P.; BUCKNELL, A.L. Rupture of the triceps tendon associated with steroid injections. American Journal of Sports Medicine, Madison, v.21, p.482-85, 1993.

STRAUSS, R.H.; LIGGETT, M.T.; LANESE, R.R. Anabolic steroid use and perceived effects in tem weight-trained women athletes. JAMA: the journal of the American Medical Association, Chicago, v 253, p. 2871-73, 1985.

STRIEGEL, H.; SIMON, P.; FRISCH, S.;ROECKER, K.; DIETZ, K.; DICKHUTH, H.H.; ULRICH, R. Anabolic ergogenic substance users in fitness-sports: a distinct group supported by the health care system. Drug and alcohol dependence, Lausanne, v.81, p.11-19, 2006.

STRUTHERS, A.D. Aldosterone blockade in cardiovascular disease. Heart, London, v.90, p.1229-34, 2004.

SUN, Y.; ZHANG, J.; LU, L.; CHEN, S.S.; QUINN, M.T.; WEBER, K.T. Aldosteroneinduced inflammation in the rat heart: role of oxidative stress. The American journal of pathology, Philadelphia, v.161, p.1773-81, 2002. 
SUN, Y.; ZHANG, J.Q.; ZHANG, J.; RAMIRES, F. J. A.; Angiotensin II, transforming growth factor- $\beta$ and repair in the infracted heart. Journal of molecular and cellular cardiology, London, v.30, p.1559-69, 1998.

SUSIC, D.; VARAGIC, J.; AHN, J.; MATAVELLI, L.; FROHLICH, E.D. Long-term mineralocorticoid receptor blockade reduces fibrosis and improves cardiac performance and coronary hemodynamics in elderly shr. American journal of physiology. Heart and circulatory physiology, Bethesda, v.11, p.1152-72, 2006.

TAKAHASHI, M.; TATSUGI, Y.; KOHNO, T. Endocrinological and pathological effects of anabolic-androgenic steroid in male rats. Endocrine Journal, Tokyo, v.51, p.425-34, 2004.

TAKALA, T.E.S.; RAMO, P.; KIVILUOMA, K.; VIHKO, V.; KAINULAINEN, H.; KETTUNEN, R. Effects of training and anabolic steroids on collagen synthesis in dog heart. European journal of applied physiology and occupational physiology, Berlin, v.62, n.1, p.1-6, 1991.

TAKEDA, M.; TATSUMI, T.; MATSUNAGA, S.; HAYASHI, H.; KIMATA, M.; HONSHO, S.; NISHIKAWA, S.; MANO, A.; SHIRAISHI, J.; YAMADA, H.; TAKAHASHI, T.; MATOBA, S.; KOBARA, M.; MATSUBARA, H. Spironolactone modulates expressions of cardiac mineralocorticoid receptor and 11beta-hydroxysteroid dehydrogenase 2 and prevents ventricular remodeling in post-infarct rat hearts. Hypertension research, Toyonaka, v.30, p.427-37, 2007.

TAKEDA, Y.; MIYAMORI, I.; YONEDA, T.; IKI, K.; HATAKEYAMA, H.; BLAIR, I.A.; HSIEH, F.Y.; TAKEDA, R. Synthesis of corticosterone in the vascular wall, Endocrinology,_Springfield, v.135, p.2283-86, 1996.

UNGER, T. The angiotensin type 2 receptor: Variations on an enigmatic theme. Journal of hypertension, London, v.17, p.1775-86, 1999. 
URATA, H.; NISHIMURA, H.; GANTER, D. Chymase-dependent angiotensin II forming system in humans. American Journal of Hypertension, New York, v. 9, p.27784, 1996.

URHAUSEN, A.; ALBERS, T.; KINDERMANN, W.Are the cardiac effects of anabolic steroid abuse in strength athletes reversible? Heart, London, v.90, n.5, p.496$501,2004$.

UZYCH, L. Anabolic-androgenic steroids and psychiatric-related effects: A review. Canadian journal of psychiatry, Ottawa, v.37, p.23-28, 1992.

VAN KATS, J.P.; DUNCKER, D.J.; HAITSMA, D.B.; SCHUIJT, M.P.; NIEBUUR, R.; STUBENITSKY, R.; BOOMSMA, F.; SCHALEKAMP, M.A.; VERDOUW, P.D.; DANSER, A.H. Angiotensin-converting enzyme inhibition and angiotensin II type 1 receptor blockade pevent cardiac remodeling in pigs after myocrdial infarction. Role of tissue angiotensin II. Circulation, Dallas, v.102, p.1556-59, 2000.

VARAGIC, J.; FROHLICH, E.D. Local cardiac renin-angiotensin system: hypertension and cardiac failure. Journal of molecular and cellular cardiology, London 2002; 34: $1435-1442$.

WANG, C.; ALEXANDER, G.; BERMAN, N.; SALEHIAN, B.; DAVIDSON, T.; MACDONALD, V.; STEINER, B.; HULL, L.; CALLEGARI, C.; SWERDLOFF, R.S. Testosterone replacement therapy improves mood in hypogonadal men - a clinical research center study. Journal of Clinical Endocrinology \& Metabolism, Springfield, v.81, n.10, p.3578-83, 1996.

WEBER K T. BRILLA C G. Pathological hypertrophy and cardiac intersticium. Fibrosis an renin-angiotensin-aldosteerone system. Circulation, Dallas, v.83, p.1849-65, 1991.

WEHLING, M.; Cardiac and vascular synthesis of aldosterone: yes, but.... Current Opinion in Endocrinological, Diabetes and Obesity, Bethesda, v.12, p.211-14, 2005. 
WHARTON, J.; MORGAN, M.; RUTHERFORD, R.A.D.; CATRAVAS, J.D.; CHESTER, A.; WHITEHEAD, B.F.; DE LEVAL, M.R.; YACOUB, M.H.; POLAK, J.M. Differential distribution of angiotensin AT2 receptors in the normal and failing human heart. The Journal of pharmacology and experimental therapeutics, Baltimore, v.284, p.323-36, 1998.

WILSON, J.D. Androgen abuse by athletes. Endocrine Reviews, Baltimore, v.9, n.2, p.181-99, 1988.

WOOD, R.I. Anabolic steroids: A fatal attaction? Journal of Neuroendocrinology, Oxon, v.18, n.3, p.227-8, 2006.

WOODIWISS, A.J.; TRIFUNOVIC, G.; PHILIPPIDES, M.; NORTON, G.R. Effect of an androgenic steroid on exercise-induced cardiac remodeling in rats. Journal of applied physiology, Bethesda, v.88, n.2, p.409-15, 2000.

WYSOCZANSKI, M.; RACHKO, M. BERGMANN, S.R. Acute Myocardial Infarction in a Young Man Using Anabolic Steroids. Angiology, New York, v.59, n.3, p.376-78, 2008.

YAMAMOTO, K.; MASUYAMA, T.; SAKATA, Y.; NISHIKAWA, N.; YOSHIDA, J.;MIWA, T.; SUGAWARA, M.; YAMAGUCHI, Y.; OOKAWARA, T.; SUZUKI, K.; HORI, M.; Myocardial stiffness is determined by ventricular fibrosis, but not by compensatory or excessive hypertrophy in hypertensive hearts. Cardiovascular research, London; v.55, n.1, p.76-82, 2002.

YE, P.; KENYON, C.J.; MACKENZIE, S.M.; SECKL, J.R.; FRASER, R.; CONNELL, J.M.C.; DAVIES, E. Regualtion of aldosterone synthase gene expression in the rat adrenal gland and central nervous system by sodium and angiotensin II. Endocrinology, Springfield, v.144, p.3321-28, 2003. 
YESALIS, C. E.; KENNEDY, N. J.; KOPSTEIN, A. N.; BAHRKE, M. S.; Anabolicandrogenic steroid use in the United States. Journal of the American Medical Association, Chicago, v.270, n.10, p.1217-1221, 1993.

YONG, M.; FUNDER, J.W. Eplerenone, but not steroid withdrawal, reverses cardiac fibrosis in deoxycorticosterone/salt-treated rats. Endocrinology,_Springfield, v.145, p.3153-57, 2004.

YOSHIMURA, M.; NAKAMURA, S.; ITO, T.; NAKAYAMA, M.; HARDA, E.; MIZUNO, Y.; SAKAMOTA, T.; YAMAMURO, M.; SAITO, Y.; NAHAO, K.; YASUE, H.; OGAWA, H. Expression of aldosterone synthase gene in failing human heart:quantitative analysis using madified real-time polynerase chain reaction. The Journal of clinical endocrinology and metabolism, Springfield, v.87, p.3936-40, 2002.

ZANNAD, F.; ALLAN, F.; DOUSSET, B.; PERZ, A.; PITT, B. Limitation of excessive extracellular matrix turnover may contribute to survival benefit of spironolactone therapy in patients with congestive heart failure. Cirulation, Dallas, v.102, p.2700-706, 2000.

ZHANG, Y.L.; ZHOU, S.X.; LEI, J.; YUAN, G.Y.; WANG, J.F. Blockades of angiotensin and aldosterone reduce osteopontin expression and interstitial fibrosis infiltration in rats with myocardial infarction. The Journal of Chinical Medinice, London, v.121, n.21, p.2192-96, 2008.

ZHU, Y.C.; ZHU, Y.Z.; LU, N.; WANG, M.J.; WANG, Y.X.; YAO, T. Role of angiotensin AT1 and AT2 receptors in cardiac hypertrophy and cardiac remodelling. Clinical and Experimental Pharmacology and Physiology, Oxford, v.30,n.12, p.911918, 2003. 